\title{
TRANSCRIPTION FACTOR REGULATION IN \\ MAMMALIAN HIBERNATION: THE THIRTEEN-LINED \\ GROUND SQUIRREL AS A MODEL
}

\author{
By \\ Manimegala Mathialagan \\ B.Sc. University of Peradeniya, Sri Lanka
}

A Thesis Submitted to the Faculty of Graduate Studies and Research in partial fulfillment of the requirements for the degree of

\author{
Master of Science \\ Department of Biology
}

Carleton University

Ottawa, Ontario, Canada

(C) copyright 2007

Manimegala Mathialagan 


$\begin{array}{ll}\begin{array}{l}\text { Library and } \\ \text { Archives Canada }\end{array} & \begin{array}{l}\text { Bibliothèque et } \\ \text { Archives Canada }\end{array} \\ \begin{array}{l}\text { Published Heritage } \\ \text { Branch }\end{array} & \begin{array}{l}\text { Direction du } \\ \text { Patrimoine de l'édition }\end{array} \\ \begin{array}{l}\text { 395 Wellington Street } \\ \text { Ottawa ON K1A 0N4 }\end{array} & \begin{array}{l}\text { 395, rue Wellington } \\ \text { Ottawa ON K1A ON4 }\end{array} \\ \text { Canada } & \begin{array}{l}\text { Canada } \\ \end{array}\end{array}$

Yourfile Votre référence

ISBN: 978-0-494-36847-3

Ourfile Notre référence

ISBN: 978-0-494-36847-3

NOTICE:

The author has granted a nonexclusive license allowing Library and Archives Canada to reproduce, publish, archive, preserve, conserve, communicate to the public by telecommunication or on the Internet, loan, distribute and sell theses worldwide, for commercial or noncommercial purposes, in microform, paper, electronic and/or any other formats.

The author retains copyright ownership and moral rights in this thesis. Neither the thesis nor substantial extracts from it may be printed or otherwise reproduced without the author's permission.
AVIS:

L'auteur a accordé une licence non exclusive permettant à la Bibliothèque et Archives Canada de reproduire, publier, archiver, sauvegarder, conserver, transmettre au public par télécommunication ou par l'Internet, prêter, distribuer et vendre des thèses partout dans le monde, à des fins commerciales ou autres, sur support microforme, papier, électronique et/ou autres formats.

L'auteur conserve la propriété du droit d'auteur et des droits moraux qui protège cette thèse. $\mathrm{Ni}$ la thèse ni des extraits substantiels de celle-ci ne doivent être imprimés ou autrement reproduits sans son autorisation.
In compliance with the Canadian

Privacy Act some supporting forms may have been removed from this thesis.

While these forms may be included in the document page count, their removal does not represent any loss of content from the thesis.
Conformément à la loi canadienne sur la protection de la vie privée, quelques formulaires secondaires ont été enlevés de cette thèse.

Bien que ces formulaires aient inclus dans la pagination, il n'y aura aucun contenu manquant.

\section{Canadä}


The undersigned hereby recommend to the Faculty of Graduate Studies and Research acceptance of this thesis

\section{"TRANSCRIPTION FACTOR REGULATION IN MAMMALIAN HIBERNATION: THE THIRTEEN-LINED GROUND SQUIRREL AS A MODEL"}

submitted by

Manimegala Mathialagan

In partial fulfillment of the requirements for the degree of Master of Science

Chair, Department of Biology

Thesis Supervisor

Carleton University 


\begin{abstract}
The thirteen-lined ground squirrel (Spermophilus tridecemlineatus) is one of a number of mammalian species that hibernate over the winter months. Hibernation is characterized by long periods of deep torpor that are interspersed with periodic arousals. This thesis investigated three transcription factor pathways and their regulation and roles in hibernation using tools including immunoblotting of protein and phospho-protein levels, analysis of nuclear versus cytoplasmic distribution, binding to DNA, PCR to quantify mRNA transcripts, and gene sequencing. The carbohydrate response elementbinding protein (ChREBP) regulates genes that are responsible for converting excess dietary carbohydrate (glucose) into triglycerides. During torpor ChREBP protein was decreased in kidney and liver and transcripts of two downstream genes (Fasn, pkl) were differentially expressed; this was consistent with carbohydrate sparing during torpor. Growth and differentiation processes are also minimized during hibernation and ETS transcription factors are important regulators of these. Although levels of ETS increased in most organs of hibernators, ETS binding activity to DNA was greatly reduced indicating a growth suppressive function during torpor. Upstream effectors of ETS (epidermal growth factor receptor, protein kinases C and D) were also evaluated. To assess transcriptional state during hibernation, the Rb-E2F pathway was investigated. Retinoblastoma protein $(\mathrm{Rb})$ associates with $\mathrm{E} 2 \mathrm{~F} 1$ and then recruits co-factors to the promoter region of target genes to suppress transcription. Rb and E2F1 proteins were elevated during hibernation and the co-factors HDAC and SUV39H1 showed parallel increases in the organs tested; oppositely, transcription of downstream genes $(\mathrm{cMyc}, \mathrm{Bcl} 2)$ was suppressed. These data confirm a reduced transcriptional state during torpor.
\end{abstract}




\section{Acknowledgements}

First of all, I would like to thank my thesis supervisor Dr. Kenneth B. Storey who accepted me into his Lab and gave me a chance to develop my skills and learn, in all aspects of Science. I really praise Dr. Storey's teaching, guidance, and support in developing my scientific knowledge. Thanks to Jan Storey, for her perfect editing, insightful suggestions and her encouragement with my writing. I am extremely grateful.

I would also like to thank the members of my committee, Dr. Jim Cheetham and Dr. Tom Moon, for their support and valuable suggestions. I acknowledge here the former lab members, Mamady for teaching me the fundamentals in the Storey lab and Tarek for the valuable suggestions in my PCR work. Many thanks also go to all my friends and lab members, for their help, support, interest and valuable scientific discussions.

Finally, I would like to give a special thanks to my parents Thangarani and Naganathan for their support and encouragement from thousands of miles away, through long distance calls. Many, many warmest thanks to my husband Mathi and my lovely children, Abirami and Bairavi for their understanding and kind cooperation, which allowed me to finish my degree within the time frame. 


\section{Table of Contents}

Title Page

Acceptance Sheet

Abstract $\quad$ iii

Acknowledgements $\quad$ iv

Table of Contents $\quad \mathrm{v}$

List of Abbreviations $\quad$ vi

List of Figures viii

List of Tables $\quad$ xi

Chapter 1 General Introduction 1

$\begin{array}{lll}\text { Chapter } 2 \text { Changes in the ChREBP pathway in hibernating thirteen- } & 17\end{array}$ lined ground squirrels.

Chapter 3 Role of Ets 1 and its upstream factors in hibernating thirteen- 52 lined ground squirrels.

Chapter 4 Roles of the Rb-E2F pathway in hibernating thirteen-lined 87 ground squirrels

$\begin{array}{lll}\text { Chapter } 5 \text { General Discussion } & 122\end{array}$

$\begin{array}{ll}\text { Contributions at Conferences } & 140\end{array}$

$\begin{array}{ll}\text { References } & 144\end{array}$ 


\section{List of Abbreviations}

\begin{tabular}{|c|c|}
\hline $\mathrm{AA}$ & amino acid \\
\hline ATP & adenosine triphosphate \\
\hline BAT & brown adipose tissue \\
\hline $\mathrm{Bcl}-2$ & B-cell leukemia/lymphoma 2 \\
\hline BLAST & Basic Local Alignment Search Tool \\
\hline cDNA & complementary deoxyribonucleic acid \\
\hline CDS & coding sequence \\
\hline ChREBP & Carbohydrate Response Element Binding Protein \\
\hline DAG & diacylglycerol \\
\hline DEPC & diethylpyrocarbonate \\
\hline DTT & dithiothreitol \\
\hline EDTA & ethylenediamine tetraacetic acid \\
\hline $\mathrm{eEF}$ & eukaryotic elongation factor \\
\hline EGFR & Epidermal Growth Factor Receptor \\
\hline eIF & eukaryotic initiation factor \\
\hline EMSA & Electrophoretic Mobility Shift Assay \\
\hline ER & endoplasmic reticulum \\
\hline ETS & v-ets erythroblastosis virus E26 oncogene homolog \\
\hline FABP & fatty acid binding protein \\
\hline HIF-1 & hypoxia-inducible factor-1 \\
\hline $\mathrm{kb}$ & kilobase \\
\hline $\mathrm{kDa}$ & kilodalton \\
\hline
\end{tabular}




$\begin{array}{ll}\text { MAPK } & \text { mitogen-activated protein kinase } \\ \text { mRNA } & \text { messenger RNA } \\ \text { ORF } & \text { open reading frame } \\ \text { PAGE } & \text { polyacrylamide gel electrophoresis } \\ \text { PCR } & \text { polymerase chain reaction } \\ \text { PDK } & \text { pyruvate dehydrogenase kinase } \\ \text { PIP } & \text { phosphatidylinositol-4,5-bisphosphate } \\ \text { PKC } & \text { protein kinase C } \\ \text { PLC } & \text { phospholipase (PL) C } \\ \text { PMSF } & \text { phenylmethanesulfonyl fluoride } \\ \text { PUFA } & \text { polyunsaturated fatty acid } \\ \text { PVDF } & \text { polyvinylidine fluoride } \\ \text { Rb } & \text { Retinoblastoma protein } \\ \text { RT } & \text { room temperature }\left(\sim 21^{\circ} \mathrm{C}\right) \\ \text { SDS } & \text { sodium dodecyl sulfate } \\ \text { Tb } & \text { body temperature } \\ \text { TEMED } & \text { N,N,N',N'-tetramethylethylenediamine } \\ \text { TF } & \text { transcription factor } \\ \text { Tris } & \text { thydroxymethyl) aminomethane } \\ & \end{array}$




\section{List of figures}

Fig. 1.1 Body temperature (Tb) of a golden-mantled ground squirrel as a function of time over the winter hibernation season.

Fig. 1.2 Distribution map for thirteen-lined ground squirrels, $S$. tridecemlineatus.

Fig. 2.1 Model of the role of ChREBP as a central regulator of the glucose signaling pathway.

Fig. 2.2 ChREBP protein expression in six tissues from euthermic (E) and hibernating $(\mathrm{H})$ ground squirrels.

Fig. 2.3 Phosphoserine levels near to the $95 \mathrm{kDa}$ protein band in six tissues from euthermic $(\mathrm{E})$ and hibernating $(\mathrm{H})$ ground squirrels.

Fig. 2.4 Distribution of ChREBP between cytoplasmic and nuclear fractions in liver and skeletal muscle of $S$. tridecemlineatus.

Fig. 2.5 ChREBP transcription factor binding to DNA in nuclear extracts from liver and muscle of euthermic and hibernating ground squirrels.

Fig. 2.6 Effect of hibernation on Fasn mRNA levels in six tissues of thirteen-lined ground squirrels.

Fig. 2.7 Partial cDNA sequence of Fasn amplified from muscle of thirteen-lined ground squirrels ( $S$. tridecemlineatus), translated amino acid sequence and alignment of Fasn amino acid sequence with human, mouse and rat sequences.

Fig. 2.8 Effect of hibernation on $P k l$ mRNA levels in liver of thirteenlined ground squirrels.

Fig. 2.9 Partial cDNA sequence of $P k l$ amplified from liver of thirteenlined ground squirrels ( $S$. tridecemlineatus), translated amino acid sequence and alignment of PK-L amino acid sequence with human, mouse and rat sequences.

Fig. 3.1 Model of EGFR-PKC- Ets1/2 pathway: As response to hypoxic condition. 
Fig. 3.2 EGFR protein expression in four tissues from euthermic (E) and hibernating $(\mathrm{H})$ ground squirrels.

Fig. 3.3 Phosphorylated EGFR (pY1173) protein levels in four tissues from Euthermic $(E)$ and Hibernating $(H)$ ground squirrels

Fig. 3.4 Phospho-EGFR (pY 1086) protein levels in four tissues from Euthermic (E) and Hibernating $(\mathrm{H})$ ground squirrels.

Fig. 3.5 PKD/ PKCmu protein levels in six tissues from Euthermic (E) and Hibernating $(\mathrm{H})$ ground squirrels.

Fig. 3.6 Phospho-PKD/ PKCmu (Ser 744/ 748) protein levels in six tissues from Euthermic $(\mathrm{E})$ and Hibernating $(\mathrm{H})$ ground squirrels.

Fig. 3.7 Phospho-PKC alpha/beta (Thr 638/ 641) protein levels in four tissues from Euthermic $(\mathrm{E})$ and Hibernating $(\mathrm{H})$ ground squirrels.

Fig. 3.8 Phospho-PKC alpha/ beta (Thr 638/641) distribution between cytoplasmic $(\mathrm{C})$ and nuclear $(\mathrm{N})$ fractions in skeletal muscle of euthermic and hibernating ground squirrels.

Fig. 3.9 Effect of hibernation on Ets1 mRNA levels in six tissues of thirteen-lined ground squirrels.

Fig. 3.10 Partial cDNA sequence of Ets 1 amplified from muscle of thirteenlined ground squirrels ( $S$. tridecemlineatus), translated amino acid sequence and alignment of Ets 1 amino acid sequence with human, mouse and rat sequences.

Fig. 3.11 Ets1/2 protein levels in six tissues from Euthermic (E) and Hibernating $(\mathrm{H})$ ground squirrels.

Fig. 3.12 Ets $1 / 2$ distribution between cytoplasmic (C) and nuclear (N) fractions in muscle and liver of euthermic and hibernating ground squirrels.

Fig. 3.13 Electrophoretic mobility shift assays (EMSA) using Ets1 binding sequence as probe with nuclear extracts from liver and muscle of 13-lined ground squirrels.

Fig. 4.1 Model of Rb-E2F pathway: The machinery that regulates cell 109 cycle entry and progression in mammalian cells. 
Fig. 4.2 Total $\mathrm{Rb}$ protein in six organs from euthermic (E) and hibernating (H) ground squirrels.

Fig. 4.3 Phospho-Rb (Ser 780) protein in six organs from euthermic (E) and hibernating $(\mathrm{H})$ ground squirrels

Fig. 4.4 Phospho-Rb (Ser 795) protein in six organs from euthermic (E) and hibernating $(\mathrm{H})$ ground squirrels.

Fig. 4.5 Rb protein distribution between cytoplasmic $(\mathrm{C})$ and nuclear $(\mathrm{N})$ fractions in euthermic and hibernating ground squirrels muscle and liver.

Fig. 4.6 E2F1 protein levels in six tissues from euthermic (E) and hibernating $(\mathrm{H})$ ground squirrels.

Fig. 4.7 E2F1 distribution between cytoplasmic (C) and nuclear (N) fractions in euthermic and hibernating ground squirrels muscle and liver.

Fig. 4.8 SUV39H1 protein levels in six tissues from euthermic (E) and hibernating $(\mathrm{H})$ ground squirrels.

Fig. 4.9 HDAC6 protein levels in brain and HDAC4 protein levels in heart from euthermic $(\mathrm{E})$ and hibernating $(\mathrm{H})$ ground squirrels.

Fig. 4.10 Electrophoretic mobility shift assays (EMSA) using E2F1 binding sequence as probe with nuclear extracts from liver and muscle of 13-lined ground squirrels.

Fig. 4.11 c-Myc protein levels in five tissues from euthermic (E) and hibernating $(\mathrm{H})$ ground squirrels.

Fig. 4.12 Effect of hibernation on $B c l 2$ mRNA levels in six tissues of 120 thirteen-lined ground squirrels.

Fig. 4.13 Partial cDNA sequence of $\mathrm{Bcl} 2$ amplified from muscle of thirteen-lined ground squirrels ( $S$. tridecemlineatus), translated amino acid sequence and alignment of $\mathrm{Bcl} 2$ amino acid sequence with human, mouse and rat sequences. 


\section{List of Tables}

Table. 2.1 List of antibodies used in this thesis together with the dilutions and the relevant supplier companies. 
Chapter 1

\section{General Introduction}

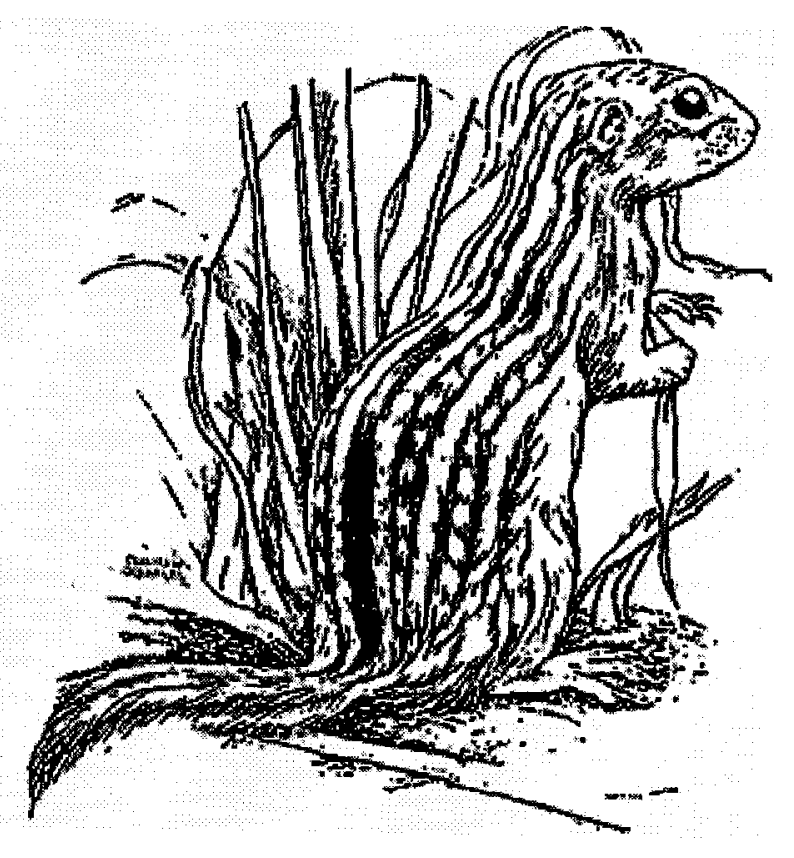




\section{INTRODUCTION}

Many small mammals undergo hibernation to survive in the environmental conditions of cold temperatures and food scarcity during the winter months. Hibernation is a state of profound torpor in which all growth and most physiological and metabolic activities are halted, but some physiological activities continue at a greatly reduced rate. For example, heart rate is reduced from its normal $200-300$ to $3-5$ beats per minute (Zatzman, 1984), respiration is reduced from $100-200$ to $4-6$ breaths per minute (McArthur and Milsom, 1991) and kidney function is strongly suppressed or stopped (Zatzman, 1984). During torpor basal metabolic rate falls to $<5 \%$ of euthermic values (Wang and Lee, 1996) and body temperature ( $\mathrm{Tb}$ ) drops from $37-38^{\circ} \mathrm{C}$ to very low values, often near $0-5^{\circ} \mathrm{C}$ for days or weeks. Despite this, hibernators do not suffer the hypothermia injuries that most other mammals would (Storey and Storey, 2004). According to Wang and Lee (1996), hibernation can save up to $90 \%$ of the energy that would otherwise be needed to maintain the euthermic Tb over the winter months. During hibernation, the overall rates of biochemical activities, including gene transcription and protein synthesis, are strongly suppressed. However, the up-regulation of selected genes may be required to support hibernation, including genes that aid the regulation of metabolic suppression, growth suppression, reorganize metabolic priorities for the torpid state, and contribute to long term preservation of viability.

\section{Preparing for hibernation}

Mammals prepare for hibernation prior to the actual event, with accumulation of fat reserves and preparation of burrows. Ground squirrels get ready for hibernation by 
eating additional food in the late summer and early autumn and storing it as body fat, often nearly doubling their body mass. Ground squirrels select a diet that is high in polyunsaturated fatty acids (PUFAs) and accumulate these in their lipids, the result being that fat depots remain fluid and can be metabolized even at near $0^{\circ} \mathrm{C} \mathrm{Tb}$ values. Ground squirrels make burrows that act as hibernacula for their winter survival. Usually, the purpose of hibernacula is to provide shelter from predators and protect them from frost. Ground squirrel hibernacula usually remain a few degrees above $0^{\circ} \mathrm{C}$ for all or most of the winter (Geiser, 1988).

Entry in to hibernation is a gradual process. A series of "test drops" occur at the early stages of hibernation, in which $\mathrm{Tb}$ of a sleeping animal falls by $10-15^{\circ} \mathrm{C}$ for a short period prior to the arousal. Eventually, the reduction in $\mathrm{Tb}$ become greater and the length of each ensuing torpor bout increases. The hibernating season consists of a series of torpor bouts interspersed with periodic arousals (Fig 1.1). During midwinter $\mathrm{Tb}$ is maintained between $0-5^{\circ} \mathrm{C}$ in between arousals back to euthermia that last for 6-24 hours.

\section{Hibernation}

Hibernators generally begin their winter sleep, when cold autumn temperatures start and they go into their hibernaculum to sleep. During torpor, all physiological and biochemical activities reduce drastically. $\mathrm{Tb}$ typically falls to $0-5^{\circ} \mathrm{C}$ and they save more energy as they become dormant. While they are hibernating, fat storing hibernators can survive for many months by slowly oxidizing stored body fuel reserves which are mainly lipids. Most organs, except brain, rely on the fatty acids and glycerol obtained from triglyceride hydrolysis as their primary fuel source. Brain uses primarily glucose (derived 
from glycogen reserves or by gluconeogenesis) and also ketone bodies (acetoacetate, $B$ hydroxybutyrate) that are by-products of fatty acid catabolism in the liver.

\section{Arousal from hibernation}

The hibernating season is characterized by periodic arousals in which these animals wake up for $12-20$ hours every $2-3$ weeks, rewarming to their normal $\mathrm{Tb}$. Arousals can take 15 minutes to several hours depending on the size of the animal. The energy required to reheat the animal consumes a very high proportion of the total winter energy budget. Physiological activities are restored to near-normal levels. Rewarming of the body is initiated by non-shivering thermogenesis in brown adipose tissue (BAT) but after the $\mathrm{Tb}$ rises to $15-20^{\circ} \mathrm{C}$ shivering thermogenesis in skeletal muscle also begins and adds to the rewarming (Wang et al., 1987). Why these periodic arousals occur is still not clear but several hypotheses have been proposed. According to Geiser and Ruf (1995), the physiological imbalances that arise during hibernation are resolved during this period. These could include the resynthesis of glucose, replenishment of body water or elimination of wastes and toxic substances that cannot be excreted during hibernation. Typically, there is gradual increase in the length of torpor bouts over the autumn and early winter with maximum length in midwinter. However, with the approach of spring, torpor bouts become shorter and shallower until the animal ceases to hibernate (Fig 1.1).

\section{Model hibernator}

The model animal for the present study, the thirteen-lined ground squirrel 
(Spermophilus tridecemlineatus), is one of many North American mammals that are capable of hibernating (Figure 1.2). Adults have characteristic lines on their backs, weigh $130-180 \mathrm{~g}$ and are about $25 \mathrm{~cm}$ long. The species can be found over the prairie regions of Canada and United States in a wide temperature range. These animals are omnivorous and obligate hibernators, remaining in their hibernacula continuously throughout the winter. They disappear into their burrows in September or early October and enter hibernation soon thereafter, emerging again in April or early May. The cycles of torpor followed by brief arousals continue throughout the winter months until the animal arises fully and return to euthermic life (Figure 1.1). During torpor bouts their core $\mathrm{Tb}$ can fall to $\sim 5^{\circ} \mathrm{C}$, heart rate slows and all metabolic functions are strongly reduced. Apnoic breathing patterns and reduced heart rate can lead to conditions of hypoxia or ischemia that would be considered lethal to most of the mammals. Therefore, hibernating thirteenlined ground squirrels provide an excellent research model to study numerous medical complications induced by hypothermia or ischemia, and to assess mechanisms that would improve the cold preservation of organs or prevent injury to oxygen sensitive organs such as brain and heart by ischemic insults such as heart attack or stroke. This thesis focuses on a variety of metabolic responses made by six tissues (brain, heart, lung, kidney, liver, and skeletal muscle) of euthermic and hibernating thirteen-lined ground squirrels.

\section{Brain}

Hibernation involves widespread changes in the activity of the nervous system and provides a natural model of cerebral ischemia tolerance. However, despite dramatically reduced electrical and metabolic activity, most of the functions of the CNS 
continue during torpor (Kilduff et al., 1990). Even though many small hibernators experience a pronounced fluctuation in blood flow during the torpor-arousal cycles, no brain damage occurs. Zhou et al. (2001) concluded that many neuroprotective actions may contribute to such ischemia tolerance. Several early response genes including transcription factors, c-fos, c-jun and junB are differentially expressed in brain during hibernation (O'Hara et al., 1999), reflecting a link between neuronal activation and immediate early gene response. El Ouezzani et al., (2001) showed an increase in the mRNA levels encoding neuropeptide Y (NPY), a transmitter in the nervous system, involved in metabolic regulation. Since NPY is involved in the regulation of feeding behavior including food intake and carbohydrate preference, the stimulation of NPY within the neurons may play an integrative role in the control of energy metabolism in hibernating jerboas.

\section{Heart}

One of the most interesting observations during hibernation is the continued and regulated contractile function of the heart. Even though many other physiological functions are halted, the heart must continue to beat at low rate. The fall in heart rate seen in mammals entering hibernation starts before their Tb falls (Milson et al., 1999). During hibernation the heart mainly depends on fatty acid oxidation rather than carbohydrate catabolism. This change is associated with the differential expression of many genes. Pyruvate dehydrogenase kinase (PDK) isozyme 4 mRNA transcript levels were elevated during hibernation and the resulting increased levels of its gene product in turn inhibits the activity of pyruvate dehydrogenase, suppressing the capacity to catabolize 
carbohydrate (Andrews et al., 1998). Other genes that are up-regulated during hibernation include heart type fatty acid binding protein (H-FABP) (Hittel and Storey, 2001) and the ventricular isoform of myosin light chain 1 (MLC1v). Hibernation induced up-regulation of MLC1v indicates a restructuring of myosin light chain subunit composition and may contribute to the heart muscle contraction during hypothermia (Fahlman et al., 2000).

\section{Lung}

Lung of hibernators has received little attention from researchers. During hibernation, respiration rate is vastly reduced and blood flow to the lung is also significantly reduced. Hence, lungs can experience a prolonged ischemia and possibly hypoxia, especially in species that show long periods of breath hold (apnea) while in torpor. Upon arousal, breathing frequency become normal and resumes its rhythmic pattern (McArthur and Milsom, 1991). The cellular and genetic basis for changes in lung metabolism during torpor-arousal cycle is not yet known. However, as in other tissues, hibernation responsive gene expression should aid lung adaptation for long term torpor.

\section{Kidney}

Even though renal meatabolism is highly reduced during hibernation, studies have reported changes in kidney function of aroused and torpid animals (Zatzman and South, 1972). However, during hibernation kidney is in a hypometabolic state, where renal blood flow is minimal and urine production is much reduced (Zatzman, 1984). These processes resume during periodic arousals paralleling the rise in $\mathrm{Tb}$ and cardiac output. 
There are only moderate effects of hibernation on plasma osmolality and electrolyte concentration and the renin-angiotensin system appears to be functional during periodic arousals (Zatzman, 1984). Hibernators must be able to protect their kidneys from damage as urine production begins immediately upon arousal. As observed in other tissues of hibernators there should be underlying mechanisms of physiological and genetic changes that support long term viability during torpor.

\section{Liver}

Liver is one of the most important organs in mammals as it plays a central role in metabolic and physiological homeostasis. Several hibernation responsive genes have been previously identified in liver including $\alpha_{2}$-macroglobulin, apolipoprotein A1 and cathepsin H (Srere et al., 1992; Epperson and Martin, 2002). $\alpha_{2}$ - Macroglobulin is a broad-spectrum protease inhibitor, synthesized by liver and excreted into the blood. It is partly responsible for the decrease in clotting capacity during hibernation and prevents spontaneous clotting at low temperatures when the rate of blood flow is very low (Srere et al., 1992). Apolipoprotein A1 is a component of high-density lipoprotein (HDL), which transports long-chain fatty acids through the plasma between storage and target tissues (Epperson and Martin, 2002). Since hibernators rely extensively on fatty acid oxidation to supply their energy needs, the proteins involved in fat metabolism and transportation should be up-regulated. The protein encoded by cathepsin $\mathrm{H}$ gene is a lysosomal cysteine proteinase important in the overall degradation of lysosomal proteins and may be involved in low-density lipoprotein (LDL) transportation (Han et al., 2003). 


\section{Skeletal Muscle}

During the hibernation season, animals are mostly inactive and skeletal muscle receives very little use. Prolonged disuse of skeletal muscles in humans and most other mammals leads to muscle atrophy, a pathological condition resulting in a loss of muscle mass and decrease in oxidative capacity. However, during hibernation, small mammals such as ground squirrels experience very little muscle atrophy over long periods of muscle disuse (Wickler et al., 1991). At the gene level, the hibernation-responsive genes that have been identified to date in skeletal muscle are very similar to those identified in the heart. An increase of H-FABP has been reported in skeletal muscle, which indicates that skeletal muscle also relies on lipid catabolism during hibernation (Hittel and Storey, 2001). Similarly, PDK4 and MLClv are also up-regulated in skeletal muscle during hibernation (Buck et al., 2002; Fahlman et al., 2000).

\section{Research Background}

The present study was built upon data generated using commercially available scanning tools. This included the use of human 19K cDNA arrays to identify genes that are putatively up-regulated in hibernating versus euthermic 13-lined ground squirrels; cDNA array scanning used gene chips from the University of Toronto Microarray centre (http://www.uhnres.utoronto.ca/facilities/microarray.htm). Separate scans used TranSignal TF protein arrays from Panomics to analyze over 200 transcription factors in nuclear extracts from ground squirrel tissues (http://www.panomics.com). The Panomics array indicated several transcription factors that showed enhanced binding during hibernation including ChREBP and Ets $1 / 2$ suggesting that they are more active in 
stimulating their gene targets during hibernation. The gene chip data, which covered over 19,000 gene targets indicated hibernation-responsive up-regulation of multiple known downstream gene targets of both chREBP and ETS 1/2.

The leads generated from array screening are highly instructive but cannot be considered as quantitative or definitive, because these tools were developed for specific model organisms (e.g. human). Hence, these data show putative up-regulation of various genes and/or enhanced binding by selected transcription factors in hibernating 13-lined ground squirrels. This provided the rationale for expanded studies of several specific transcription factors and their downstream targets using techniques including Western blotting, RT-PCR, TF-binding arrays, and Electro Mobility Shift Assays (EMSA).

\section{OBJECTIVES}

\section{Regulation of ChREBP during hibernation}

During hibernation, most organs switch from carbohydrate catabolism to a primary dependence on lipid oxidation as their major fuel, except for the brain. Obligate hibernators like $S$. tridecemlineatus accumulate huge fat depots towards the end of the summer as a fuel base for an entire winter that will be spent without eating. The carbohydrate response element-binding protein (ChREBP) is a recently identified transcription factor which plays an important role in glucose metabolism. ChREBP regulates genes that are responsible for converting excess dietary carbohydrate (glucose) into triglycerides. 
Objective 1: My first objective was to analyze the responses of the transcription factor ChREBP and several of its downstream targets in ground squirrel organs in order to assess the role of ChREBP-mediated functions in carbohydrate metabolism during hibernation.

Chapter 2 studies this transcription factor by examining changes in the protein levels of ChREBP between euthermic and hibernating conditions, as well as the DNAbinding activity of ChREBP, and the responses of two downstream genes under ChREBP control: fatty acid synthase (Fasn) and the liver isozyme of pyruvate kinase (Pkl). DNAbinding activity of ChREBP was reduced in liver but increased in skeletal muscle during torpor. Fasn transcript levels were increased in heart and muscle but reduced in brain and liver. $P k l$ transcript levels were also decreased in liver.

\section{Differential regulation of the Ets1 pathwav during hibernation}

Hibernators need to protect themselves against multiple stresses during torpor. During hibernation both heart beat and breathing are highly reduced and organ perfusion rate can be reduced to about $10 \%$ of euthermic values (Frerichs et al., 1994). Many hibernators breath irregularly during hibernation which leads oxygen limitation in most of tissues. Hence, different organs of the hibernators may experience different levels of oxygen which may even lead to hypoxic conditions in these animals. There are many pathways that are activated as a result of hypoxic conditions. Activation of these pathways begins with the activation of growth factor receptors. For example, the epidermal growth factor receptor (EGFR) is known to be activated as a result of hypoxic conditions (Wang et al., 2007). Hypoxia-induced changes have been shown to increase 
the levels of EGFR and its subsequent phosphorylation (Franovic et al., 2007). EGFR signaling typically activates protein kinase C (PKC) (King and Cooper, 1986). In turn, PKCs, mainly PKCa, regulate Ets 1 transcriptional activities in stressed cells (Lindemann et al., 2003) by phosphorylating them. Depending on the domain of the Ets 1 phosphorylation, this can either activate or suppress downstream genes needed or not needed during hibernation. Hence, the activated or deactivated transcription factor Ets 1 can regulate specific genes that function to help maintain cellular viability.

Objective 2: The second objective was to study the transcription factor activity of Ets1, analyzing its organ-specific expression during hibernation and assessing the corresponding responses of its upstream factors to evaluate how Ets1 is regulated. A particular focus for regulation is on the EGFR dependent pathway which involves PKC phosphorylation of Ets1.

Chapter 3 analyzes this objective by examining the protein levels of EGFR and phosphorylated EGFR (phospho-EGFR), PKC $\mu$, phospho-PKC $\mu$, phospho-PKC $\alpha / \beta$, and Ets 1 as well as the relative mRNA transcript levels of Ets1. Ets1 DNA-binding activity was also evaluated. The EGFR, phospho-EGFR, PKC and phospho-PKC protein levels increased in an organ specific manner in parallel with the increase in Ets1, which possibly leads to a PKC dependant phosphorylation of Ets1 during hibernation. Ets 1 mRNA transcript levels were increased in most of the organs except for brain. Ets 1 DNA-binding activity also decreased in liver of hibernating squirrels but was unchanged in skeletal muscle. 


\section{INTRODUCTION}

Many small mammals undergo hibernation to survive in the environmental conditions of cold temperatures and food scarcity during the winter months. Hibernation is a state of profound torpor in which all growth and most physiological and metabolic activities are halted, but some physiological activities continue at a greatly reduced rate. For example, heart rate is reduced from its normal $200-300$ to $3-5$ beats per minute (Zatzman, 1984), respiration is reduced from $100-200$ to $4-6$ breaths per minute (McArthur and Milsom, 1991) and kidney function is strongly suppressed or stopped (Zatzman, 1984). During torpor basal metabolic rate falls to $<5 \%$ of euthermic values (Wang and Lee, 1996) and body temperature ( $\mathrm{Tb}$ ) drops from $37-38^{\circ} \mathrm{C}$ to very low values, often near $0-5^{\circ} \mathrm{C}$ for days or weeks. Despite this, hibernators do not suffer the hypothermia injuries that most other mammals would (Storey and Storey, 2004). According to Wang and Lee (1996), hibernation can save up to $90 \%$ of the energy that would otherwise be needed to maintain the euthermic Tb over the winter months. During hibernation, the overall rates of biochemical activities, including gene transcription and protein synthesis, are strongly suppressed. However, the up-regulation of selected genes may be required to support hibernation, including genes that aid the regulation of metabolic suppression, growth suppression, reorganize metabolic priorities for the torpid state, and contribute to long term preservation of viability.

\section{Preparing for hibernation}

Mammals prepare for hibernation prior to the actual event, with accumulation of fat reserves and preparation of burrows. Ground squirrels get ready for hibernation by 
during hibernation in an organ-specific manner. Levels of c-Myc protein and $B c l 2$ transcript levels were also measured as examples of the downstream targets of the RbE2F pathway; both were significantly reduced in most of the organs tested. This clearly indicates a reduced gene transcriptional state in thirteen-lined ground squirrels during hibernation. 
Fig. 1.1: Body temperature $(\mathrm{Tb})$ of a golden-mantled ground squirrel (S. lateralis) as a function of time over a one year period, showing the summer active and winter hibernation season. The enlargement shows a region encompassing three torpor-arousal cycles. The different stages are entrance into torpor (EN) lasting $\sim 12 \mathrm{~h}$; early torpor (ET) lasting $\sim 48 \mathrm{~h}$; late torpor (LT) about 7-14 days; arousal (AR) lasting $\sim 2 \mathrm{~h}$, and interbout arousal (IBA) with duration of $\sim 20 \mathrm{~h}$. This figure is adopted from Carey et al. (2003a). 
Figure 1.1

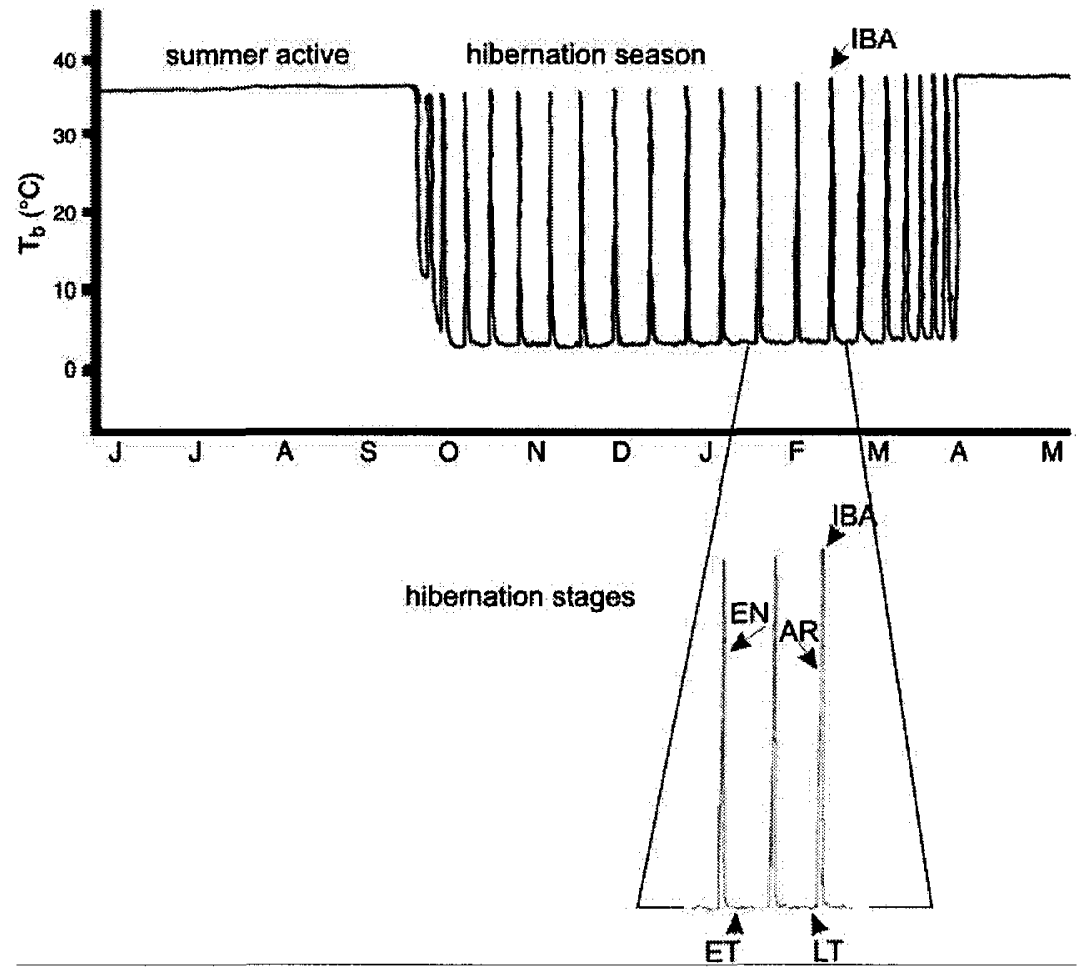


Fig. 1.2: Distribution map for thirteen-lined ground squirrels, $S$. tridecemlineatus. The range of thirteen-lined ground squirrels extends from Central Alberta, Manitoba, and Saskatchewan in the North to Texas and New Mexico in the South, and from Central Ohio in the east to Colorado in the west. Taken from Cleary and Craven (1994). 
Figure 1.2

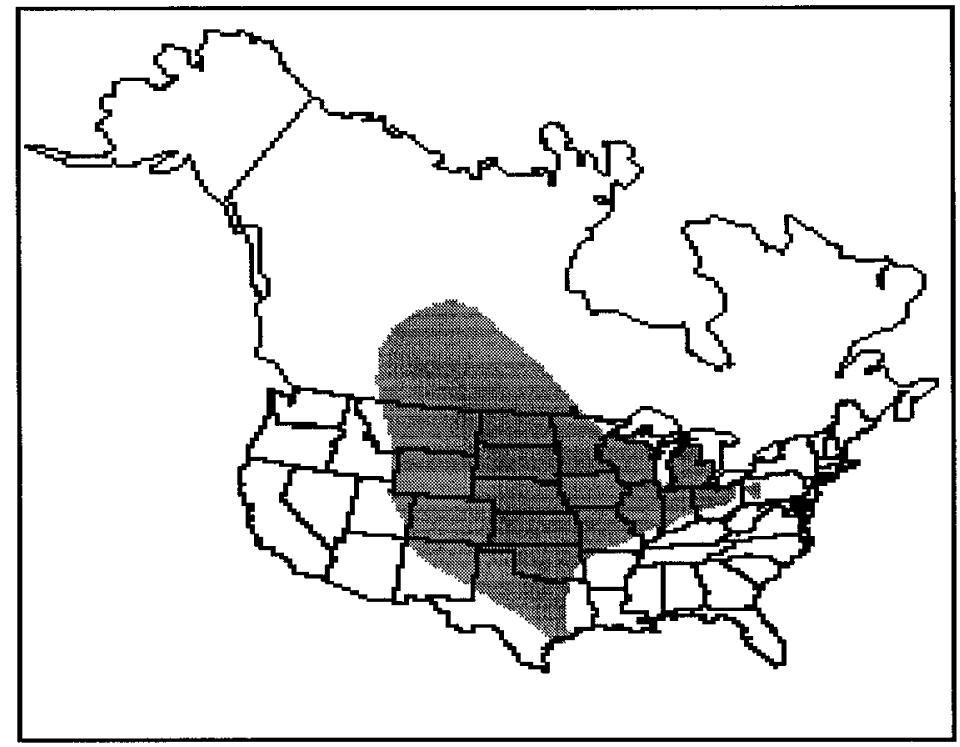




\section{Chapter 2}

\section{Changes in the ChREBP pathway in hibernating}

\section{thirteen-lined ground squirrels}




\section{INTRODUCTION}

Hibernation is a state of greatly suppressed metabolic and physiological activity that is used by many small mammals to survive long and cold winters (Boyer and Barnes, 1999; Storey, 2000). By hibernating with only brief periodic arousals over the winter these animals save $\sim 90 \%$ of the energy compared with the costs of remaining euthermic over the winter (Storey, 2000). Most fat-storing hibernators' energy intake increases during summer body mass gain phase and towards the end of this phase. An increased activity of lipogenic enzymes and hormones are observed during this period. During the winter hibernation phase the stored lipids are utilized slowly in a programmed manner.

In the absence of food intake, the only sources for glucose are liver and muscle glycogen reserves and glucose produced via gluconeogenesis. In hibernators glucose concentrations are found at reduced levels (Catex et al., 1984). Furthermore, radiolabeled glucose incorporation into $\mathrm{CO}_{2}$ is significantly suppressed during hibernation (Tashima et al., 1970). In addition, the activities of many enzymes important for glycolytic activity such as phosphofructokinase (PFK), pyruvate kinase (PK) and pyruvate dehydrogenase $(\mathrm{PDH})$ are actively reduced during hibernation via the mechanism of reversible protein phosphorylation (Brooks and Storey, 1992; Buck et al., 2002). In fact, most hibernators rely almost entirely on the oxidation of stored lipid reserves as the primary fuel source during hibernation, with most organs switching to fatty acid oxidation by mitochondria as the main means of generating ATP. The exception to this is brain and a few other tissues that can only catabolize glucose (e.g. erythrocytes, retina, etc). Indeed, even brain which does not take up and oxidize triglycerides directly, still has a way of utilizing a lipidbased fuel during hibernation to supplement glucose. This is by oxidizing ketone bodies 
that are produced during lipid catabolism in the liver and then transported to the brain for use as a fuel.

Even though multiple metabolic processes are gradually shut down during entry into the hypometabolic state, they must be retained in readiness in order to rapidly regain their activity during arousal. Hence, metabolic pathways are not degraded and, instead, they are controlled by reversible mechanisms (e.g. reversible phosphorylation of enzymes) (Storey and Storey, 2004). For example, inhibition of carbohydrate catabolism during hibernation is aided by the phosphorylation of PDH, the enzyme that regulates carbohydrate entry into the tricarboxylic acid cycle. The amount of the active dephosphorylated form of PDH in ground squirrel tissues falls from $60-80 \%$ in euthermia to less than 5\% in hibernation (Brooks and Storey, 1992; Storey, 1997).

By considering all the above factors, I predicted that hibernators may need regulatory mechanisms to control the conversion of carbohydrates into fat and these mechanisms may be controlled by reversible protein phosphorylation. The recently identified transcription factor ChREBP plays an important role in regulating the expression of genes whose protein products are involved in converting dietary carbohydrates into fat. Intake of excess dietary carbohydrate leads to the activation of key enzymes involved in lipogenesis (Yamashita et al., 2001). These lipogenic genes contain "carbohydrate responsive elements, ChORE" within their promoters to which ChREBP can bind. ChREBP is regulated at two levels, nuclear entry and DNA binding, by a reversible phosphorylation mechanism. In the presence of cAMP, ChREBP is phosphorylated on Ser 196 by cAMP-dependent protein kinase (PKA), an action that prevents nuclear entry. The DNA binding activity is also inactivated by PKA, this time 
by phosphorylation at Thr 666 of ChREBP (Kawaguchi et al., 2001a) (Fig. 2.1). Elevated lipid levels in cells feed back to inhibit the glucose utilization (Kawaguchi et al., 2001b). Fatty acids increase the AMP concentration in the liver which activates AMP dependant kinase (AMPK). ChREBP is phosphorylated by AMPK at Serine 568, which inhibits DNA binding activity to suppress the transcription of lipogenic genes. High glucose leads to a reversal of this effect via the action of protein phosphatase (PP2A) (Uyeda et al., 2002) (Fig 2.1). This chapter examines the organ-specific responses of ChREBP, its possible phosphorylation status, nuclear entry and ChREBP DNA-binding activities during hibernation. Furthermore, the responses of selected downstream genes known to be under ChREBP control are examined including fatty acid synthase (fasn) and liver type pyruvate kinase $(P k l)$ the gene encoding the liver $(\mathrm{L})$ isozyme of $\mathrm{PK}$. 


\section{MATERIALS AND METHODS}

\section{Animal experiments and tissue collection}

Thirteen-lined ground squirrels, Spermophilus tridecemlineatus (130-180 g), were captured by a licensed trapper (TLS Research, Michigan) and transported to the Animal Hibernation Facility at the National Institute of Neurological Disorders and Stroke (NIH, Bethesda, MD). All animal experiments were conducted by the laboratory of Dr. J.M. Hallenbeck using their standard protocols (Chen et al., 2001) that are approved by the NIH Institutional Animal Care and Use Committee. Briefly, animals were kept on a fall day/night light cycle at $21^{\circ} \mathrm{C}$ in shoebox cages containing wood shavings and fed ad libitum until they entered and finished the pre-hibernation phase of hyperphagia that maximizes lipid stores. A sensor chip was introduced under the squirrel skin and the Body temperature $(\mathrm{Tb})$ of each animal was monitored electronically. When squirrels had reached a plateau weight of $220-240 \mathrm{~g}$, they were placed in their cages into a cold chamber at $4^{\circ} \mathrm{C}$ and $60 \%$ humidity. The hibernaculum was kept in constant darkness, except for a photographic red safe light (3-5 lux), and could be entered only through a darkened anteroom. Noise within the chamber was kept to a minimum. Individuals settled into hibernation after different lengths of time but all were sampled on the same day after each individual had been hibernating for $2-5$ days (as indicated by continuous $\mathrm{Tb}$ readings of $\sim 6^{\circ} \mathrm{C}$ ). Animals that had not entered torpor after at least 3 days in the cold room and that showed continuous high $\mathrm{Tb}\left(36-38^{\circ} \mathrm{C}\right)$ were sampled as controls. All animals were killed by decapitation and tissues were excised, frozen immediately in liquid nitrogen and transported to Ottawa on dry ice where they were placed at $-80^{\circ} \mathrm{C}$ until use. 
Table 2.1

List of antibodies used in this thesis together with the dilutions and the relevant supplier companies. Note that all secondary antibodies were purchased from Cell Signaling.

\begin{tabular}{|c|c|c|c|}
\hline Antibody & $\begin{array}{l}\text { Primary } \\
\text { Antibody }\end{array}$ & $\begin{array}{l}\text { Supplier of } \\
\text { primary }\end{array}$ & $\begin{array}{l}\text { Secondary } \\
\text { Antibody }\end{array}$ \\
\hline ChREBP & $\begin{array}{l}\text { Goat polyclonal } \\
1: 5000\end{array}$ & $\begin{array}{l}\text { SantaCruz } \\
\text { Biotechnologies }\end{array}$ & $\begin{array}{l}\text { Donkey anti-goat } \\
1: 2000\end{array}$ \\
\hline Phospho serine & $\begin{array}{l}\text { Rabbit polyclonal } \\
1: 5000\end{array}$ & Stressgen & $\begin{array}{l}\text { Anti rabbit } \\
1: 2000\end{array}$ \\
\hline EGFR & $\begin{array}{l}\text { Rabbit monoclonal } \\
1: 5000\end{array}$ & Epitomics & $\begin{array}{l}\text { Anti rabbit } \\
1: 2000\end{array}$ \\
\hline $\begin{array}{l}\text { Phospho EGFR } \\
\text { (Tyr 1173) }\end{array}$ & $\begin{array}{l}\text { Rabbit monoclonal } \\
1: 5000\end{array}$ & Epitomics & $\begin{array}{l}\text { Anti rabbit } \\
1: 2000\end{array}$ \\
\hline $\begin{array}{l}\text { Phospho EGFR } \\
\text { (Tyr 1086) }\end{array}$ & $\begin{array}{l}\text { Rabbit monoclonal } \\
1: 5000\end{array}$ & Epitomics & $\begin{array}{l}\text { Anti rabbit } \\
1: 2000\end{array}$ \\
\hline PKC $\mu /$ PKD & $\begin{array}{l}\text { Rabbit polyclonal } \\
1: 5000\end{array}$ & Cell Signaling & $\begin{array}{l}\text { Anti rabbit } \\
1: 2000\end{array}$ \\
\hline $\begin{array}{l}\text { PPKC } \mu / \text { PKD } \\
(\text { Ser 916) }\end{array}$ & $\begin{array}{l}\text { Rabbit polyclonal } \\
1: 5000\end{array}$ & Cell Signaling & $\begin{array}{l}\text { Anti rabbit } \\
1: 2000\end{array}$ \\
\hline $\begin{array}{l}\operatorname{PPKC}(\alpha / \beta \text { II) } \\
(T h r 638 / 641)\end{array}$ & $\begin{array}{l}\text { Rabbit polyclonal } \\
1: 5000\end{array}$ & Cell Signaling & $\begin{array}{l}\text { Anti rabbit } \\
1: 2000\end{array}$ \\
\hline Ets1 & $\begin{array}{l}\text { Rabbit polyclonal } \\
1: 5000\end{array}$ & $\begin{array}{l}\text { Santa Cruz } \\
\text { Biotechnologies }\end{array}$ & $\begin{array}{l}\text { Anti-rabbit } \\
1: 2000\end{array}$ \\
\hline Total Rb & $\begin{array}{l}\text { Mouse monoclonal } \\
1: 2000\end{array}$ & Cell Signaling & $\begin{array}{l}\text { Anti mouse } \\
1: 2000\end{array}$ \\
\hline $\begin{array}{l}\text { Phospho Rb } \\
\text { (Ser 780) }\end{array}$ & $\begin{array}{l}\text { Rabbit polyclonal } \\
1: 2000\end{array}$ & Cell Signaling & $\begin{array}{l}\text { Anti rabbit } \\
1: 2000\end{array}$ \\
\hline $\begin{array}{l}\text { Phospho Rb } \\
\text { (Ser 795) }\end{array}$ & $\begin{array}{l}\text { Rabbit polyclonal } \\
1: 2000\end{array}$ & Cell Signaling & $\begin{array}{l}\text { Anti rabbit } \\
1: 2000\end{array}$ \\
\hline E2F1 & $\begin{array}{l}\text { Rabbit polyclonal } \\
1: 5000\end{array}$ & $\begin{array}{l}\text { Santa Cruz } \\
\text { Biotechnologies }\end{array}$ & $\begin{array}{l}\text { Anti rabbit } \\
1: 2000\end{array}$ \\
\hline HDAC 4 & $\begin{array}{l}\text { Rabbit polyclonal } \\
1: 5000\end{array}$ & Cell Signaling & $\begin{array}{l}\text { Anti rabbit } \\
1: 2000\end{array}$ \\
\hline HDAC 6 & $\begin{array}{l}\text { Rabbit polyclonal } \\
1: 5000\end{array}$ & Cell Signaling & $\begin{array}{l}\text { Anti rabbit } \\
1: 2000\end{array}$ \\
\hline SUV39H1 & $\begin{array}{l}\text { Goat polyclonal } \\
1: 5000\end{array}$ & $\begin{array}{l}\text { Santa Cruz } \\
\text { Biotechnologies }\end{array}$ & $\begin{array}{l}\text { Donkey anti-goat } \\
1: 2000\end{array}$ \\
\hline c-Myc & $\begin{array}{l}\text { Rabbit monoclonal } \\
1: 5000\end{array}$ & Epitomics & $\begin{array}{l}\text { Anti rabbit } \\
1: 2000\end{array}$ \\
\hline
\end{tabular}




\section{Protein extraction and Western blot analysis}

Western blotting was used to examine the levels of ChREBP protein in tissue samples from euthermic and hibernating animals. Cell-free extracts were prepared by homogenizing frozen tissue samples $(500 \mathrm{mg})$ using a Polytron homogenizer and $1 \mathrm{ml}$ of homogenizing buffer containing $20 \mathrm{mM}$ Tris-base, $150 \mathrm{mM} \mathrm{NaCl}, 1 \mathrm{mM}$ EDTA, $1 \mathrm{mM}$ EGTA, $1 \mathrm{mM} \mathrm{NaF}, 10 \mathrm{mM}$ B-glycerophosphate, $1 \% \mathrm{v} / \mathrm{v}$ Triton X-100 and $1 \mathrm{mM}$ phenylmethylsulfonyl fluoride. After $15 \mathrm{~min}$ centrifugation at $10,000 \mathrm{x}$, supernatant was removed and soluble protein concentrations were determined using the BioRad protein assay (BioRad Laboratories, Hercules, CA). Sample protein concentrations were then adjusted slightly to a constant value of $20 \mu \mathrm{g} / \mu \mathrm{l}$ by addition of homogenizing buffer. Aliquots of supernatant were then mixed 1:1 v/v with 2X SDS-PAGE sample buffer (100 $\mathrm{mM}$ Tris-HCl pH 6.8, 4\% w/v SDS, $20 \% \mathrm{v} / \mathrm{v}$ glycerol, $0.4 \% \mathrm{w} / \mathrm{v}$ bromophenol blue) with freshly added $10 \% \mathrm{v} / \mathrm{v} 2$-mercaptoethanol. Samples were boiled and stored at $-20^{\circ} \mathrm{C}$ until use. Equal amounts of protein from control and hibernating lysates (10-20 $\mu \mathrm{g}$ depending on the experiment) were then layered on 10 or $12 \%$ SDS polyacrylamide gels $(10 \%$ or $12 \%$ acrylamide, $0.4 \mathrm{M}$ Tris $\mathrm{pH} 8.8,0.1 \%$ SDS, $0.1 \%$ APS, 0.04\% TEMED), covered with a $5 \%$ stacking gel (5\% acrylamide, $0.13 \mathrm{M}$ Tris $\mathrm{pH} 6.8,0.1 \%$ SDS, $0.1 \%$ APS, $0.1 \%$ TEMED) and separated at $180 \mathrm{~V}$ for $1 \mathrm{~h}$. Kaleidoscope prestained molecular mass markers (Bio-Rad) were used to estimate the size and positions of proteins on the gel. Proteins were then electroblotted onto polyvinylidene difluoride (PVDF) membranes (Pall) by wet transfer with pre-chilled solution containing $25 \mathrm{mM}$ Tris (pH 8.5), $192 \mathrm{mM}$ glycine, and $20 \% \mathrm{v} / \mathrm{v}$ methanol at $4{ }^{\circ} \mathrm{C}$ for $90 \mathrm{~min}$ at $400 \mathrm{~mA}$. After the transfer of proteins, membranes were blocked for $15 \mathrm{~min}$ in Tris buffered saline containing Tween- 
20 (TBST)(20 mM Tris base, $140 \mathrm{mM} \mathrm{NaCl}, 0.05 \% \mathrm{v} / \mathrm{v}$ Tween-20) with $1.25 \%$ non-fat dried milk added. The blots were then incubated at $4^{\circ} \mathrm{C}$ overnight with primary antibody diluted 1:5000 v/v in TBST. Goat anti-ChREBP polyclonal antibodies (Santa Cruz Biotechnology Inc., Santa Cruz, CA) and rabbit anti-phosphoserine polyclonal antibodies (Stressgen) were used as primary antibody (Catalogue number KAP-ST210). After incubation, blots were washed several times with TBST and then incubated at room temperature for $90 \mathrm{~min}$ with a 1:2000 v/v dilution of secondary antibody, donkey antigoat IgG or and anti-rabbit polyclonal IgG conjugated to horseradish peroxidase (Cell Signaling Technology Inc., Danvers, MA). Detection of signal on the PVDF membrane was done using an enhanced chemiluminescence (ECL) system as recommended by the manufacturer (Immobilon). If multiple bands were observed in first trials, then blocking procedures were used and optimized until a single band was obtained at the right molecular weight (Figure 2.1 A). Typically, optimum blocking was achieved with 1.25$2.5 \%$ non-fat milk and incubation for $15-45$ minutes. Confirmation that the antibody was crossreacting with the correct protein was accomplished with competition studies using the relevant immunizing peptide (the antigen that was used to generate the particular antibody). When incubated in the presence of antibody + peptide, the band representing the correct protein disappeared (in selected cases this method also showed that other minor bands on the blot represented nonspecific binding). A further confirmation technique such as 2D-gel electrophoresis also can be performed but was not necessary with any of the proteins analyzed in this thesis.

Quantification was performed using the ChemiGenius Bio Imaging System and the associated GeneTools software (Syngene, MD, USA). Equal protein loading was 
confirmed by Coomassie blue staining of the membrane. Operational information about analyzing bands by the GeneTools software is available at the following website: http://www.nebiogroup.com/pdf/syngeneapps/Gold $\% 20$ Stained $\% 20$ Immunoblots $\% 20=\%$ 20Note\%2038.pdf

\section{Preparation of cytoplasmic and nuclear extracts}

Nuclear extracts from muscle of euthermic and hibernating ground squirrels were prepared using a slight modification of the method described by Dignam et al. (1983). Briefly, $0.5 \mathrm{~g}$ of tissue was disrupted at $4^{\circ} \mathrm{C}$ in $1 \mathrm{ml}$ homogenization buffer $(10 \mathrm{mM}$ HEPES, $\mathrm{pH} 7.9,10 \mathrm{mM} \mathrm{KCl}, 10 \mathrm{mM}$ EDTA, $10 \mathrm{mM}$ DTT) with $1.5 \mu$ protease inhibitor cocktail (Sigma) added using a Douce homogenizer. Nuclei were pelleted by centrifugation at $10000 \mathrm{xg}$ for $10 \mathrm{~min}$. The supernatant, which represents the cytoplasmic extract, was removed and the pellet was washed with the same buffer before being resuspended in $150 \mu 1$ of extraction buffer (20 mM HEPES, pH 7.9, $400 \mathrm{mM} \mathrm{NaCl}$, $1 \mathrm{mM}$ EDTA, $10 \% \mathrm{v} / \mathrm{v}$ glycerol, $10 \mathrm{mM}$ DTT, and $1.5 \mu \mathrm{l}$ protease inhibitor cocktail) and mixed at $4^{\circ} \mathrm{C}$ for $1 \mathrm{~h}$ with gently shaking. After centrifugation at $10,000 \mathrm{xg}$ for $10 \mathrm{~min}$ the supernatant (nuclear extract) was collected. Protein concentrations in the cytoplasmic and nuclear fractions were determined by the Bio-Rad protein assay. To confirm the separation of these two fractions, $10 \mu \mathrm{g}$ of protein from cytoplasmic and nuclear extracts of both euthermic and hibernating animals were separated by SDS-PAGE and then gels were subjected to Western blotting with anti-histone $\mathrm{H} 3$ antibody (Cell Signaling) at a dilution of 1: 5000, followed by anti-rabbit secondary antibody at a dilution of 1:2000. The histone H3 band was found only in the nuclear extracts and not in the cytoplasmic 
extracts, thereby confirming the integrity of the nuclei when separated from the cytoplasmic fraction (data not shown). In addition, separation of the nuclear vs cytoplasmic fractions was verified by immunoblotting with ChREBP antibody; the ChREBP band found in the nuclear fraction was more intense than the cytoplasmic fraction.

\section{Total RNA extraction}

All materials and solutions were treated with $0.1 \% \mathrm{v} / \mathrm{v}$ diethylpyrocarbonate (DEPC) and autoclaved prior to use. Total RNA was isolated from tissues of control and hibernating ground squirrels using Trizol ${ }^{\mathrm{TM}}$ reagent (Invitrogen), essentially following manufacturer's instructions. Briefly, 50-100 mg of tissue was homogenized in $1 \mathrm{ml}$ Trizol using a Polytron homogenizer followed by the addition of $200 \mu 1$ of chloroform and then centrifugation at $10,000 \times \mathrm{g}$ for $15 \mathrm{~min}$ at $4^{\circ} \mathrm{C}$. The upper aqueous phase that contains total RNA was removed to a fresh tube and RNA was precipitated by adding $500 \mu \mathrm{l}$ of isopropanol followed by incubation at room temperature for $10 \mathrm{~min}$. After a second centrifugation at $10,000 \times \mathrm{g}$ for $15 \mathrm{~min}$ at $4^{\circ} \mathrm{C}$, the total RNA pellet was washed with $1 \mathrm{ml}$ of $70 \%$ ethanol and then centrifuged as above. The supernatant was removed and the pellet was air-dried for 10-15 min. A volume of $50 \mu 1$ DEPC-treated water was added to resuspend the RNA pellet. Four samples of each tissue were separately extracted. The quality of total RNA was judged based on the ratio of absorbances at $260 \mathrm{~nm}$ and 280

$\mathrm{nm}$. In addition, all RNA samples were assessed using 1\% agarose gel electrophoresis with ethidium bromide staining to check for the integrity of $18 \mathrm{~S}$ and $28 \mathrm{~S}$ ribosomal RNA (rRNA) bands. 


\section{First strand cDNA synthesis and PCR amplification}

Approximately $15 \mu \mathrm{g}$ of total RNA was diluted with DEPC water to $10 \mu \mathrm{L}$ final volume and used to synthesize cDNA. Briefly, $1 \mu \mathrm{l}$ of $200 \mathrm{ng} / \mu \mathrm{l}$ oligo-dT (5'TTTTTTTTTTTTTTTTTTTTTTV-3'; V=A or G or C) (Sigma Genosys) that forms a hybrid with the poly A tail of mRNA was added to the RNA sample and placed at $65^{\circ} \mathrm{C}$ in a PCR machine (Mastercycler, Eppendorf) for $5 \mathrm{~min}$. The mixture was then chilled rapidly on ice and $4 \mu \mathrm{l}$ of $5 \mathrm{X}$ first strand buffer, $2 \mu 110 \mathrm{mM} \mathrm{DTT}, 1 \mu \mathrm{dNTPs}$ and $1 \mu \mathrm{l}$ reverse transcriptase enzyme Superscript II (all reagents from Invitrogen) were added for a total volume of $19 \mu 1$. The mixture was incubated at $42^{\circ} \mathrm{C}$ for $45 \mathrm{~min}$ and then held at $4^{\circ} \mathrm{C}$. The resulting cDNA from both control and hibernating samples were serially diluted $\left(10^{-1}, 10^{-2}, 10^{-3}, 10^{-4}, 10^{-5}\right)$ and then amplified by the polymerase chain reaction (PCR) using Fasn or Pkl primers. Primers were designed based on the consensus sequence of mammalian (human, mouse and rat) Fasn and $P k l$ using the Primer Designer program, version 3.0 (Scientific and Educational Software). Primers were ordered from Sigma Genosys. The nucleotide sequences of the Fasn primer pairs used were: forward 5' GATAGCCTGGTAGGCGTTGT - 3' and reverse 5' - TGCTTCTGACAGGCATCAAC - 3'. Nucleotide sequences of the $P k l$ primer pairs were: forward 5' TCCTGGCTCAGAAGATGATG - 3' and 5' - CTGATGGCCAGACAACACTC - 3'. The PCR reaction of $25 \mu \mathrm{l}$ final volume was composed by mixing $14 \mu \mathrm{l}$ of sterile water, 5 $\mu \mathrm{l}$ of diluted cDNA, $1.25 \mu \mathrm{l}$ of primer mixture ( $0.5 \mu \mathrm{M}$ forward and $0.5 \mu \mathrm{M}$ reverse), 2.5 $\mu 1$ of 10X PCR buffer (Invitrogen), $1.25 \mu \mathrm{l}$ of $50 \mathrm{mM} \mathrm{MgCl} 2,0.5 \mu 1$ of $10 \mathrm{mM}$ dNTPs and $0.5 \mu$ l of Taq Polymerase (Invitrogen). Amplification of Fasn began with an initial step of $4 \mathrm{~min}$ at $94^{\circ} \mathrm{C}$ followed by 35 cycles of $30 \mathrm{sec}$ at $94^{\circ} \mathrm{C}, 30 \mathrm{sec}$ at $62^{\circ} \mathrm{C}$, and $30 \mathrm{sec}$ 
at $72^{\circ} \mathrm{C}$. The final step was $72^{\circ} \mathrm{C}$ for $7 \mathrm{~min}$. The PCR conditions for $P k l$ were the same except that the annealing temperature was $61^{\circ} \mathrm{C}$. The housekeeping gene $\alpha$-tubulin was amplified as an internal control; the primers used for this were forward (5' AAGGAAGATGCTGCCAATAA - 3') and reverse (5' - GGTCACATTTCACCATCTG - 3'). PCR products were separated on a $1 \%$ agarose gel, stained with ethidium bromide, and the intensity of the most dilute cDNA sample that was visible was used for quantification purposes to make sure that the products had not reached their amplification saturation. Quantification was performed using the ChemiGenius Bio Imaging System and Gene Tools software (Syngene, MD, USA). Band densities of Fasn or $P k l$ were standardized against $\alpha$-tubulin band densities for the same dilution of the same sample.

\section{Sequencing}

RT-PCR products were sequenced by Canadian Molecular Research Services (Ottawa, ON). Sequences were verified as encoding the $P k l$ or Fasn using the program BLASTN (http://www.ncbi.nlm.nih.gov/blast) at the NIH. The deduced amino acid sequences were also verified as being PKL or Fasn by using the program BLASTP at the same site.

\section{ChREBP DNA binding assay}

The assay kit for the ChREBP DNA binding assay was purchased from Cayman Chemicals. This kit contains a 96-well microplate to which the ChREBP consensusbinding site oligonucleotide was immobilized. Nuclear extracts were prepared from liver and skeletal muscle as described above and then binding assays were performed 
according to the manufacturer's protocol. Briefly, $90 \mu$ of binding buffer was added to each sample and positive control well followed by $10 \mu \mathrm{l}$ of nuclear extract from euthermic or hibernating liver or muscle and positive control nuclear extracts, respectively. The nuclear extracts were standardized to contain a concentration of $1 \mu \mathrm{g} / \mu \mathrm{l}$ prior to the experiment. Nonspecific and blank wells contained $100 \mu \mathrm{l}$ of binding buffer. Competitive wells were prepared containing $80 \mu$ l binding buffer, followed by $10 \mu 1$ competitor dsDNA and $10 \mu \mathrm{l}$ nuclear extract. ChREBP binding was allowed to proceed for $2 \mathrm{~h}$ at $21^{\circ} \mathrm{C}$ without agitation. The microplates were then washed five times with 200 $\mu l$ of $1 \mathrm{X}$ wash buffer per well to remove unbound transcription factors. Anti-ChREBP specific primary antibody diluted 1:100 v:v in antibody binding buffer was then added to each well except the blank wells and incubated for $90 \mathrm{~min}$ at $21^{\circ} \mathrm{C}$ without shaking. The wells were again washed five times with $200 \mu$ washing buffer and then secondary antibody (HRP-linked goat anti-rabbit IgG) was added to the wells (except the blank wells) in a 1:100 v/v dilution in antibody binding buffer and incubated for $1 \mathrm{~h}$ at $21^{\circ} \mathrm{C}$ without shaking. The wells were then washed five times with washing buffer and then the manufacturer's developing solution $(100 \mu \mathrm{l})$ was added and incubated for $45 \mathrm{~min}$ in the dark. The stop solution $(100 \mu \mathrm{l})$ was then added, allowed to develop for $5 \mathrm{~min}$, and color development was quantified spectrophotometrically by absorbance readings at $450 \mathrm{~nm}$.

\section{Statistical analysis}

RT-PCR ( $n=3-4)$ and Western Blotting $(n=3-5)$ data were gathered from independent tissue extracts from different animals, a total pool size of $n=5$ individuals being available for each treatment group. RT-PCR band densities for Fasn and $P k l$ were 
normalized relative to $\alpha$-tubulin band densities obtained from the same cDNA dilution. Western blot bands specific to ChREBP protein were normalized against the combined densities of a group of three Coomassie stained protein bands that did not change in intensity between euthermic and hibernating conditions and that were well-separated from the ChREBP band on the blot. Data are expressed as means with corresponding SEM. Statistical testing of normalized band intensities from euthermic versus hibernating samples used the Student's $t$-test with significance levels of $\mathrm{P}<0.05$. The relative amount of protein or RT-PCR product in euthermic and hibernating samples was then calculated and plotted in histograms.

\section{RESULTS}

\section{ChREBP protein levels in $S$. tridecemlineatus}

ChREBP expression levels were assessed in six tissues (brain, heart, kidney, liver, muscle and brown adipose tissue [BAT]) of ground squirrels via western blotting. A goat anti-ChREBP antibody cross reacted with a single protein band at $\sim 95 \mathrm{kDa}$ (Fig. $2.2 \mathrm{~A}$ and B) that corresponded with the known size of the ChREBP protein in other mammals. Figure 2.2C shows that ChREBP protein levels changed significantly $(\mathrm{P}<0.05)$ in all tissues during hibernation, increasing in four tissues and decreasing in two. ChREBP protein levels rose during hibernation by 6.5 -fold in heart, by 1.3 -fold in skeletal muscle and by 2 -fold in brain and BAT. Protein levels fell in kidney and liver of hibernating animals to about $40 \%$ and $20 \%$, respectively, of the corresponding euthermic values 


\section{Phosphoserine protein levels in S. tridecemlineatus tissues}

ChREBP protein is regulated via phosphorylation and dephosphorylation of multiple serine residues. In order to assess whether the phosphorylation status of ChREBP protein changed during hibernation, an antibody was used that recognized all phosphoserine residues. The relative phosphorylation state of the $95 \mathrm{kDa}$ protein band was then quantified. This type of procedure for the phosphorylation status was carried out due to the lack of commercially available phospho specific ChREBP antibody. Figure 2.3 shows that the relative amount of phosphorylated serine residues on the protein band at $95 \mathrm{kDa}$ increased significantly during hibernation in four out of five organs tested (except skeletal muscle). Levels of serine phosphorylated proteins at $95 \mathrm{kDa}$ increased by 1.75 fold in brain, 1.45 -fold in heart, 1.4 fold in liver and 2.4 fold in kidney.

\section{Distribution of ChREBP in cytoplasmic and nuclear extracts}

The distribution of ChREBP between cytoplasmic and nuclear fractions of liver and muscle was also assessed using western blotting. Figure 2.4A shows representative Western blots and histograms of ChREBP protein levels in subcellular fractions from muscle of euthermic versus hibernating animals. The relative amount of ChREBP in the nuclear fraction was significantly lower than the respective cytoplasmic level in euthermic skeletal muscle. However, during hibernation, nuclear ChREBP content increased greatly to about 3 -fold higher $(\mathrm{P}<0.05)$ than the cytoplasmic amount. Figure 2.4 B shows the same analysis for liver of euthermic versus hibernating animals. In euthermic liver, the relative amounts of ChREBP in cytoplasmic and nuclear fractions 
were similar. However, during hibernation the relative amount of ChREBP in the nuclear fraction decreased significantly to about $75 \%$ of the amount in the cytoplasmic fraction.

\section{ChREBP Binding activity in S. tridecemlineatus}

Transcription factor binding to DNA is key to the ability to trigger transcriptional activity of target genes. To assess the amount of ChREBP binding to DNA, an assay kit from Cayman Chemicals was used which contains the ChREBP consensus-binding site oligonucleotide immobilized to wells on a microplate. The binding activity of ChREBP was assessed in nuclear extracts from liver and muscle of euthermic and hibernating ground squirrels as a function of the change in absorbance at $460 \mathrm{~nm}$ after ChREBP binding. Figure 2.5 shows that DNA binding activity was $0.336 \pm 0.01$ for liver nuclear extracts from euthermic animals and $0.200 \pm 0.001$ ( $\mathrm{n}=3$ independent trials; $\mathrm{P}<0.05$ ) for liver nuclear extracts from hibernating animals. In muscle, binding activities were $0.07 \pm$ 0.003 and $0.138 \pm 0.005(\mathrm{n}=4$ independent trials; $\mathrm{P}<0.05)$ for nuclear extracts from euthermic and hibernating animals, respectively.

\section{Analysis of Fasn mRNA levels}

Using RT-PCR and primers designed from the consensus sequence of Fasn from other mammalian species, a $196 \mathrm{bp}$ cDNA was amplified from skeletal muscle of ground squirrels. After sequencing, the PCR product was confirmed as encoding a portion of the Fasn gene using the program BlastN at the NCBI website.

These primers were then used to assess the relative levels of Fasn mRNA in six tissues (brain, heart, lung, kidney, liver, skeletal muscle) of euthermic versus hibernating 
ground squirrels. Figure 2.6A shows representative bands for Fasn transcript levels and corresponding bands for $\alpha$-tubulin, amplified as a control, from the same samples. Previous studies in our lab showed no changes in $\alpha$-tubulin mRNA levels between euthermic and hibernating animals. Fasn band intensities were normalized against $\alpha$ tubulin band intensities for each sample and then mean normalized Fasn mRNA levels are plotted in Figure 2.6B. Fasn transcript levels were significantly higher in heart and muscle during hibernation by 7.4 and 3.2-fold, respectively, as compared with transcript levels in the same tissues from euthermic animals. Transcript levels were unchanged in lung and kidney but decreased significantly in brain and liver to about $20 \%$ and $50 \%$ of the euthermic values respectively.

\section{Analysis of $P k l$ mRNA levels}

The liver isozyme of pyruvate kinase (PK-L) is another downstream target of the transcription factor ChREBP. Using RT-PCR and primers designed from the consensus sequence of other mammalian species (Human, Mouse and Rat), a $330 \mathrm{bp}$ cDNA of pkl was amplified from liver of ground squirrels. After sequencing, a search using the NCBI website confirmed that the product encoding for a portion of the $\mathrm{Pkl}$ gene.

Then these primers were used to assess $P k l$ mRNA levels in liver of euthermic and hibernating animals. Figure 2.8A shows representative bands for $P k l \mathrm{mRNA}$ content compared with $\alpha$-tubulin levels in the same samples. $P k l$ mRNA levels were normalized against $\alpha$-tubulin mRNA levels amplified from the same samples and then mean normalized $P k l$ mRNA levels were plotted (Figure 2.8B). Pkl transcript levels decreased significantly in liver during hibernation by more than $50 \%$ compared with control values. 


\section{Nucleotide and amino acid sequences}

Figure 2.7A shows the 196 bp cDNA partial nucleotide sequence of Fasn that was amplified from ground squirrel muscle together with the deduced amino acid sequence. An amino acid sequence alignment is shown in Figure 2.7B and compares the 64 amino acids of the ground squirrel Fasn sequence with the corresponding sequences for the human, mouse and rat proteins. The nucleotide comparison was made over the sequenced 196 bp. The nucleotide sequence had $83 \%$ identity with other mammals' (human, mouse and rat) Fasn cDNA and the deduced amino acid sequence shared $90 \%$ identity with other mammals' Fasn protein (Data not shown).

The total length of the Fasn gene sequence is around 7500 bp and Fasn protein is about 2500 amino acid residues in other mammals (human, mouse and rat). Hence, only about $2.5 \%$ of the total Fasn gene and protein sequences from ground squirrels have been compared in this study.

Figure 2.9A shows the nucleotide sequence of ground squirrel $P k l$ along with the deduced amino acid sequence of PK-L. Nucleotide and the amino acid sequence alignments with other mammalian species are shown in Figure 2.9B. The $P k l$ nucleotide sequence showed $87 \%$ identity with other mammals' (human, mouse and rat) $P k l$ cDNA over the segment sequenced and the deduced amino acid sequence shared $96 \%$ identity with other mammals' PK-L protein (Data not shown).

The total length of the $P k l$ gene sequence is around $1650 \mathrm{bp}$ and $\mathrm{PK}-\mathrm{L}$ protein is about 550 amino acid residues in other mammals (human, mouse and rat). Hence, only about $22 \%$ of the total $P k l$ gene and PK-L protein sequences from ground squirrels have been compared in this study. 


\section{DISSCUSSION}

Cold temperatures, snow cover and death of their plant foods are all factors that make it impossible for thirteen-lined ground squirrels to remain active and euthermic over the winter months. Instead, this species enters hibernation for 7 or more months of the year (Fig. 1.1). While hibernating, thirteen-lined ground squirrels do not eat and so, before entering hibernation, they must have large reserves of fuels stored in their bodies, chiefly as large lipid depots. Even though metabolic rate is reduced greatly during each torpor, hibernating animals still require a lot of metabolic fuel both for long term survival and to power the high rates of thermogenesis needed to rewarm the animals during interbout arousals. Several studies have indicated the reduction in carbohydrate oxidation during hibernation and a switch to mainly fat catabolism. Measurements of glycolytic rate and glycolytic enzyme activities support this (Burlington and Wiebers, 1966; Brooks and Storey, 1992) and studies using radiolabeled glucose as a carbon source also showed that less glucose is oxidized during hibernation (Tashima et al., 1970). Furthermore, Brooks and Storey (1992) reported a strong suppression of PDH activity in heart and kidney of ground squirrels which is a clear indication of a reduced carbohydrate oxidation in hibernators. Data on the up-regulation of various genes also supports the switch in fuel oxidation during hibernation. Andrews (2004) reported the up-regulation of pyruvate dehydrogenase kinase isoenzyme 4 (PDK4) and pancreatic triacylglycerol lipase (PTL). Increased activities of PDK4 during hibernation in different organs of 13-lined ground squirrels are the basis for PDH inactivation by converting PDH to its inactive phosphorylated form. PDH inactivation blocks carbohydrate oxidation by the mitochondria by blocking the conversion of pyruvate to acetyl-CoA. On the other hand, 
up-regulation of PTL provides increased capacity for hydrolyzing tryglycerides into free fatty acids, which can then be used as a fuel during hibernation (Andrews, 2004; Carey et al., 2003). Levels of fatty acid binding proteins are also enhanced during hibernation; these provide intracellular transport of fatty acids from the cell surface or from internal lipid droplets to the mitochondria for oxidation (Hittel, 2001).

Other studies also support a switch from carbohydrate metabolism to fat metabolism during hibernation. Liver fatty acid synthase activities of euthermic prairie dogs were significantly higher than those of the hibernating animals. Glucose-6phosphate dehydrogenase (G6PDH) activities also were found to be reduced in prairie dogs during hibernation, which is a clear indication of a reduced carbohydrate metabolism in hibernation (Frank et al, 1998). These findings also suggest a reduction in fatty acid synthesis from carbohydrate. Clearly FAS activity directly influences CHO to lipid conversion and G6PDH is key to NADPH production which is required for fatty acid synthesis.

The carbohydrate responsive element binding protein (ChREBP) is a transcription factor that plays an important role in carbohydrate metabolism. ChREBP is a member of the basic helix-loop-helix/leucine zipper (bHLH/ZIP) family of transcription factors and contains several potential functional domains including a nuclear localization signal (NLS), a proline-rich stretch (PRO), a bHLH/ZIP, and a ZIP-like domain (Shih et al., 1995; Yamashita et al., 2001). No previous studies have reported any research on ChREBP in hibernators. Hence, I began my research by measuring ChREBP protein levels in six different organs of thirteen-lined ground squirrels. In brain, heart, muscle and brown adipose tissue (BAT) increased levels of ChREBP were found during 
hibernation. But, ChREBP levels in kidney and liver were strongly decreased during hibernation. Hence, these data provide evidence of organ specific needs for ChREBP and for proteins that are under the control of ChREBP during hibernation. Dentin et al. (2005) observed that PUFAs suppress the ChREBP expression by accelerating ChREBP mRNA decay. The fatty acids of hibernators have a high content of PUFAs and this may be one influence on the reduced levels of ChREBP protein in kidney and liver. Previous studies have shown that despite an overall protein synthesis suppression, selected proteins continue to transcribe in organs of hibernators (Hittel and Storey 2002; Knight et al., 2000). Increased levels of ChREBP protein in brain, heart and muscle may indicate that this protein is needed in these organs during hibernation or there could be possible posttranslational modifications of ChREBP, such as reversible phosphorylation, which could prevent activity of ChREBP even though its protein content increased.

Since lipid reserves are laid down prior to hibernation, ChREBP probably plays a more important role in the pre-hibernation period rather than during hibernation. The composition of dietary fatty acid intake by hibernators prior to the hibernation months highly influences the energy expenditure of these animals during hibernation. Further, most of the fat reserves that needed during the hibernation are stored in organs of hibernators by beginning of the winter season. Hence, a lower level of ChREBP protein in the liver and kidney during hibernation may indicate that the ChREBP is not actively converting the $\mathrm{CHO}$ into fat as most of the fat reserves are stored prior to the hibernation period. In heart and muscle ChREBP protein levels are elevated during hibernation. When compared to kidney and liver, heart continues its functioning during hibernation and muscle is used extensively during interbout arousals. There could be two possible 
reason for this, as an immediate early response, ChREBP levels may increase and could be modified via post-tranaslational modifications such as reversible phosphorylation where ChREBP cannot function as active transcription factor that activate lipogenic gene transcription. The second possible reason could be still the ChREBP may actively transcribe genes involved in the fat production, where these genes' activity could be altered by reversible phosphorylation so as to prevent their activity as these are mainly enzymes. However, Hittel and Storey (2001) showed an increased expression of hearttype fatty acid binding protein (H-FABP) and adipose type fatty acid binding protein (AFABP) in heart, muscle and BAT of thirteen-lined ground squirrels during hibernation. These observations clearly indicate the oxidation of fat during hibernation in these organs. As fat getting oxidized, there could be reduced level of fat in these organs, which could activate ChREBP production in turn.

ChREBP is known to be regulated by reversible phosphorylation. In the presence of cAMP, serine residue at 196 position of the ChREBP is phosphorylated preventing nuclear entry of the transcription factor (Kawaguchi et al., 2001a). Hence, I looked at the overall level of phosphorylated serine associated with the 95kDa ChREBP band on the SDS-PAGE gels. The amount of phosphoserine in the ChREBP band was elevated significantly in brain, heart, kidney and liver during hibernation whereas in muscle no change in phosphoserine levels was observed. Hence, it is possible that in all these organs that despite elevated total ChREBP protein in brain and heart, that activity of the transcription factor is low because phosphorylation prevents the protein from entering the nucleus. To further explore this, the subcellular localization of ChREBP in muscle and liver of euthermic and hibernating ground squirrels was assessed. The results indicated 
that in muscle, ChREBP showed increased movement into the nuclei during hibernation whereas in liver ChREBP levels in the nucleus were reduced. This also agrees with the serine phosphorylation studies that showed higher phosphoserine content in the $95 \mathrm{kDa}$ ChREBP band in hibernator liver, consistent with inhibition of nuclear translocation of ChREBP in liver during hibernation. However, the amount of phosphoserine detected for muscle ChREBP did not change.

There was a significant reduction in ChREBP DNA-binding activity in liver nuclei during hibernation. These results agree with the phosphorylation studies, with the reduced amount of nuclear and overall ChREBP levels seen in liver of hibernators. Since the content of phospho-Serine was elevated in liver during hibernation, the nuclear entry and DNA binding activity of the ChREBP was reduced (nuclear entry is prevented by phosphorylation at Ser 196 and binding activity is inhibited by phosphorylation at Ser 568; Kawaguchi et al., 2001a), this suggests the involvement of a mechanism of ChREBP deactivation during hibernation that is probably protein phosphorylation. Eventhough, both Ser 196 and Thr 666 phosphorylation have been traced to the action of protein kinase A (Kawaguchi et al., 2001a) phosphorylation of ChREBP at Serine 568 catalyzed by AMPK (Kawaguchi et al., 2001b). A decreased level of nuclear localization of ChREBP in liver during hibernation could also be due to elevated amounts of (Polyunsaturated fatty acid) PUFA in the organ as ground squirrels have a high PUFA content in their body lipids due to consumption of a diet rich in PUFA prior to hibernation. Dentin et al. (2005) observed that a PUFA rich CHO diet inhibited the nuclear localization of ChREBP. Decreased DNA binding activity of ChREBP in rats fed with a high fat, versus a high carbohydrate, diet also implicated ChREBP in the 
mechanism of fatty acid inhibition of glycolysis and lipogenesis (Kawaguchi et al., 2002; Yamashita et al., 2001). However, in skeletal muscle the DNA binding activity of ChREBP increased during hibernation. In muscle, increased levels of ChREBP protein, increased nuclear localization, and an increased binding activity (although unchanged Ser phosphorylation levels) suggests an active stage of ChREBP in muscle tissues.

Fatty acids or their metabolites can activate many different pathways influencing the gene expression. For example, proteins and pathways that are activated by the peroxisome proliferator-activated receptor (PPAR) $\alpha$ and PPAR $\gamma$, hepatocyte nuclear factor $4 \alpha(\mathrm{HNF} 4 \alpha)$, sterol regulatory element binding protein 1c (SREBP1c), Nuclear factor kappa B (NFkB) and ChREBP are few of the transcription factors known to be associated with dietary fats (Jump and Clarke, 1999; Pégorier et al., 2004). ChREBP controls many of the lipogenic genes including L-type pyruvate kinase $(P k l)$, Fatty acid synthase (Fasn) and Acetyl CoA carboxylase (Acc) (Towle et al., 1997; Towle, 2005; Ma et al., 2006; Ishii et al., 2004; Uyeda et al., 2002). Hence, to determine if changes in ChREBP levels in hibernator organs led to corresponding changes in the expression of genes under ChREBP control during hibernation, the mRNA transcript levels of two genes were quantified. Fasn transcript levels were measured in five organs and transcript levels of $\mathrm{Pkl}$, encoding the liver-specific isozyme of PK, were measured in liver of euthermic versus hibernating ground squirrels. Fasn transcript levels were reduced in brain and liver and unchanged in lung and kidney, but elevated significantly in heart and skeletal muscle. Reduced Fasn transcript levels are in line with my other findings for brain and liver that showed higher levels of phosphorylated ChREBP during hibernation and, for liver, greater retention of ChREBP in the cytosol. Phosphoserine levels were also 
high in kidney. In case of muscle, the significant elevation of Fasn transcript levels could be linked with the greater nuclear localization of ChREBP and elevated DNA binding during hibernation. A possible reason for increased Fasn transcript levels in heart could be due to the fact that the ChREBP protein levels were increased nearly 6-fold during hibernation whereas overall phosphoserine content only increased about 1.75 -fold, which would suggest a higher proportion of the dephosphorylated form of ChREBP in hibernator heart which could, in turn, result in increased expression of ChREBP regulated genes.

Transcript levels of $P k l$ in liver were reduced during hibernation. This observation agrees with the responses of its transcription factor ChREBP in liver; ChREBP movement to the nucleus was reduced during hibernation as was ChREBP binding to DNA. PK is the second ATP-producing enzyme of glycolysis and the final regulatory enzyme of the pathway. Control of PK in liver is extremely important in determining the relative flux of carbon through glycolysis versus gluconeogensis and this control is mediated via phosphorylation of PK which inhibits it. Previous studies showed that PK was phosphorylated during hibernation in the jumping mouse Zapus hudsonius as part of the overall glycolytic suppression in torpor (Storey, 1987) but PK phosphorylation state did not apparently change in liver of a ground squirrel (S. lateralis) (Brooks and Storey, 1992). My data suggests that PK control in hibernation is at least partly controlled by reduced transcription of the $P k l$ gene and likely also reduced translation of the protein.

Partial nucleotide sequences of Fasn and $\mathrm{Pkl}$, representing $\sim 2.5 \%$ and $\sim 22 \%$ of the full nucleotide sequence from other mammals, were also obtained and analyzed in this chapter. The nucleotide sequence of the Fasn gene showed about $83 \%$ identity with 
the sequence of nonhibernating mammals (human, mouse and rat) with a number of variations in the ground squirrel gene, compared with the others. The cloned part of the ground squirrel Fasn short sequence occurred near to the N-terminal region of the protein as compared with the gene from other mammals. The nucleotide sequence of the $P k l$ gene showed $80 \%$ identity with the nonhibernating mammals (human, mouse and rat) over the $22 \%$ of the total gene sequenced. The cloned part of the $P k l$ sequence occurred in the middle region of the whole gene.

Overall, these data show coordination among the different parameters of ChREBP status that were evaluated: ChREBP protein levels, its phosphorylation status, nuclear versus cytoplasmic location, and DNA binding activity. ChREBP behavior also correlated well with the transcriptional status of two downstream genes under ChREBP control. Hence the overall conculsion is that ChREBP must be shut down during hibernation so as to preserve more valuable $\mathrm{CHO}$ resources. ChREBP could be a valuable resource for the hibernators during the prehibernation period in order to convert the consumed $\mathrm{CHO}$ to fat as their fuel store for the hibernating season. 
Fig. 2.1. Model of the role of ChREBP as a central regulator of the glucose signaling pathway. When glucose is elevated ChREBP is activated and partially dephosphorylated. The transcription factor moves into the nucleus where it is fully dephosphorylated and then able to activate the expression of downstream genes. ChREBP also interacts with its cofactor Mlx to efficiently bind to downstream gene targets. Taken from www.Biocarta.com. 
Fig. 2.1:

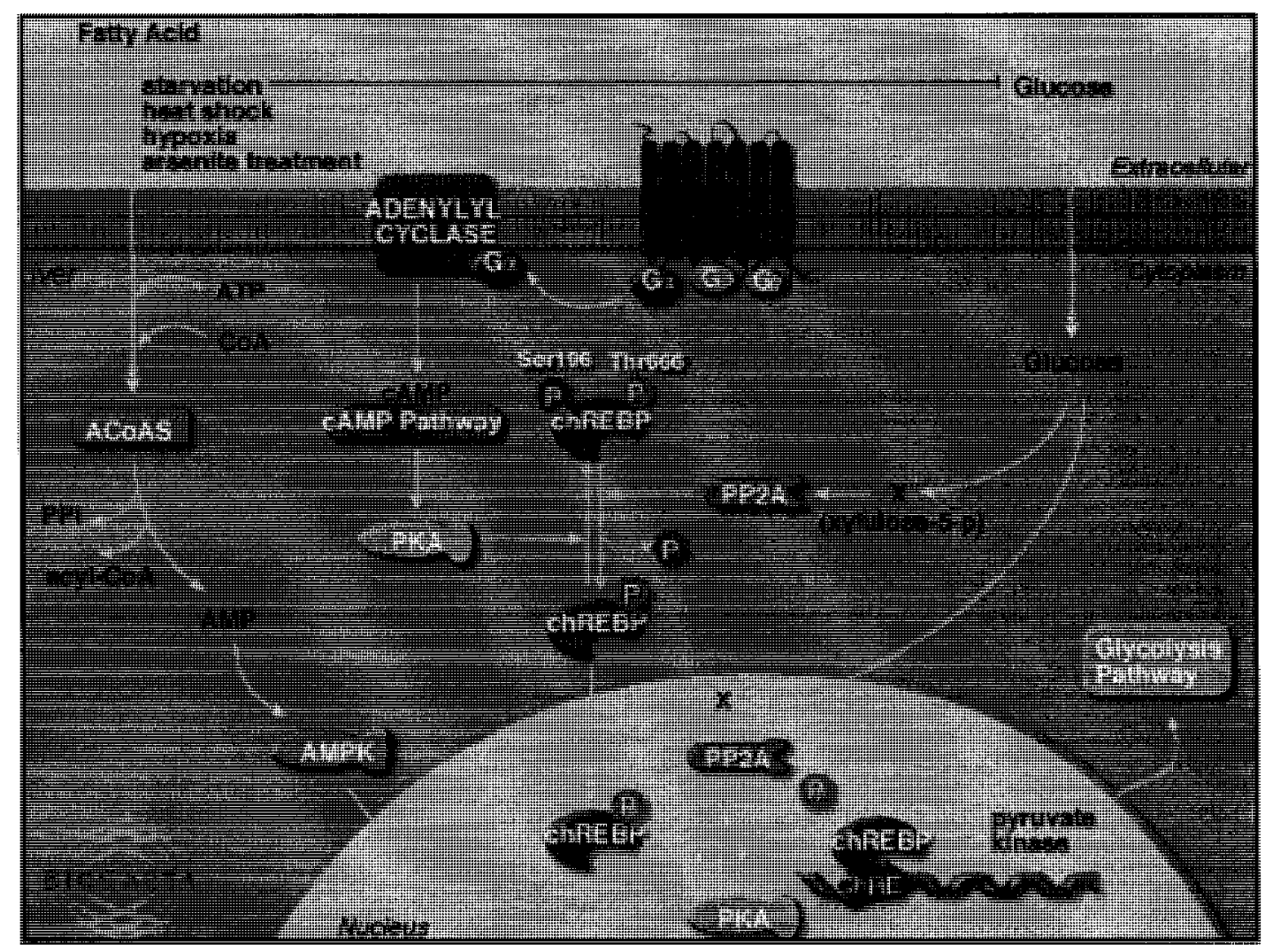


Fig. 2.2. (A) Sample Western blot, showing how a single band was obtained for ChREBP at $95 \mathrm{kDa}$. Lanes E1-E4 and $\mathrm{H} 1-\mathrm{H} 4$ represent the euthermic and hibernator samples respectively. Lane M shows the Kaleidoscope prestained molecular mass markers (BioRad) and each numbers represent the molecular weight in $\mathrm{kDa}$ (B) Representative Western blots showing ChREBP protein levels in six tissues from euthermic (E) and hibernating $(\mathrm{H})$ ground squirrels. The antibody cross reacted with a single protein band at $95 \mathrm{kDa}$ in each organs, consistent with the known molecular mass of ChREBP in other mammals. (C) Histogram showing the mean levels ChREBP protein band at $95 \mathrm{kDa}$ in euthermic and hibernating animals. Data are means \pm S.E.M., $n=4-5$ independent trials. BAT is brown adipose tissue; muscle is hind leg skeletal muscle. * - Significantly different from the corresponding euthermic value, $\mathrm{P}<0.05$. 
Fig. 2.2:

A. ChREBP Levels in Heart of 13-lined ground squirrels

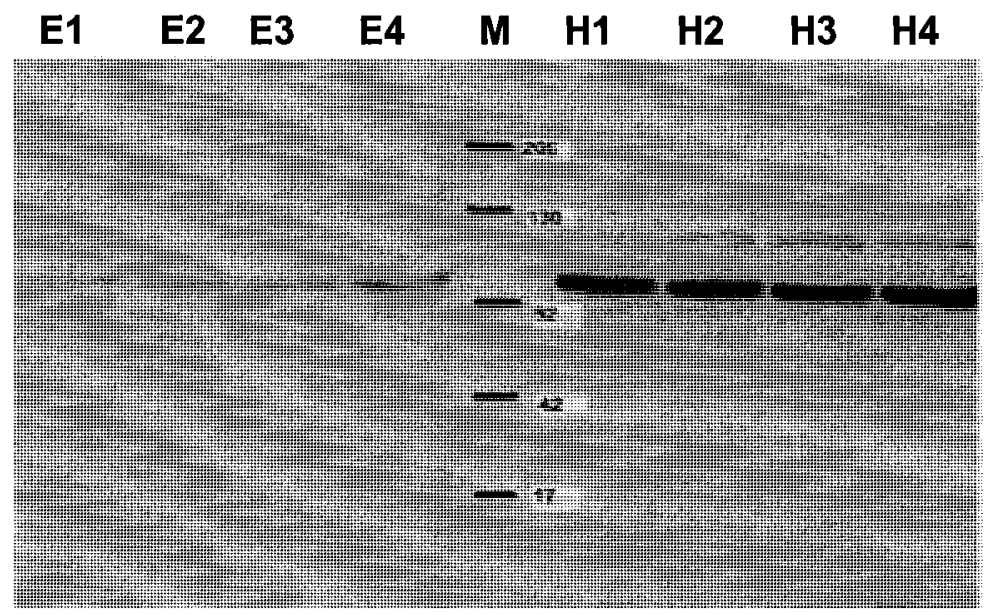

B.

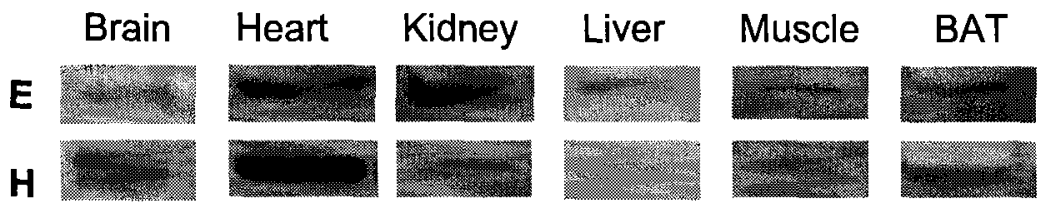

c.

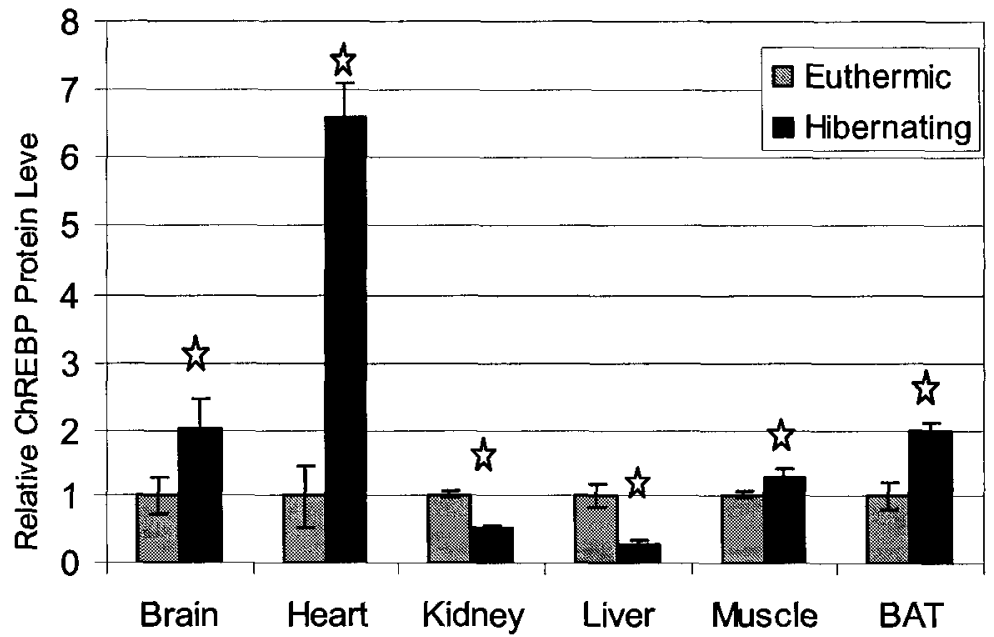


Fig. 2.3: (A) Representative Western blots showing protein phosphorylation on serine residues in the $95 \mathrm{kDa}$ molecular weight protein band in six tissues from euthermic (E) and hibernating $(\mathrm{H})$ ground squirrels. (B) Histogram showing mean levels of serine phosphorylation levels at $95 \mathrm{kDa}$. Data are means \pm S.E.M., $\mathrm{n}=4-5$ independent trials. BAT is brown adipose tissue; muscle is hind leg skeletal muscle. * - Value for hibernating sample is significantly different from the corresponding euthermic value, $\mathrm{P}<$ 0.05 . 
Fig. 2.3:

A.
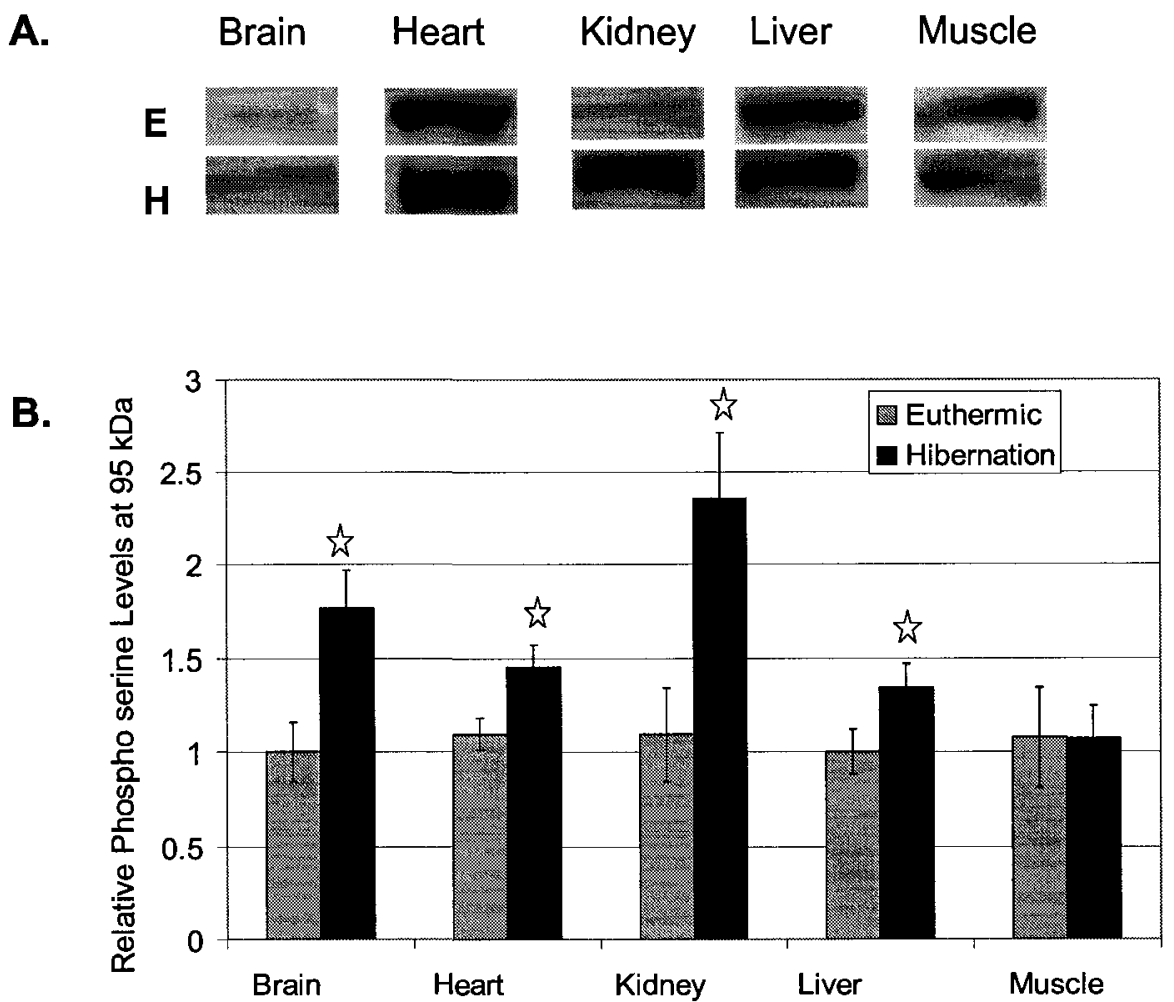
Fig. 2.4: (A) Representative Western blots and histograms showing ChREBP protein levels in cytoplasmic (C) vs nuclear (N) fractions of skeletal muscle from euthermic and hibernating ground squirrels. (B) Representative Western blots and histograms showing ChREBP protein levels in cytoplasmic (C) vs nuclear (N) fractions of liver from euthermic and hibernating ground squirrels. Data are means \pm S.E.M., $n=3$ independent trials. Muscle is hind leg skeletal muscle; * - Values for the nuclear fractions are significantly different from the corresponding cytoplasmic values, $\mathrm{P}<0.05$. 
Fig. 2.4:

A.

Euthermic

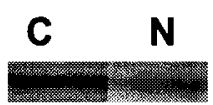

Hibernating

\section{C $\mathbf{N}$}

moxy

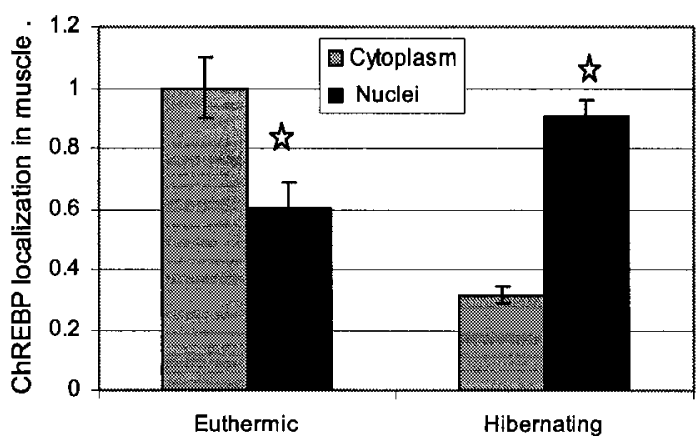

B.

Euthermic Hibernating

$\begin{array}{llll}C & \mathbf{N} & \mathbf{C} & \mathbf{N}\end{array}$
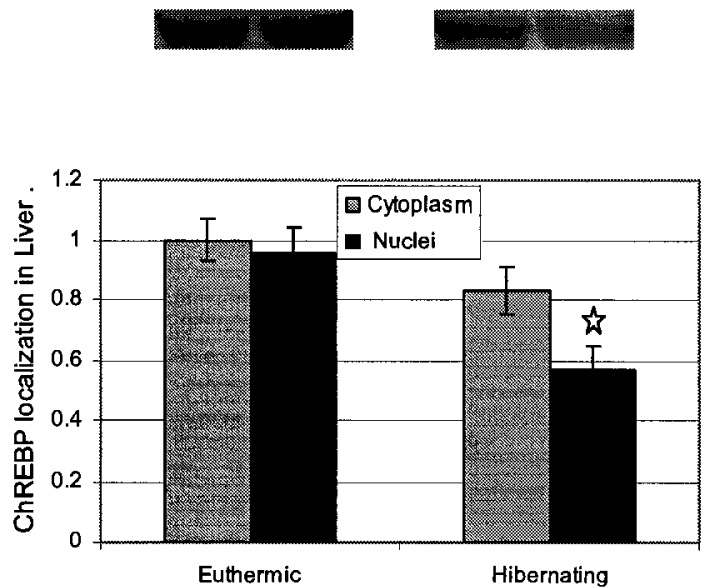
Fig. 2.5: ChREBP transcription factor binding to DNA in nuclear extracts from liver and muscle of euthermic and hibernating ground squirrels. Samples were assayed according to manufacturer's instructions with absorbance at $460 \mathrm{~nm}$ being directly proportional to the amount of bound ChREBP. Values are mean \pm SEM for $n=4$ independent trials.

* - Significantly different from the corresponding euthermic values $(\mathrm{P}<0.05)$. 
Fig. 2.5:

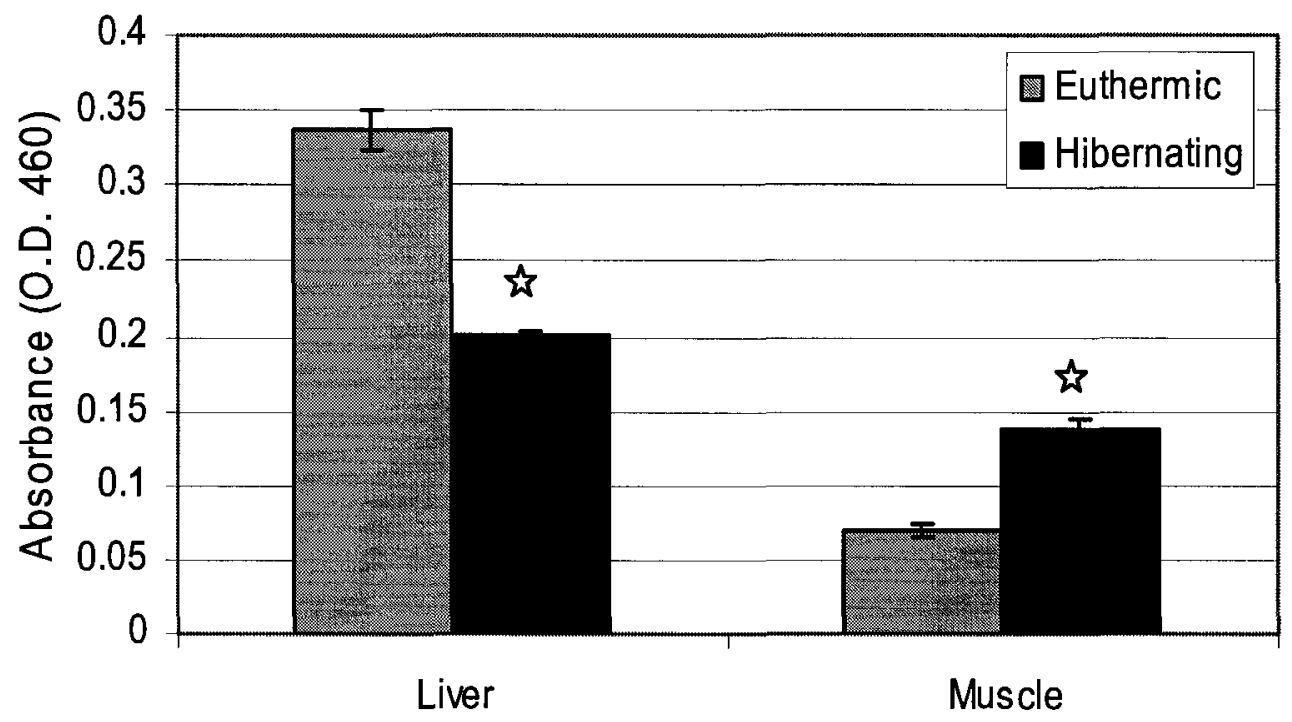


Fig. 2.6: Effect of hibernation on Fasn mRNA levels in six tissues of thirteen-lined ground squirrels. (A) Representative RT-PCR product bands for Fasn and $\alpha$-tubulin amplified from mRNA samples from tissues of euthermic and hibernating squirrels. (B) Histogram showing the mean values of normalized PCR product levels of Fasn in tissues from hibernating versus euthermic ground squirrels. The highest dilutions for Fasn $\left(10^{-2}\right.$ or $10^{-3}$ ) and $\alpha$-tubulin (from the same sample tube) which gave visible PCR product bands were chosen for quantification. Data are means \pm S.E.M., $n=4$ independent trials. Muscle is hind leg skeletal muscle; $\mathrm{E}$ - euthermic, $\mathrm{H}$ - hibernating. * - Values for hibernating samples are significantly different from the corresponding euthermic value, $\mathrm{P}$ $<0.05$. 
Fig. 2.6:

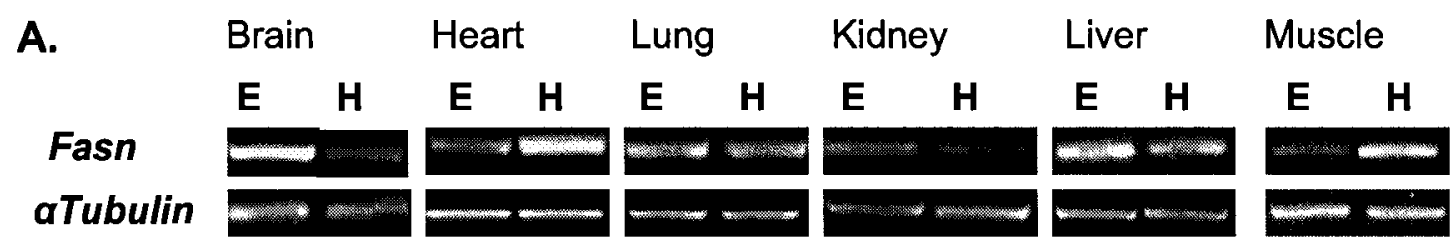

B.

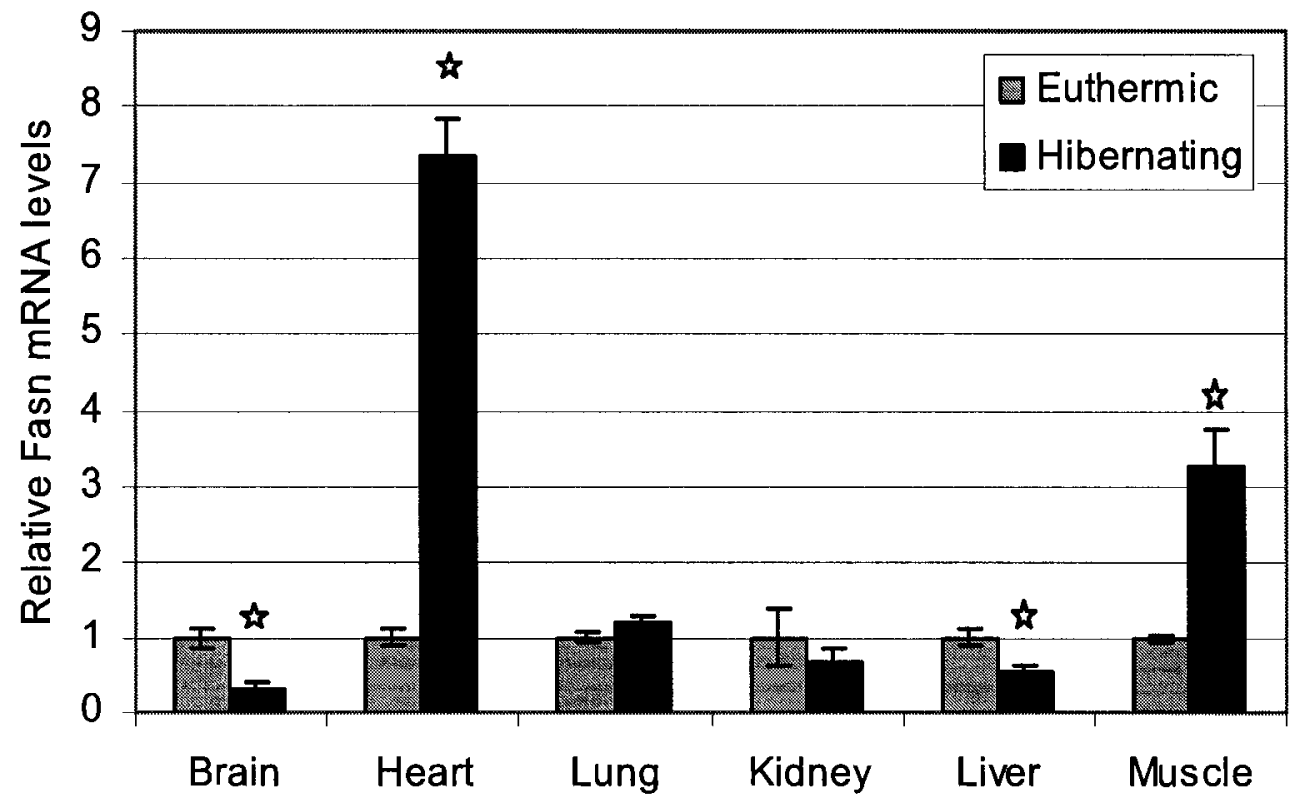


Fig. 2.7: (A) Partial cDNA sequence of Fasn amplified from muscle of thirteen-lined ground squirrels ( $S$. tridecemlineatus) along with the translated amino acid sequence. Nucleotides and amino acids are numbered on the left. An open reading frame was predicted from the nucleotide sequence and encoded a polypeptide with 64 amino acid residues. (B) Thirteen lined ground squirrel Fasn partial amino acid sequence aligned with human (Homo sapiens), mouse (Mus musculus) and rat (Rattus norvegicus) sequences (Genbank accession numbers NP_004095.4, NP_032014.3 and NP_059028.1 respectively). Dashes (-) represent amino acids in the human, mouse or rat sequences that are identical with the squirrel sequence. Periods are present in the alignment to indicate where an amino acid is not present in the sequence of one of the species. 


\section{Fig. 2.7:}
A.
1
GAGCTTCGAAGCATCGGAAGCCCTGAGCCGGGACCCTGAGACGCTCCTAGGCTACAGCAT
1 $\begin{array}{llllllllllllllllllll}S & \mathrm{E} & \mathrm{E} & \mathrm{A} & \mathrm{S} & \mathrm{E} & \mathrm{A} & \mathrm{L} & \mathrm{S} & \mathrm{R} & \mathrm{D} & \mathrm{P} & \mathrm{E} & \mathrm{T} & \mathrm{L} & \mathrm{L} & \mathrm{G} & \mathrm{Y} & \mathrm{S} & \mathrm{M}\end{array}$
61 GGTGGGCTGCCAGCGAGCCATGATGGCCAACAGGCTCTCCTTCTTCTTTGACTTCAAAGG $\begin{array}{llllllllllllllllllll}\mathrm{V} & \mathrm{G} & \mathrm{C} & \mathrm{Q} & \mathrm{R} & \mathrm{A} & \mathrm{M} & \mathrm{M} & \mathrm{A} & \mathrm{N} & \mathrm{R} & \mathrm{L} & \mathrm{S} & \mathrm{F} & \mathrm{F} & \mathrm{F} & \mathrm{D} & \mathrm{F} & \mathrm{K} & \mathrm{G}\end{array}$
121 AGGGCCCAGCATCGCCCTGGACACAGCCTGCTCCTCCAGCCTGATGGCACTGCACAACGC 41 $\begin{array}{lllllllllllllllllllll}G & \mathrm{P} & \mathrm{S} & \mathrm{I} & \mathrm{A} & \mathrm{L} & \mathrm{D} & \mathrm{T} & \mathrm{A} & \mathrm{C} & \mathrm{S} & \mathrm{S} & \mathrm{S} & \mathrm{L} & \mathrm{M} & \mathrm{A} & \mathrm{L} & \mathrm{H} & \mathrm{N} & \mathrm{A}\end{array}$
181 CACAAAGGCTATCAGG
61

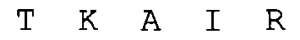

B.

\begin{tabular}{|c|c|}
\hline Squirrel-Fasn-P & FEASEALSRDPETLLGYSMVGCQRAMMANRLSFFFDFKGG \\
\hline Human-Fasn & 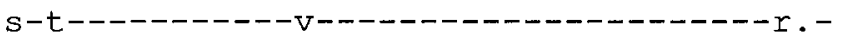 \\
\hline Mouse-Fasn & $\mathrm{S}-------------------------------------$, \\
\hline Rat-Fasn & S-n---- \\
\hline Squirrel-Fasn-P & PSIALDTACSSSLMALHNATKAIR \\
\hline Human-Fasn & $----------------\mathrm{q}--y \mathrm{q}--\mathrm{h}$ \\
\hline Mouse-Fasn & $-------------1--\mathrm{q}--y \mathrm{q}---$ \\
\hline Rat-Fasn & $-------------1--\mathrm{q}^{-}-\mathrm{yq}---$ \\
\hline
\end{tabular}


Fig. 2.8: The $P k l$ mRNA levels in liver of thirteen-lined ground squirrels. (A) Representative RT-PCR product bands for $P k l$ and $\alpha$-tubulin amplified from mRNA samples from tissues of euthermic and hibernating squirrels. (B) Histogram showing the mean values of normalized PCR product levels of $P k l$ in liver from euthermic versus hibernating ground squirrels. The highest dilutions for $P k l\left(10^{-2}\right.$ or $\left.10^{-3}\right)$ and $\alpha$-tubulin (from the same sample tube) which gave visible PCR product bands were chosen for quantification. Scanned intensities of $P k l$ bands were normalized against the corresponding intensity of the $\alpha$-tubulin band from the same sample tube and then mean normalized band intensities were calculated for both euthermic and hibernating states. Data are means \pm S.E.M., $\mathrm{n}=4$ independent trials using mRNA isolated from liver samples of different animals. E - euthermic, H - hibernating. * - Value for hibernating sample is significantly different from the corresponding euthermic value, $\mathrm{P}<0.05$. 
Fig. 2.8:

A. Liver

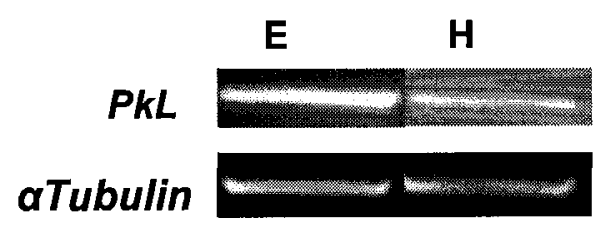

B.

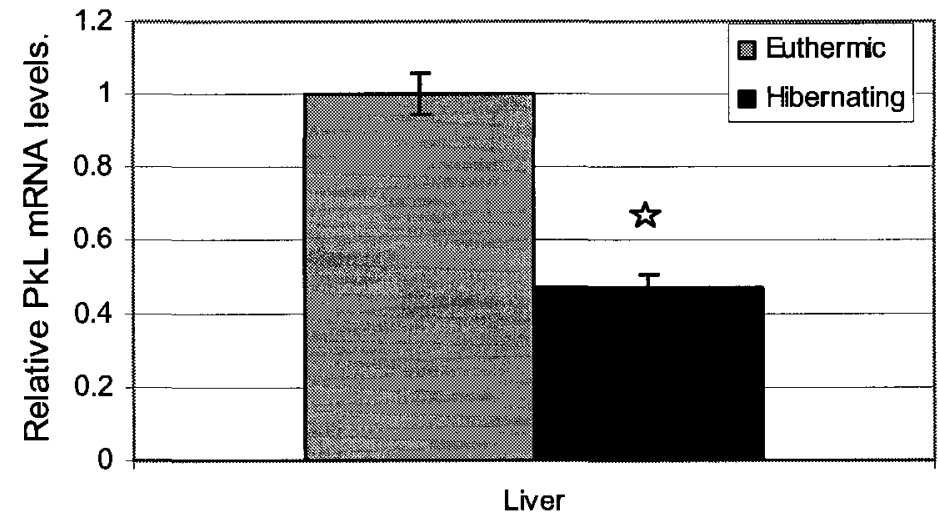


Fig. 2.9: Partial cDNA sequence of $P k l$ amplified from liver of thirteen-lined ground squirrels (S. tridecemlineatus) along with the translated amino acid sequence. Nucleotides and amino acids are numbered on the left. An open reading frame was predicted from the nucleotide sequence and encoded a polypeptide with 110 amino acid residues. (B) Ground squirrel (Spermophilus tridecemlineatus) Pkl partial amino acid sequence aligned with human (Homo sapiens), mouse (Mus musculus) and rat (Rattus norvegicus) sequences (Genbank accession numbers NP_000289.1, NP_001093249.1 and NP_036756.2 respectively). Dashes (-) represent amino acids in the human, mouse or rat sequences that are identical with the squirrel sequence. Periods are present in the alignment to indicate where an amino acid is not present in the coding region of one of the species. 


\section{Fig. 2.9:}

A.

1

1

TGTCCCCAGATGCTGGAGAGCATGATTACTAAGCCCCGGCCAACACGGGCCGAGACCAGC

61

GATGTGGCCAATGCTGTACTGGATGGGGCAGACTGCATCATGCTGTCAGGGGAGACTGCC

$\begin{array}{llllllllllllllllllll}D & V & A & N & A & V & L & D & G & A & D & C & I & M & L & S & G & E & T & A\end{array}$

121 AAAGGCCACTTCCCCGTGGAGGCCGTAAAGATGCAGCACGCGATTGCACGGGAGGCCGAG $\begin{array}{llllllllllllllllllllll}41 & K & G & H & F & P & V & E & A & V & K & M & Q & H & A & I & A & R & E & A & E\end{array}$

181 GCCGCGGTGTACCACCGGCAGTTGTTTGAGGAGCTGCGCAGGGCAGCACCACTGAGCCGG $\begin{array}{lllllllllllllllllllll}61 & A & A & V & Y & H & R & Q & L & F & E & E & L & R & R & A & A & P & L & S & R\end{array}$

241 GACCCCACTGAGGTGACTGCCATCGGGGCTGTGGAGGCCGCTTTCAAGTGCTGTGCTGCT $\begin{array}{llllllllllllllllllllll}81 & \mathrm{D} & \mathrm{P} & \mathrm{T} & \mathrm{E} & \mathrm{V} & \mathrm{T} & \mathrm{A} & \mathrm{I} & \mathrm{G} & \mathrm{A} & \mathrm{V} & \mathrm{E} & \mathrm{A} & \mathrm{A} & \mathrm{F} & \mathrm{K} & \mathrm{C} & \mathrm{C} & \mathrm{A} & \mathrm{A}\end{array}$

$301 \quad$ GCCATCATCGTTCTGACCACTACTGGCCGG

101

\section{B.}

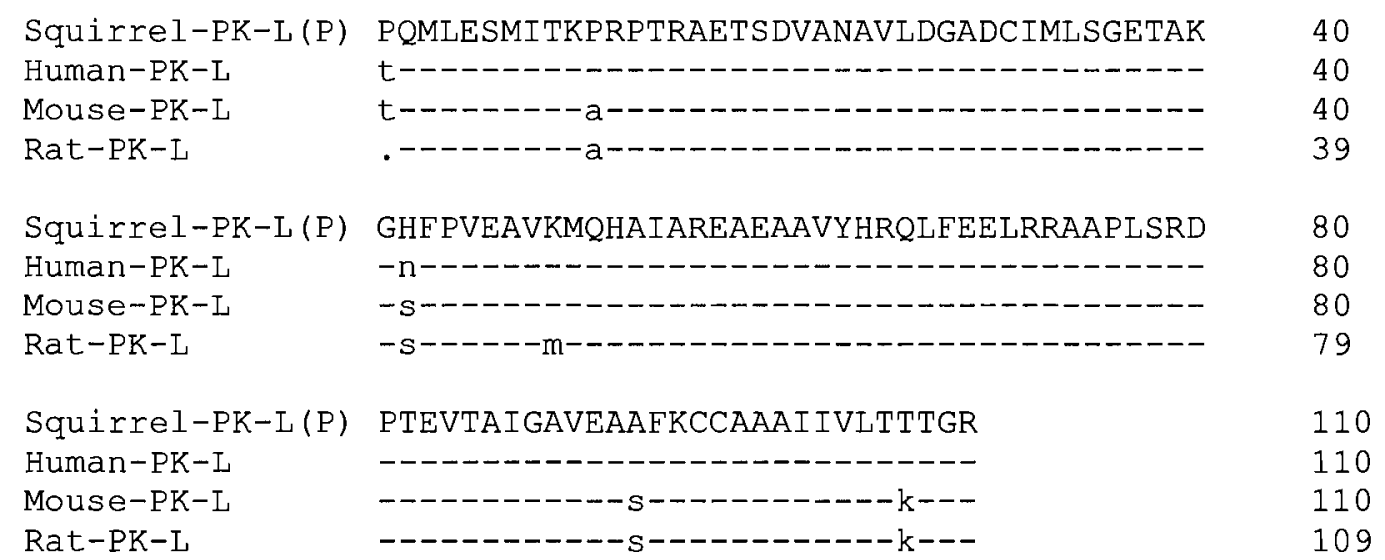




\section{Chapter 3}

Role of Ets1 and its upstream factors in

\section{hibernating thirteen-lined ground squirrels}




\section{INTRODUCTION}

Hibernation is characterized by a prolonged reduction in heart rate and breathing (sometimes including long periods of breath hold or apnea) which can lead to hypoxic or ischemic conditions in some organs the animals. Barros et al. (2001) showed a link between hypoxia and hypothermia in mammals; when oxygen is limiting, body temperature falls. This hypoxia-hypothermia connection was shown to be one of the mechanisms that could help initiates and manage the fall in body temperature as animals enter hibernation (Barros et al., 2001; Storey, 2003). The evidence of hypoxic conditions in hibernating ground squirrels and the up-regulation of the hypoxia inducible factor (HIF) $1 \alpha$ during torpor has been previously reported by our lab (Morin and Storey, 2005).

Hypoxia also leads to differential expression of many genes that are needed for cell survival under this stress. The Epidermal Growth Factor Receptor (EGFR) is also known to be activated by hypoxic conditions (Franovic et al., 2007; Wang et al., 2007). EGFR exists on the cell surface and is activated by specific ligands such as the epidermal growth factor or stress such as hypoxia. Upon activation, EGFR dimerizes from its inactive monomer to form an active dimer. Dimerization induces its intracellular proteintyrosine kinase activity and results in autophosphorylation of five tyrosine residues in the c-terminal domain of the EGFR (Y992, Y1045, Y1068, Y1148 and Y1173). This autophosphorylation induces downstream activation and signaling by several other proteins (Oda et al., 2005). EGFR is connected through phosphatidylinositol-4,5bisphosphate $\left(\mathrm{PIP}_{2}\right)$ to protein kinase $\mathrm{C}(\mathrm{PKC})$ and protein kinase $\mathrm{D}(\mathrm{PKD})$, which is also known as PKC $\mu$ (King and Cooper, 1986; Ma et al., 2005) (Fig 3.1). PKC $\alpha$ regulates the transcriptional activity of Ets1 (Lindemann et al., 2003; Vetter et al., 2004) and induces 
phosphorylation of Etsl. PKC $\alpha$ could have a dual effect on Etsl by binding and stimulating Ets1 activity first and then inhibiting its activity by inducing phosphorylation of the Exon VII domain (Lindemann et al., 2003).

Ets proteins comprise a family of transcription factors that share a unique DNA binding domain called the "Ets" domain. Ets transcription factors control specific genes that perform roles including growth and differentiation, anti/pro apoptotic function, angiogenesis etc. The DNA binding activity of Ets1 is controlled by kinases and other transcription factors. So far two phosphorylation sites have been identified in Ets1, threonine-38 and an array of serines within the exon VII domain. Phosphorylation of Thr38 by ERK $1 / 2$ activates Ets1 whereas phosphorylation of the exon VII domain by CaMKII and PKCs inhibits Etsl binding activity (Dittmer, 2003). The genes containing the Ets binding site (EBS) within their promoter are regulated by the Ets family of transcription factors.

A model of the Ets pathway and its upstream effectors has been studied in this chapter. The organ-specific responses of Ets1, its upstream effectors EGFR, phosphoEGFR, PKC, phospho-PKC protein levels were studied in six organs using western blotting techniques. The EtsI transcript levels were investigated using RT-PCR techniques. Finally the Ets1 sub cellular distribution and Ets1 DNA-binding activity were analyzed in liver and skeletal muscle of the euthermic versus hibernating animals. 


\section{METHODS AND MATERIALS}

\section{Animals}

All animals were captured, housed, experimentally hibernated, and organs harvested as previously described in Chapter 2 . The skeletal muscle used was a mixture of several hind limb muscles.

\section{Western Blotting}

Western blotting was performed as described in Chapter 2. Total protein was isolated from samples of brain, heart, lung, kidney, liver and skeletal muscle of euthermic and hibernating ground squirrels. Aliquots containing 20-30 $\mu \mathrm{g}$ of protein were loaded into each well of $10 \%$ SDS gels, followed by electrophoresis, and then transfer to PVDF membrane. Rabbit monoclonal antibodies to EGFR, phospho-EGFR (pY1173), and phospho-EGFR (pY1086) were kind gift from Epitomics Inc. (Burlingame, CA). Rabbit polyclonal antibodies to $\mathrm{PKD} / \mathrm{PKC} \mu$, phospho $\mathrm{PKD} / \mathrm{PKC} \mu$ (Ser744/748), and phospho PKC alpha/ betaII (Thr638/641) were from Cell Signalling and rabbit polyclonal antibodies to Ets $1 / 2$ were from Santa Cruz Biotechnologies. Anti-rabbit polyclonal antibody against the above primary antibodies was purchased from Cell Signalling. Prior to the addition of primary antibody, blots were blocked for $15-30 \mathrm{~min}$ in TBST containing $1 \%$ or $2.5 \%$ non-fat dried milk. All primary antibody incubations were carried out at $4^{\circ} \mathrm{C}$ overnight in $1 \mathrm{X}$ TBST at 1:5000 v/v dilution. Each blot was then washed for $5 \mathrm{~min}$ in $1 \mathrm{X}$ TBST three times prior to the addition of secondary antibody. Secondary antibody (1:2000 v/v dilution) incubations were carried out for $90 \mathrm{~min}$ at room 
temperature and followed by 3 washes in $1 \mathrm{X}$ TBST for 5 min each. Signal detection and quantification were as described previously in Chapter 2.

\section{Distribution of Ets1/2 and phospho- PKC $\alpha / \beta$ II (Thr638/641) in cytoplasmic and nuclear extracts}

Cytoplasmic and nuclear extracts from skeletal muscle were prepared as described in Chapter 2. Protein samples from each fraction $(60 \mu \mathrm{g})$ were separated on $10 \%$ SDSPAGE minigels at $180 \mathrm{~V}$ for $45 \mathrm{~min}$, transferred onto PVDF membranes, and immunoblotted with Ets $1 / 2$ or phospho- PKC $\alpha / \beta$ II (Thr638/641) antibodies as described above.

\section{RNA isolation}

Total RNA was isolated from brain, heart, lung, kidney, liver and skeletal muscle of euthermic and hibernating ground squirrels using Trizol reagent (Invitrogen) according to the manufacturer's protocol as previously described in Chapter 2 .

\section{First strand cDNA synthesis and PCR amplification}

cDNA was synthesized as described in Chapter 2. The resulting cDNA samples from both euthermic and hibernating tissues were serially diluted $\left(10^{-1}, 10^{-2}, 10^{-3}, 10^{-4}\right.$, and $10^{-5}$ ) and amplified by the polymerase chain reaction (PCR) with Ets 1 primers that were designed from the consensus sequences of Etsl from several other mammals, using the Primer Designer program, version 3.0 (Scientific and Educational Software). The nucleotide sequences of the Ets1 primer pairs were 
forward 5' - CGATAGTTGCGACCGCCTCA - 3' and reverse 5' - TGACAGGCTTGTCCTTGTTG - 3'.

The PCR reaction for Ets 1 consisted of $25 \mu 1$ final volume composed as described previously. The reaction started with an initial step of 4 min at $94^{\circ} \mathrm{C}$ followed by 35 cycles of $30 \mathrm{sec}$ at $94^{\circ} \mathrm{C}, 30 \mathrm{sec}$ at $62^{\circ} \mathrm{C}$, and $30 \mathrm{sec}$ at $72^{\circ} \mathrm{C}$. The final step was $72^{\circ} \mathrm{C}$ for 7 min. The housekeeping gene $\alpha$-tubulin also amplified as an internal control. PCR products were separated on a $1 \%$ agarose gel, stained with ethidium bromide, and the intensity of the most dilute cDNA sample that was visible was used for quantification purposes to make sure that the products had not reached their amplification saturation. Quantification was performed as described in Chapter 2.

\section{Sequencing}

RT-PCR products were sequenced by Canadian Molecular Research Services (Ottawa, ON). Sequences were verified as encoding EtsI using the program BLASTN (http://www.ncbi.nlm.nih.gov/blast) at the NIH. The deduced amino acid sequences were also verified as being Ets 1 by using the program BLASTP at the same site.

\section{Statistical analysis}

RT-PCR ( $n=3-4)$ and Western Blotting $(n=3-5)$ data were gathered from independent tissue extracts from different animals. RT-PCR bands for Ets1 were normalized relative to $\alpha$-tubulin bands obtained from the same cDNA reaction whereas Western blot bands specific to Ets1 protein were normalized against three Coomassie 
stained protein bands that did not change in intensity between euthermic and hibernating conditions. Data are expressed as means with corresponding SEM. Statistical testing of normalized band intensities from euthermic versus hibernating samples used the Student's $t$-test with significance levels of $\mathrm{P}<0.05$.

\section{Nuclear extract preparation and electrophoretic mobility shift assay (EMSA)}

The EMSA Ets1 Gel-Shift kit was purchased from Panomics Inc. (Fremont, CA). Nuclear extracts from liver and muscle of euthermic and hibernating ground squirrels were prepared as described in Chapter2. The EMSA was performed as described by the manufacturer using biotin-labeled synthetic oligonucleotides (probe) containing a sequence corresponding to a cis-acting element, the Ets1 binding site (5'GGAGGAGGGCTGCTTGAGGAAGTATAAGAAT-3') in the $B c l 2$ promoter (Ets1 binding site is underlined). Initially, $1 \mu \mathrm{l}$ of liver or muscle nuclear extract (10 $\mu \mathrm{g}$ protein $/ \mu \mathrm{l})$ from euthermic or hibernating animals, positive control nuclear extracts, and nuclear extract for non-specific binding were incubated with $1 \mu$ poly $d(I-C)(1 \mu \mathrm{g} / \mu \mathrm{l})$ in $2.0 \mu \mathrm{l}$ of $5 \mathrm{X}$ binding buffer at room temperature for $5 \mathrm{~min}$. Then $1 \mu \mathrm{l}$ of biotin-labelled TF probe $(10 \mathrm{ng} / \mu \mathrm{l})$ and $5 \mu \mathrm{l}$ of distilled water were added to each of the reaction vials except for the non-specific binding vial where $5 \mu$ of the unlabelled probe was added instead of distilled water together with the $1 \mu$ of biotin-labelled TF probe. Reactions were incubated for $30 \mathrm{~min}$ at $18^{\circ} \mathrm{C}$. DNA-protein complexes were separated from unbound DNA probe by electrophoresis on $6.0 \%$ polyacrylamide native gels at $120 \mathrm{~V}$ for $1 \mathrm{~h}$ in chilled $0.5 \mathrm{X}$ TBE buffer $(0.05 \mathrm{M}$ Tris, $0.045 \mathrm{M}$ boric acid, $0.005 \mathrm{M}$ EDTA). Bound probes were electroblotted onto pre-soaked Biodyne nylon membranes (Pall) by 
wet transfer with pre-chilled $0.5 \mathrm{X}$ TBE buffer at $4^{\circ} \mathrm{C}$ for $45 \mathrm{~min}$ at $300 \mathrm{~mA}$. After the transfer of probes, the membrane was baked for $1 \mathrm{~h}$ at $80^{\circ} \mathrm{C}$. The membrane was then blocked with $1 \mathrm{X}$ blocking buffer for 15 min followed by the addition of StreptavidinHRP conjugate (1:1000 v:v) and incubation for $15 \mathrm{~min}$ at room temperature with gentle shaking. The membrane was then washed three times with $1 \mathrm{X}$ wash buffer. Finally, $20 \mathrm{ml}$ of $1 \mathrm{X}$ detection buffer was added and incubated for $5 \mathrm{~min}$ at room temperature, followed by the addition of $2 \mathrm{ml}$ working substrate solution and incubation at room temperature for 5 min. Detection of signal on the nylon membrane was done using an enhanced chemiluminescence (ECL) system as recommended by the manufacturer (Immobilon). The membrane was scanned using the SynGene and the resulting image was analyzed.

\section{RESULTS}

\section{EGFR protein levels in S. tridecemlineatus}

The EGFR is a $170 \mathrm{kDa}$ transmembrane glycoprotein receptor tyrosine kinase that is activated by EGF and affects cell growth and differentiation. EGFR is the upstream factor that activates several protein kinase $\mathrm{C}$ isozymes (PKCs). Western blotting was performed to study the expression levels of EGFR in four tissues (brain, lung, kidney and liver) of euthermic and hibernating ground squirrels. The rabbit monoclonal IgG cross reacted with a single protein band at $170 \mathrm{kDa}$ (Fig. $3.2 \mathrm{~A}$ ) in ground squirrel extracts that correspond with the known size of the EGFR protein in other mammals. Figure 3.2B shows the mean EGFR protein levels in brain, lung, kidney and liver of euthermic and hibernating animals. EGFR protein levels were significantly $(P<0.05)$ elevated in brain, lung and kidney during hibernation, but did not change between the euthermic and 
hibernating states in liver. In lung EGFR protein level was 3-fold higher in hibernators whereas the increase was 1.7 and 2-fold, respectively, for brain and kidney.

\section{Phospho EGFR (pY 1173) protein levels in S. tridecemlineatus}

Expression levels of the phosphorylated form of EGFR protein (Tyr 1173) were also assessed in four organs of ground squirrels via western blotting. A rabbit monoclonal anti-phospho-EGFR (pY1173) antibody cross reacted with a single protein band at 170 $\mathrm{kDa}$ in ground squirrel extracts (Fig. 3.3 A) that corresponded with the known size of phospho-EGFR (pY1173) in other mammals. Figure $3.3 \mathrm{~B}$ shows that phospho-EGFR (pY1173) content increased significantly $(\mathrm{P}<0.05)$ in lung and liver during hibernation, by 1.7- and 1.6-fold respectively. However, phospho-EGFR (pY1173) content did not change significantly in brain or kidney during hibernation.

\section{Phospho EGFR (pY 1086) protein levels in S. tridecemlineatus}

EGFR can also be phosphorylated on tyrosine 1086 and expression levels of this

phosphoprotein form were also assessed in ground squirrel organs. A rabbit monoclonal anti-phospho-EGFR (pY1086) antibody cross reacted with a single protein band at 170 $\mathrm{kDa}$ (Fig. 3.4 A) that corresponded with the known size of the phospho-EGFR (pY1086) protein in other mammals. Figure $3.4 \mathrm{~B}$ shows the mean phospho-EGFR (pY1086) protein levels in brain, lung, kidney and liver of euthermic and hibernating animals. Phospho-EGFR (pY1086) content increased significantly $(\mathrm{P}<0.05)$ in all four organs during hibernation by 1.7-, 2.7-, 1.5- and 1.6-fold for in brain, lung, kidney and liver, respectively. 


\section{$\mathrm{PKD} / \mathrm{PKC} \mu$ protein levels in S. tridecemlineatus}

PKCs are important signal transduction enzymes for the activation or deactivation of Ets1. Western blotting was performed to study the expression levels of PKC $\mu$ / PKD in six tissues (brain, heart, lung, kidney, liver and skeletal muscle) of ground squirrels. Rabbit polyclonal IgG cross reacted with a single protein band of $\sim 115 \mathrm{kDa}$ (Fig. $3.5 \mathrm{~A}$ ) that corresponds with the known size of the PKC $\mu$ / PKD protein in other mammals (the alternate name for PKCmu is PKD). Figure 3.5B shows that PKC $\mu$ / PKD protein levels were significantly $(\mathrm{P}<0.05)$ elevated in five organs during hibernation but did not change in kidney. PKC $\mu$ / PKD protein levels increased by 1.75 -fold in brain, heart and muscle, by as 2.3 -fold in lung, and by 1.5 -fold in liver.

\section{Phospho PKD/ PKC $\mu$ (Ser 744/ 748) protein levels in S. tridecemlineatus}

The activity of PKCs depends on their phosphorylation status. Therefore, Western blotting was performed to assess the levels of phospho-PKC $\mu$ / PKD (Ser 744/ 748) in ground squirrel tissues. The rabbit polyclonal IgG cross reacted with a single protein band $\sim 115 \mathrm{kDa}$ (Fig. 3.6 A) that corresponds with the known size of phospho-PKC $\mu$ / PKD (Ser 744/748) protein in other mammals. Figure 3.6B shows the mean relative levels of phospho-PKCmu/ PKD (Ser 744/ 748) levels in the six organs. PKC $\mu$ / PKD protein levels were significantly elevated $(\mathrm{P}<0.05)$ in brain, heart, lung, kidney and liver during hibernation but did not change in muscle. Levels of the phospho-enzyme increased by 2-2.3 fold in brain, lung and kidney during hibernation and by 1.4 and 1.7fold, respectively, in heart and liver. 


\section{Phospho PKCa/ $\beta$ II (Thr 638/641) protein levels in S. tridecemlineatus}

Western blotting was also used to study expression levels of phospho- PKC $\alpha / \beta$ II (Thr 638/ 641) in six tissues of ground squirrels. The rabbit polyclonal IgG cross reacted with a single protein band of $\sim 80 \mathrm{kDa}$ (Fig. $3.7 \mathrm{~A}$ ) that corresponds with the known size of phospho- PKCa/ $\beta$ II (Thr 638/641) in other mammals. Figure 3.7B shows that phospho- $\mathrm{PKC} \alpha / \beta \mathrm{II}(\mathrm{Thr} 638 / 641)$ protein levels were significantly elevated $(\mathrm{P}<0.05)$ in all tissues except brain during hibernation. Phospho- PKC $\alpha / \beta \mathrm{II}$ (Thr 638/ 641) rose by $~ 3.4$-fold in heart, 3 -fold in kidney, about 2.2 -fold in liver and skeletal muscle and 1.6-fold in lung.

Distribution of phospho- PKCa/ $\beta$ II (Thr 638/ 641) in cytoplasmic and nuclear extracts

Nuclear and cytoplasmic extracts were prepared from skeletal muscle of euthermic and hibernating squirrels and the distribution of phospho- PKC $\alpha / \beta$ II (Thr 638/ 641) between these two cellular compartments was assessed by western blotting. Figure 3.8A shows representative Western blots of phospho- PKCa/ $\beta$ II (Thr 638/ 641) distribution in the two subcellular fractions and Figure 3.8 B shows that the relative amount of phospho- PKC $\alpha / \beta$ II (Thr 638/641) in the nuclear fraction increased substantially during hibernation. The amount of enzyme in the nuclear fraction from hibernating animals was 4-fold greater than the amount in the cytoplasmic fraction compared with a 1.7-fold difference under euthermic conditions. 


\section{Analysis of Ets1 mRNA levels}

Using RT-PCR and primers designed from the consensus sequence of Ets 1 from other mammals (human, mouse and rat) a 243 bp cDNA was amplified from skeletal muscle extracts of ground squirrels. Using the NCBI website the product was confirmed as encoding a part of the Ets 1 gene.

Then these primers were used to assess Ets 1 mRNA levels relative to $\alpha$-tubulin in six tissues (brain, heart, lung, kidney, liver and muscle) of euthermic and hibernating animals. Figure 3.9 A shows the intensity of Ets 1 PCR product relative to the $\alpha$-tubulin amplified from the same samples. Since previous studies in our lab showed no changes in $\alpha$-tubulin mRNA levels between euthermic and hibernating ground squirrels, Ets 1 mRNA levels were normalized against the $\alpha$-tubulin mRNA amplified from the same samples. Mean relative Ets $1 \mathrm{mRNA}$ levels were then plotted in Figure 3.9 B. Ets 1 transcript levels increased significantly in lung, kidney, liver and muscle of hibernating ground squirrels by 1.9-, 1.8-, 2.5- and 4.9-fold, respectively, as compared with the euthermic state. However, Est 1 transcript levels were unchanged in heart and decreased in brain to about $20 \%$ of euthermic values.

Figure 3.10A shows the nucleotide sequence of Ets 1 from skeletal muscle and the deduced amino acid sequence. A segment of 80 amino acids was predicted according to the Blast $\mathrm{X}$ matches. Figure 3.10B shows an amino acid sequence alignment with the sequences of the mouse, rat and human Etsl. The ground squirrel nucleotide sequence showed $95 \%$ identity with other mammals' (human, mouse and rat) Ets 1 cDNA and the deduced amino acid sequence shared 93\% homology with mammals' Ets1 protein (Data not shown). 


\section{Ets1/2 protein levels in S. tridecemlineatus}

Ets1 expression levels were assessed in six tissues of euthermic and hibernating ground squirrels via western blotting. A rabbit anti-Ets $1 / 2$ antibody crossreacted with a protein band at $55 \mathrm{kDa}$ (Fig. $3.11 \mathrm{~A}$ ) that corresponded with the known size of Ets1 in other mammals. Figure $3.11 \mathrm{~B}$ shows that Ets1 protein levels were significantly elevated $(\mathrm{P}<0.05)$ in heart, lung, kidney, liver and muscle during hibernation, but unchanged in brain. In kidney Ets 1 protein content was 4.5 -fold higher in hibernating animals compared with euthermic squirrels and Ets1 levels were 3.4-, 3-, 2.25- and 1.5-fold higher in heart, muscle, liver and lung, respectively, compared with euthermic values.

\section{Distribution of Ets1/2 in cytoplasmic and nuclear extracts}

The distribution of Ets1 in cytoplasmic and nuclear extracts of liver and muscle tissues were assessed by western blotting. Figure 3.12A shows representative Western blots and histograms for Ets 1 in subcellular fractions of muscle. The amount of Ets1 in the cytoplasmic fraction of muscle was significantly higher $(\mathrm{P}<0.05)$ than the nuclear content in extracts from both euthermic and hibernating muscle. However, Figure 3.12B shows that in liver there was no significant difference between cytoplasmic and nuclear fractions during euthermia but the relative amount of Ets 1 in the cytoplasmic fraction of liver increased strongly during hibernation.

\section{Ets1 Binding activity in S. tridecemlineatus}

The transcription factor Ets1 regulates many genes involved in cell growth, differentiation, anti-apoptosis, pro-apoptosis, and angiogenesis. In order to determine 
whether Ets l could be involved in the hibernation responsive expression of these genes, the relative level of Etsl binding to DNA was assessed in extracts from euthermic and hibernating skeletal muscle and liver. The interaction between Ets 1 and the promoter sequence to which it binds on downstream genes was investigated using an electrophoretic mobility shift assay with biotin-labeled oligonucleotides containing the Ets 1 binding site (EBS). Figure 3.13 shows that the biotin-labeled probes bound to three major protein complexes in the gel (I, II and III). Competition studies were done with (Lane 2) and without (Lane 1) excess added unlabelled probe and these showed that band II represents true Ets binding. Bands I and III were determined to represent nonspecific binding. The amount of Ets 1 binding in liver was less in hibernator extracts (Lane 4) than in euthermic extracts (Lane 3). However, in skeletal muscle Ets1 binding appeared to be not changing between hibernating conditions (Lane 7) and the euthermic conditions (Lane 6).

\section{DISCUSSION}

During hibernation all aspects of an animal's physiological activity are slowed down. Metabolic rate (oxygen consumption) can fall to $<5 \%$ of euthermic resting rate and heart beat, breathing and all other vital functions are also reduced dramatically. In hibernators, the torpor-arousal cycle has multiple features of an ischemia-reperfusion cycle which can cause differential oxygen levels leading to hypoxic conditions in different organs due to under perfusion. Evidence of hypoxic conditions due to reduced breathing in ground squirrels has been found by several investigators in the past (Drew et al., 2004 and references therein). The first evidence of hypoxic conditions in hibernators 
was shown by Hiestand et al. (1950) via a comparison of hypoxic conditions in hibernating and non-hibernating mammals. The study showed a better tolerance of hypoxic conditions by hibernators than by non-hibernators. Furthermore, hypoxia has been shown to suppress metabolic rate in hibernating species leading to a cooling of body temperature; this hypoxia-induced hypothermic response was stronger in hibernators than in non-hibernators (Barros et al., 2001). Other metabolic responses may also be stimulated by hypoxic conditions such as a reduction in glycolysis during cold-hypoxia; this was shown to be related to hibernator specific metabolic adaptations which are key to survival of hypothermia during torpor bouts (Churchill et al., 2004). Multiple changes in cellular processes could also be stimulated by hypoxia such as activation of cell receptors, activation of kinases, phosphatases, phosphorylation of transcription factors and changes in transcription factor activity. Recently, Morin and Storey (2005) reported the activation of HIF-1 $\alpha$ during hibernation in ground squirrels. Another transcription factor that changes as part of the immediate-early response to hypoxia is the v-ets erythroblastosis virus E26 oncogene homolog (Ets) (Peters et al., 2003; Oikawa et al., 2001). Ets proteins belong to the super family of winged helix-turn-helix (wHTH) DNAbinding proteins. A connection between the hypoxia inducible transcription factors HIF-1 and Ets1 has long been established (Cummins and Taylor, 2005).

Ets family members can act as both upstream and downstream effectors of signaling pathways. As upstream effectors they are responsible for the expression of many growth receptors and as downstream effectors, they activate or repress specific gene targets (Yordy and Muise-Helmericks, 2000). Activities of Ets1 are mostly controlled by reversible phosphorylation reactions as discussed below. Ets1 proteins 
include a family of transcription factor that share a unique DNA binding domain, the Ets domain (Sharrocks et al., 1997; Graves and Petersen, 1998; Ghysdael and Boureux, 1997; Dittmer and Nordheim, 1998). Other family members include Ets2, ERG, ELK1, PU-1 Fli and E74 (Watson et al., 1988; Klemsz et al.,1990; Fisher. et al.,1992). Ets1 contains a DNA-binding ETS domain, a transactivation domain, a pointed domain and a regulatory domain (exon VII). The Ets domain is located between amino acids 331-415 and possesses a winged helix-turn-helix motif. The Ets domain recognizes and binds to a specific DNA sequence, GGAA/T, in the promoter region of its downstream genes (Graves and Petersen, 1998; Ghysdael and Boureux, 1997; Dittmer, 2003). Ets1 plays an important role in growth, differentiation, migration, angiogenesis, morphogenesis and pro-/anti-apoptosis (Dittmer, 2003).

Hypoxia-induced transcriptional changes are mediated through protein kinase signaling pathways. For example, HIF-1 $\alpha$ DNA-binding activity can be upregulated by phosphorylation of p42/p44 mitogen activated protein kinases (MAPKs; also known as ERK2 and ERK1, respectively) (Dery et al., 2005). Recently it has also been shown that hypoxia activates protein kinase C (PKC), particularly $\mathrm{PKC} \alpha$, which is involved in many signaling pathways (Goldberg et al., 1997). Further studies showed an upregulation of PKC $\beta$ as a result of hypoxic conditions in rat (Yan et al., 2000). Avaldano and Bazan (1975) also reported PKC activation via diacylglycerol (DAG), which is an intermediate of the EGFR - PKC - Ets pathway (Fig3.1).

The protein kinase $\mathrm{C}$ (PKC) family of proteins is divided into three groups. The first group is conventional PKCs ( $\alpha, \beta$ I, $\beta$ II, $\gamma$ ) which need $\mathrm{Ca}^{2+}$ to be activated in the presence of phosphatidylserine (Nishizuka, 1992). The second group is novel PKCs $(\delta, \varepsilon$, 
$\eta, \theta)$ that are independent of $\mathrm{Ca}^{2+}$ (Ono et al., 1988). The third group is the atypical PKCs $(\zeta, 1, \lambda, \mu)$, which do not belong to either of the above groups and are dependent on phosphatidylserine but not affected by diacylglycerol, phorbol ester, or $\mathrm{Ca}^{2+}($ Nishizuka, 1992; Johannes et al., 1994). PKD activation triggered via PKC activity can be initiated either by membrane receptors such as the EGFR or hypoxic conditions (Song et al., 2007; King and Cooper, 1986; Yan et al., 2001).

EGFR is a transmembrane glycosylated polypeptide, with its $\mathrm{N}$-terminal extending outside the cell and it's C-terminal inside the cell (Hunter and Cooper, 1985). The C-terminal is responsible for its autophosphorylation activity and contains three main auto-phosphorylation sites at amino acids 1068, 1086 and 1173 (Downward et al., 1985). EGFR controls many important biological responses including cell proliferation, differentiation, migration, and antiapoptotic signaling (Prenzel et al., 2001). Hypoxia is one of the stimuli that activate EGFR which is particularly sensitive to stress-induced activation (Franovic et al., 2007; Wang et al., 2007). Other stimuli that activate EGFR include the plasma epidermal growth factor (EGF) and the transforming growth factor $\alpha$ (TGF $\alpha$ ) (Goldkorn et al., 1998; Fisher et al., 2004). When a stress stimulus is received, EGFR is activated and autophosphorylated and then phosphorylates downstream targets such as PKCs and, in turn, Ets1 (Downward et al., 1985; Lindemann et al., 2001, 2002).

The present study analyzed the protein levels of EGFR, phospho-EGFR (pY1173 and pY1086), $\mathrm{PKC} \mu$, phospho-PKC $\mu$ (Ser 744/748), phospho-PKCa/ $\beta$ II and Ets1 as well as Ets1 binding to DNA and EtsI transcript levels in different organs of thirteenlined ground squirrels. Total EGFR levels increased in brain, lung and kidney of hibernating squirrels. The amount of phosphorylated active EGFR also increased in 
hibernation in selected cases as evidenced by increased pY1173 levels in lung and liver and increased pY1086 content in all four organs tested. Franovic et al., 2007 found that the hypoxic stress induces EGFR activation, and so it is probable that hypoxic stress in hibernators may also underlie the activation of EGFR during torpor in ground squirrels. These results also agree with the findings of Downward et al. (1985) that when EGFR is activated it leads to autophosphorylation of EGFR itself at three sites: pY1068, pY1086, and pY1173. Although pY1068 was not assessed in my study, autophosphorylation during hibernation was clearly indicated by the enhanced levels of pY1086 in all organs tested and the elevated levels of pY1173 in lung and liver.

As discussed earlier, autophosphorylation of EGFR activates the PKCs. Hence, the levels of relevant PKCs were also quantified in ground squirrel tissues. Total PKC $\mu$ protein levels were elevated in brain, heart, lung, liver and muscle during hibernation (with no change in kidney), indicating a correlation with the activated EGFR. Phospho$\mathrm{PKC} \mu$ (Ser 744/748) levels, the active form, also increased in parallel in five organs but not in skeletal muscle. Phosphorylated PKC $\alpha / \beta$ (Thr 638/641) levels were also increased in five ground squirrel organs during hibernation (but not in brain). According to the findings of Mehrani and Storey (1997), the most active form of PKC in hibernator brain is $\mathrm{PKC} \gamma$ (of the $\mathrm{PKC} \alpha / \beta / \gamma$ isoforms) but no study has been made previously of $\mathrm{PKC} \mu$ in hibernators. It is evident from this study that $\mathrm{PKC} \mu$ also elevated in brain of the torpid animals. During hibernation, protein kinase activation appears to be a key to reversible control over the activities of many cellular enzymes and functional proteins to achieve both an overall coordinated suppression of metabolic activity and a reorganization of the 
priorities for energy use during torpor (Storey, 1987; MacDonald and Storey, 2005; Mehrani and Storey, 1997; Holden et al., 1998).

In order to activate or repress genes and transcription factors, PKCs should move into the nuclei. Hence, the subcellular distribution of phosphorylated PKC $\alpha / \beta$ (Thr 638/ 641) was analyzed in muscle between euthermic and hibernating conditions. Nuclear localization studies showed a significant increase in the amount of phosphorylated PKC $\alpha$ $/ \beta(\operatorname{Thr} 638 / 641)$ in the nuclear fraction of hibernating animals suggesting that the kinase may be active in the phosphorylation of transcription factors and other proteins in the nucleus during torpor. Since PKC is one of the upstream effectors that phosphorylates Ets1 (Dittmer, 2003), the increased level of active PKCs in tissues of hibernators may be responsible for phosphorylation of Ets1.

Next, the mRNA levels and protein levels of Ets1 were measured in different organs of the hibernators. Ets1 transcript levels increased in lung, kidney, liver and muscle during hibernation whereas in brain Ets1 mRNA levels were reduced. Ets1 protein levels also increased in lung, kidney, liver and muscle (but decreased in brain) suggesting transcriptional regulation of Ets1 expression during hibernation. The opposite response of brain compared with other organs may suggest that brain is protected from hypoxic stress by other stress molecules or mechanisms during hibernation such as those that involve JNK or PKB pathways (Lee et al., 2002). Ets1 plays an important role in stress-induced changes such as oncogenesis, migration, apoptosis and cellular integrity (Dittmer, 2003). Hence, these data on Ets1 in hibernation suggest that this transcription factor may have an important influence over the hibernation cycle. Two more important 
concepts were then studied in order to better understand the role of Ets 1 during hibernation: its phosphorylation status and DNA binding activity.

Etsl protein is known to be regulated by reversible phosphorylation. Several kinases can phosphorylate Ets 1 and modulate its activity. Calmodulin-dependant kinase II (CaMKII) induces phosphorylation of the exon VII domain (Cowley and Graves, 2000; Liu and Grundstrom, 2002) which then blocks Ets1 DNA binding activity to inhibit Ets1 transcriptional activity. Furthermore, this inactivation can convert Ets1 from an activator to a repressor ( $\mathrm{Liu}$ and Grundstrom, 2002). Protein kinase $\mathrm{C} \alpha$ also phosphorylates the exon VII domain of Ets1 and leads to its inactivity (Lindemann et al., 2001, 2002). Other pathways that are known to activate Ets1 include the Ras/ Raf/ MEK/ (MAPK/ ERK kinase1)/ extra-cellular-signal-regulated kinase (ERK 1/ 2) pathways. From the above findings, it is evident that phosphorylation in different domains of Etsl regulates its activity differently (Liu and Grundstrom, 2002; Foulds et al., 2004).

In this study, the increased levels of phosphorylated PKC in brain, heart, lung, kidney and liver may play a role in exon VII domain phosphorylation of Ets1, which lead to the inactivation of Ets1 transcription factor activity. Apart from the observation of increased levels of PKCs in tissues of hibernating ground squirrels, the mitogen-activated protein kinase, ERK, was also elevated in brain, muscle and heart whereas decreased activities were observed kidney and liver. MAPKAPK-1 was also elevated in brain and muscle (but not in kidney, liver and heart) whereas MAPKAPK-2 was increased in brain, muscle and heart (MacDonald and Storey, 2005). Overall, then, MAPK/ERK activities have been shown to be high in brain, muscle and heart of hibernators, whereas PKC and its phosphorylated levels are elevated in brain, heart, lung, kidney, liver and muscle. 
Hence, brain, heart and muscle Ets1 might be phosphorylated by either the PKC or MAPK/ERK pathways, whereas lung, kidney and liver may be regulated more by the PKC pathway leading to the inactivation of Ets1. The elevated levels of phosphorylated PKC together with an increased level of Ets 1 protein in lung, kidney and liver indicates a possible phosphorylation of Ets1 in these organs leading to inactivation of Ets1 activity.

The transcriptional regulation of Ets proteins depends on the interaction with nuclear proteins since protein-protein interactions are important for every step of cell signaling (Li et al., 2000). Jonsen et al. (1996) showed a negative regulation of Ets1 binding activity via two inhibitory regions flanking the minimal DNA-binding domain on Ets 1 which are functionally and structurally coupled. They also confirmed that conformational changes play an important role in binding activity.

Next the level of Ets1 nuclear localization and degree of binding in liver and muscle were analyzed. Nuclear localization studies revealed that the increased level of Ets1 during hibernation was highly localized in the cytoplasmic fraction rather than the nuclear fraction in liver. The nuclear fraction of Ets 1 did not change much between euthermic and hibernating conditions in muscle. Furthermore, this also indicates that the lower level of Ets1 in the nuclear fraction is consistent with a decreased transcriptional activity. It was confirmed by the EMSA studies. The EMSA results showed a decrease in binding activity during hibernation in liver and an almost unchanged level of binding in muscle between euthermic and hibernating conditions. A reduced level of binding in liver may indicate a reduced transcriptional state of growth and apoptosis related genes in this organ. An unchanged level of binding in muscle may be an indication that there may be still transcription of genes which may support the survival and function of muscle during 
hibernation since muscle is extensively used in shivering thermogenesis during interbout arousals.

Analysis of the sequence of Ets1 from thirteen-lined ground squirrel indicated a strong homology with the protein (93\%) and the nucleotide $(95 \%)$ from other nonhibernating mammals (human, mouse and rat). A few amino acid substitutions were observed in the ground squirrel sequence. These amino acid changes may play a role in allowing Ets 1 to function during hibernation or cell survival at low body temperatures by creating changes in protein conformation. These amino acid substitutions also may be due to the species specific substitutions that may be unique to the ground squirrel.

Overall, the data presented in this chapter support the survival of ground squirrels during hibernation by switching "on" or "off" different genes in an organ specific manner. The hypoxic condition imposed during hibernation may trigger EGFR activation and its autophosphorylation. Then, the activated EGFR in turn stimulates production of PKCs and their phosphorylation. The increased levels of phospho-PKCs then phosphorylate transcription factors such as Ets1 and halt the activation of genes related to the growth and differentiation and may also activate genes that aid hibernation. 
Fig. 3.1: Model of EGFR-PKC- Ets $1 / 2$ pathway: As response to hypoxic condition. Upon stimulation by the stress or growth factors, the Epidermal Growth Factor Receptor (EGFR) is activated and hence activate PKCs. Activated PKCs move into the nucleus and phosphorylate the transcription factors such as ETS 1/2. The activated transcription factors in turn bind to downstream targets to up-regulate or down-regulate the genes. Taken from www.Sigmaaldrich.com. 
Fig. 3.1:

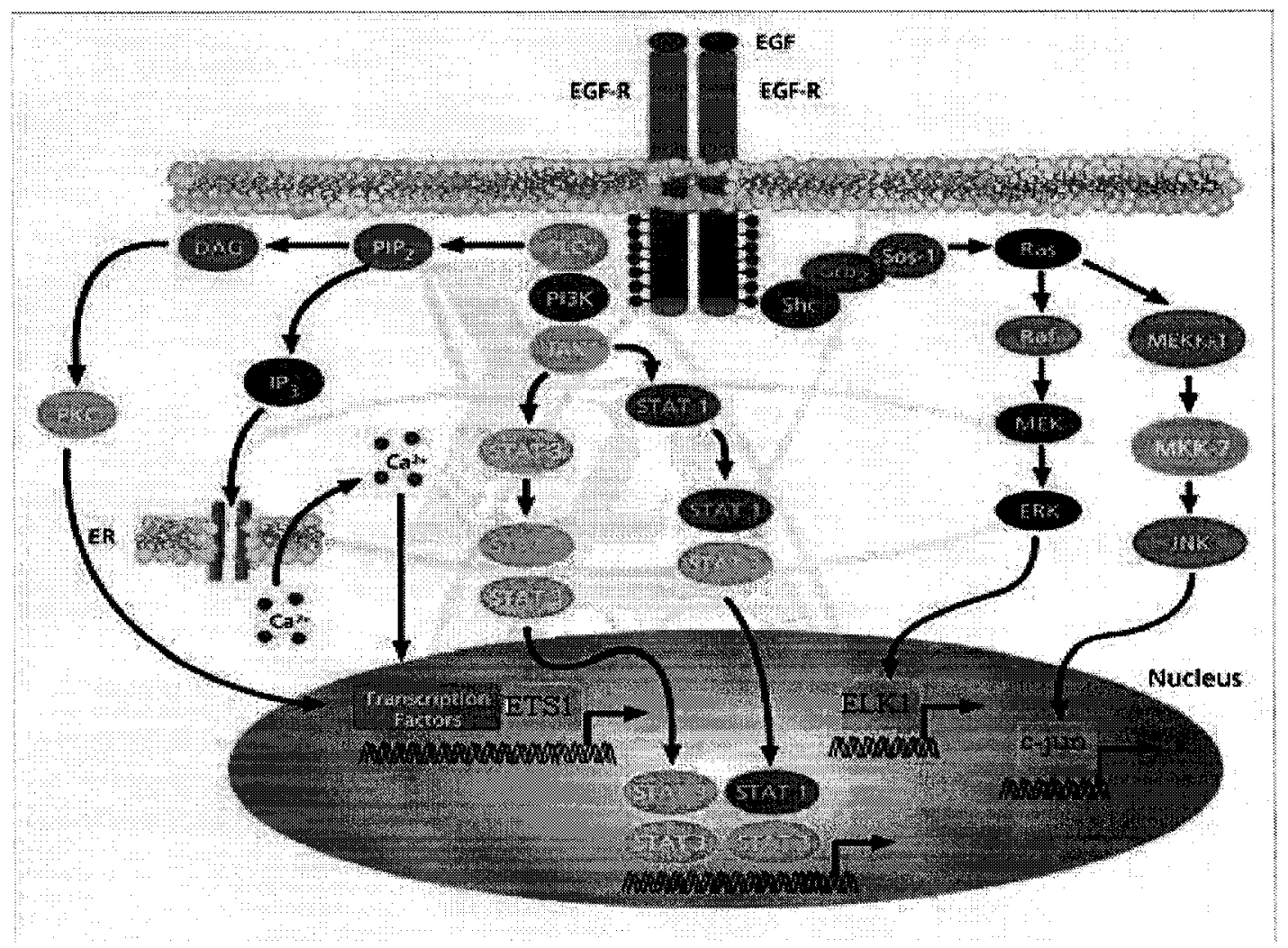


Fig. 3.2: (A) Representative Western blots showing EGFR protein levels in four tissues from Euthermic (E) and Hibernating (H) ground squirrels. (B) Histogram showing the relative mean normalized intensities of the EGFR protein bands in euthermic and hibernating animals. Data are means \pm S.E.M., $n=4-5$ independent trials. ${ }^{*}$ - Value for hibernating sample is significantly different from the corresponding euthermic value, $\mathrm{P}<$ 0.05 . 
Fig. 3.2:

A.

\begin{tabular}{llllllll} 
Brain & & Lung & \multicolumn{3}{c}{ Kidney } & \multicolumn{2}{c}{ Liver } \\
E & H & E & H & E & H & E & H
\end{tabular}

B.

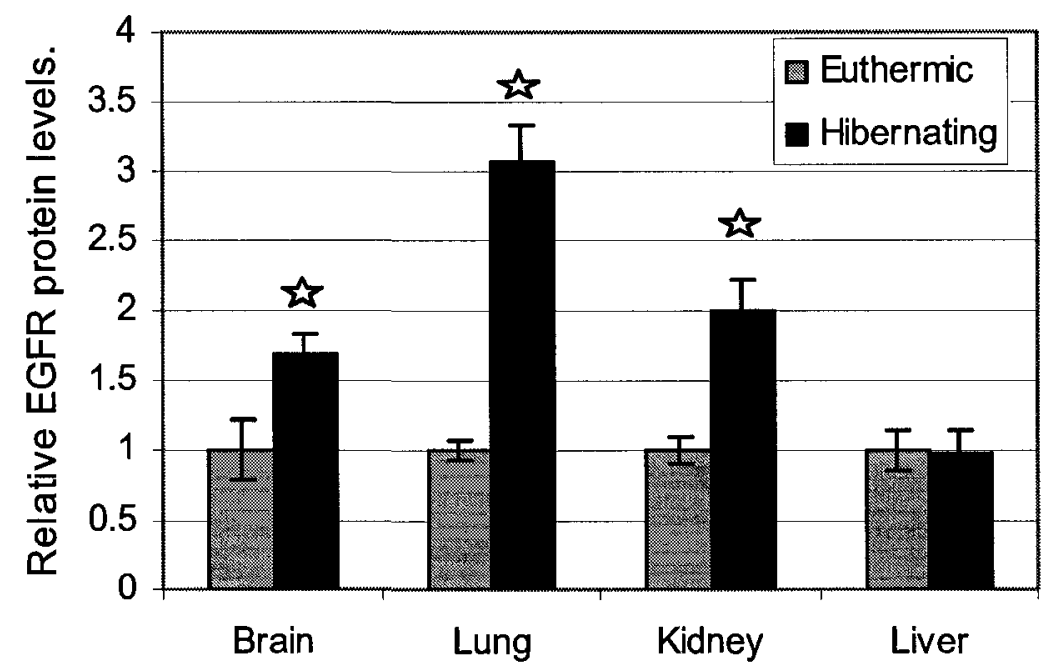


Fig. 3.3: (A) Representative Western blots showing phosphorylated EGFR (pY1173) protein levels in four tissues from Euthermic $(\mathrm{E})$ and Hibernating $(\mathrm{H})$ ground squirrels. (B) Histogram showing the relative mean normalized intensities of the phospho-EGFR (pY1173) protein bands in euthermic and hibernating animals. Data are means \pm S.E.M., $\mathrm{n}=4-5$ independent trials. * - Value for hibernating sample is significantly different from the corresponding euthermic value, $\mathrm{P}<0.05$. 
Fig. 3.3:

A.

\begin{tabular}{cccccccc}
\multicolumn{2}{c}{ Brain } & & Lung & \multicolumn{3}{c}{ Kidney } & \multicolumn{2}{c}{ Liver } \\
E & H & E & H & E & H & E & H \\
\hline & & & & & & &
\end{tabular}

B.

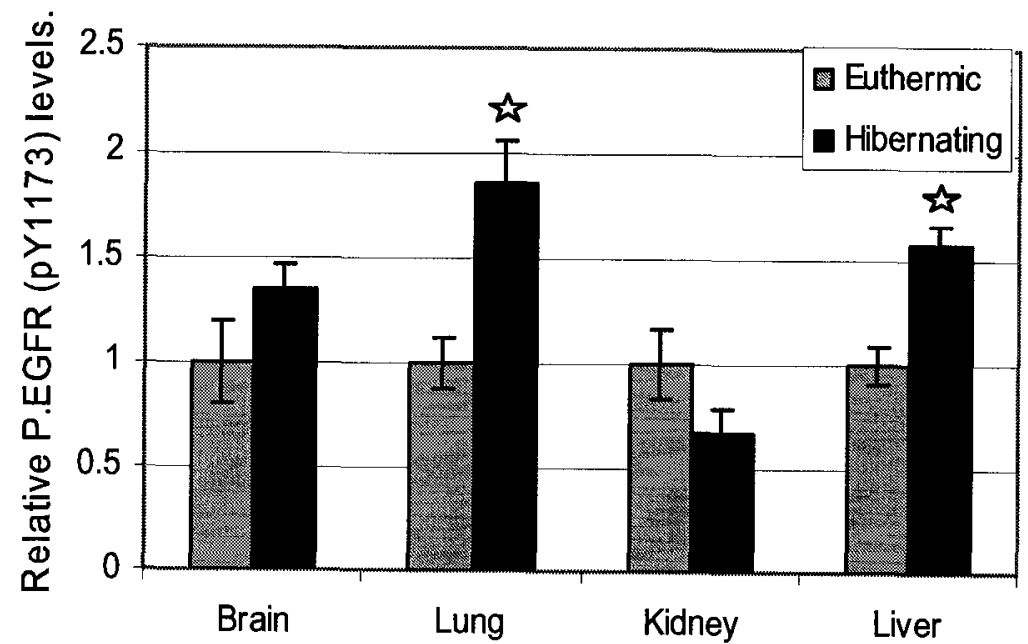


Fig. 3.4: (A) Representative Western blots showing phospho-EGFR (pY 1086) protein levels in four tissues from Euthermic $(\mathrm{E})$ and Hibernating $(\mathrm{H})$ ground squirrels. (B) Histogram showing the relative mean normalized intensities of the EGFR (pY1086) protein bands in euthermic and hibernating animals. Data are means \pm S.E.M., $n=4-5$ independent trials. * - Value for hibernating sample is significantly different from the corresponding euthermic value, $\mathrm{P}<0.05$. 
Fig. 3.4:

A. Brain Lung Kidney Liver

\begin{tabular}{llllllll}
$E$ & $H$ & $E$ & $H$ & $E$ & $H$ & $E$ & $H$ \\
\hline
\end{tabular}

B.

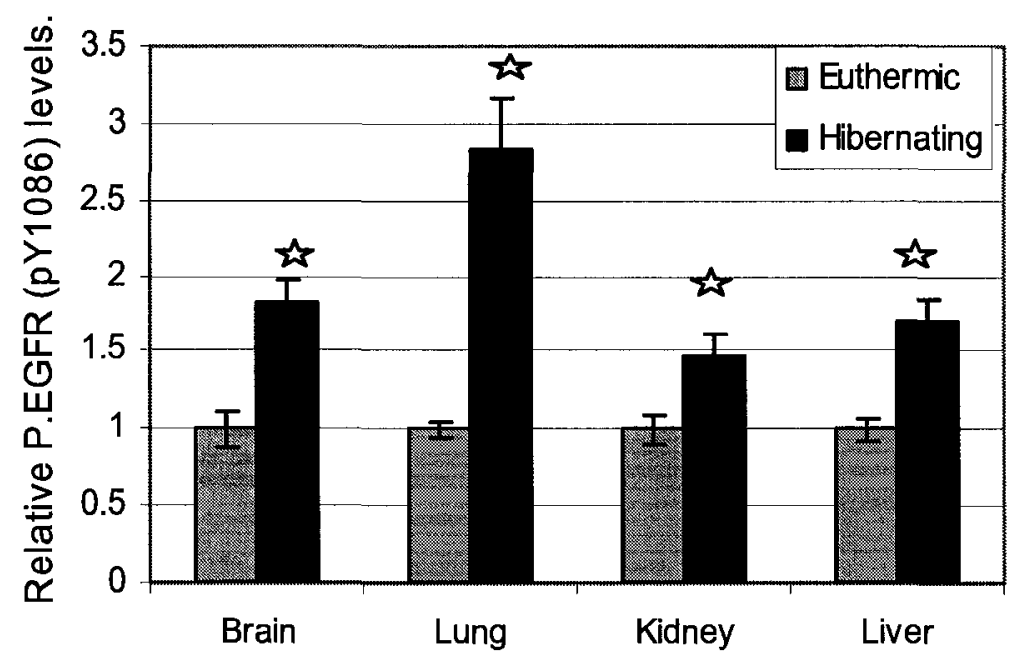


Fig. 3.5: (A) Representative Western blots showing $\mathrm{PKD} / \mathrm{PKCmu}$ protein levels in six tissues from Euthermic (E) and Hibernating (H) ground squirrels. (B) Histogram showing the relative mean normalized intensities of the $\mathrm{PKD} / \mathrm{PKCmu}$ protein bands in euthermic and hibernating animals. Data are means \pm S.E.M., $n=4-5$ independent trials. Muscle is hind leg skeletal muscle. ${ }^{*}$ - Value for hibernating sample is significantly different from the corresponding euthermic value, $\mathrm{P}<0.05$. 
Fig. 3.5:

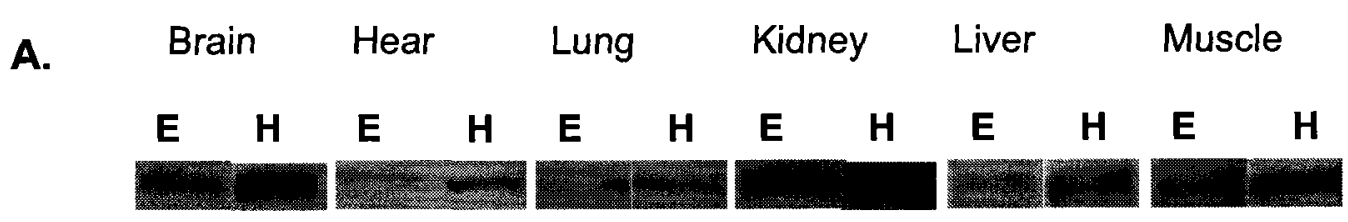

B.

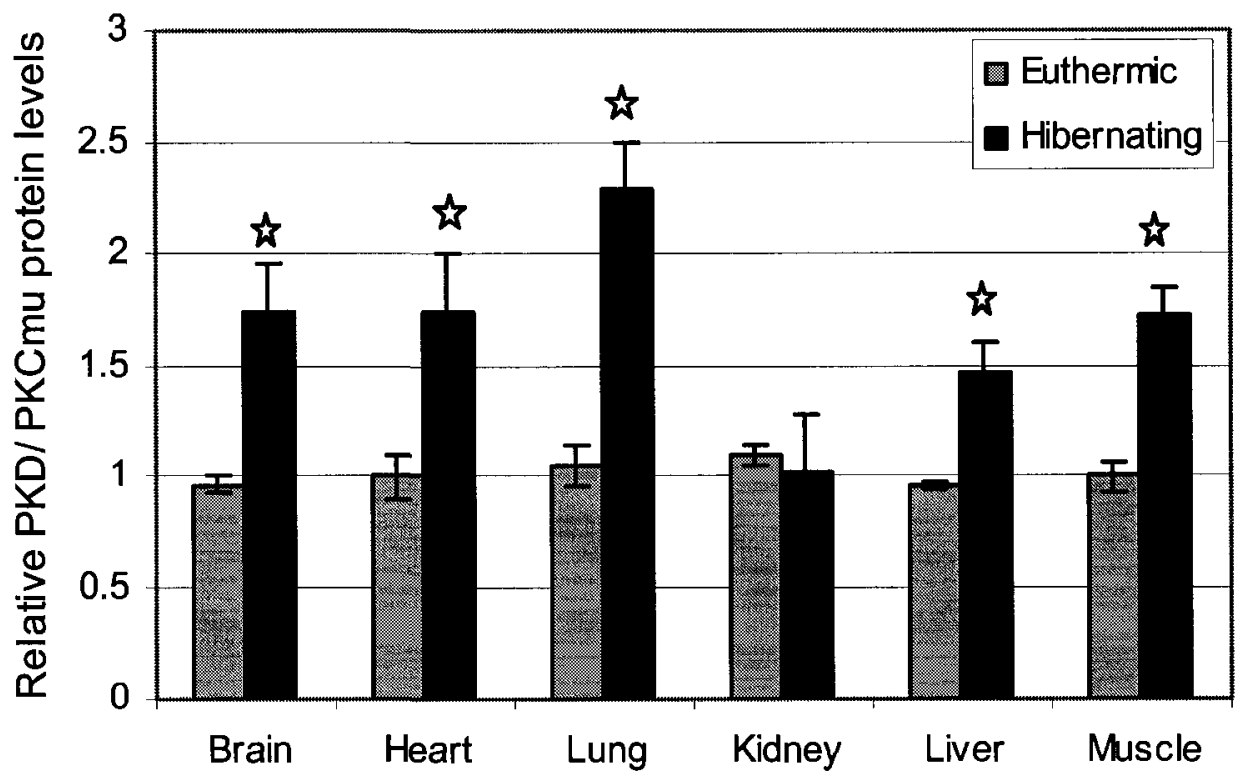


Fig. 3.6: (A) Representative Western blots showing phospho-PKD/ PKCmu (Ser 744/ 748) protein levels in six tissues from Euthermic (E) and Hibernating $(\mathrm{H})$ ground squirrels. (B) Histogram showing the relative mean normalized intensities of the phospho-PKD/PKCmu (Ser 744/ 748) protein bands in euthermic and hibernating animals. Data are means \pm S.E.M., $n=4-5$ independent trials. Muscle is hind leg skeletal muscle. * - Value for hibernating sample is significantly different from the corresponding euthermic value, $\mathrm{P}<0.05$. 
Fig. 3.6:

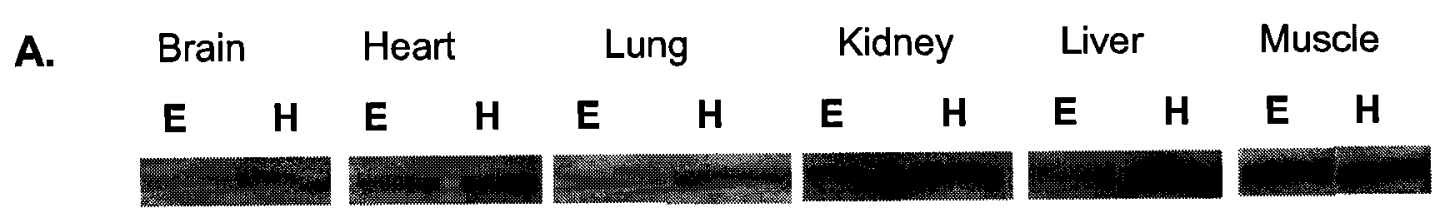

B.

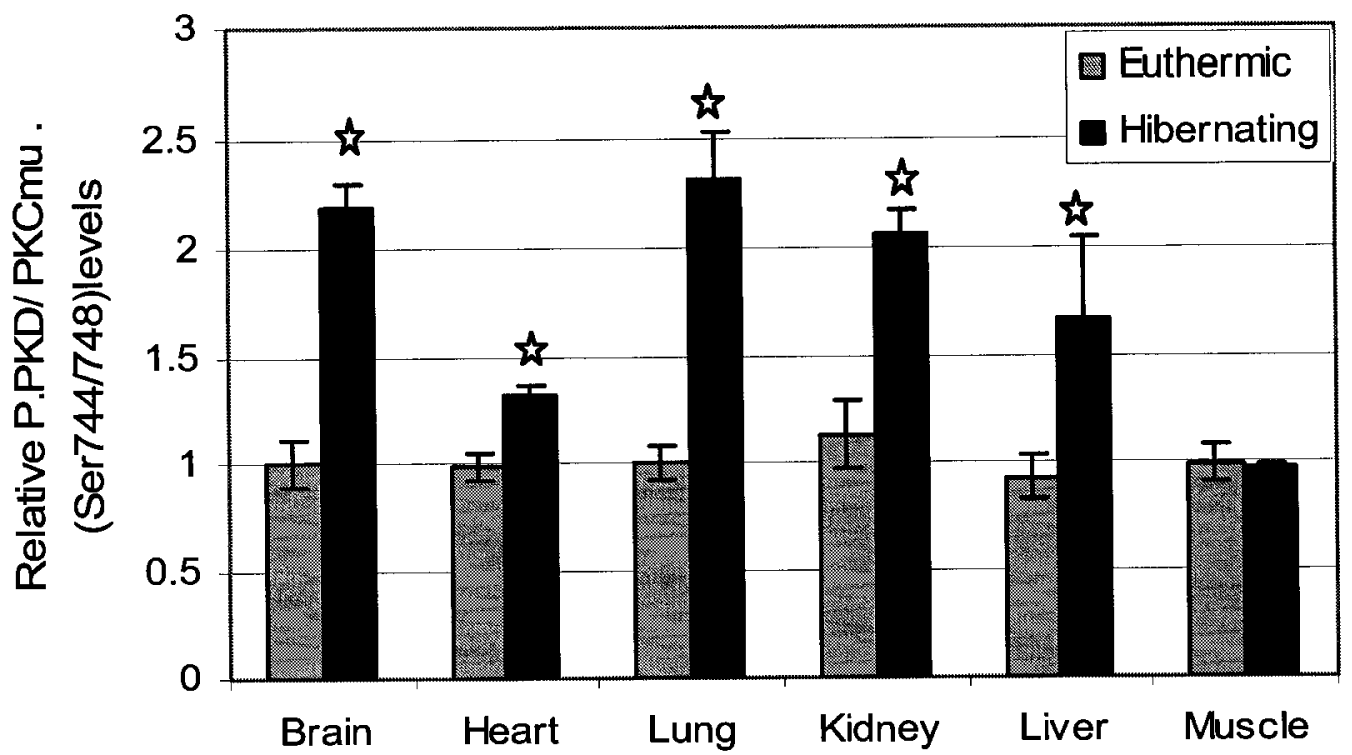


Fig. 3.7: (A) Representative Western blots showing phospho-PKC alpha/beta (Thr 638/ 641) protein levels in four tissues from Euthermic (E) and Hibernating $(H)$ ground squirrels. (B) Histogram showing the relative mean normalized intensities of the phospho PKC alpha/ beta (Thr 638/641) protein bands in euthermic and hibernating animals. Data are means \pm S.E.M., $\mathrm{n}=4-5$ independent trials. Muscle is hind leg skeletal muscle. * - Value for hibernating sample is significantly different from the corresponding euthermic value, $\mathrm{P}<0.05$. 
Fig. 3.7:

A.

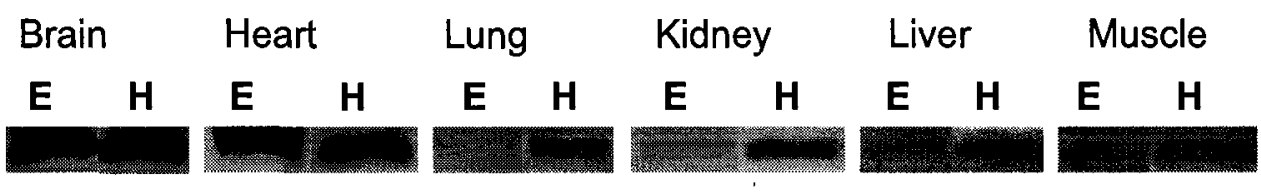

B

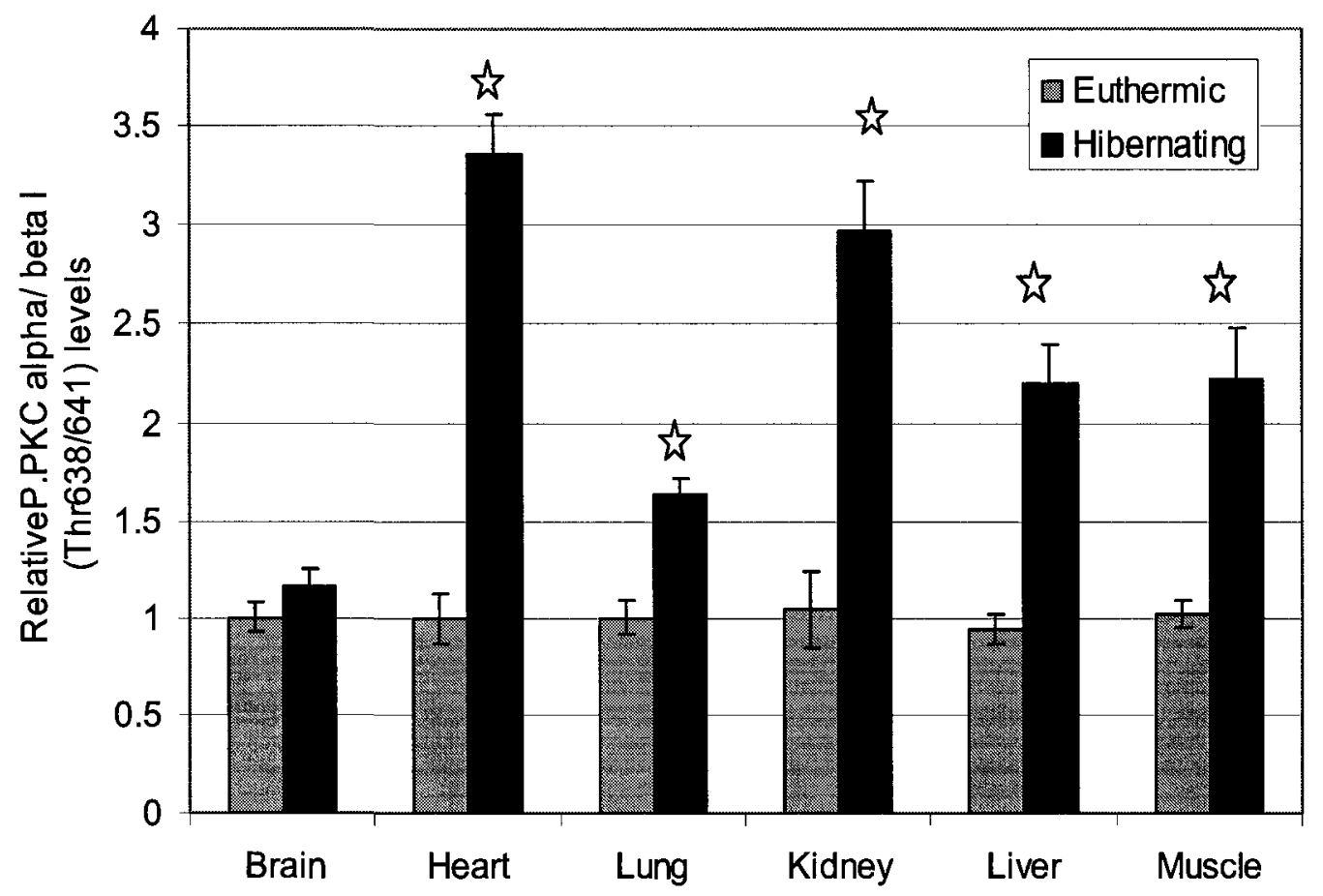


Fig. 3.8: Analysis of phospho-PKC alpha/ beta (Thr 638/641) distribution between cytoplasmic (C) and nuclear $(\mathrm{N})$ fractions in skeletal muscle of euthermic and hibernating ground squirrels. (A) Representative Western blots showing detection of phospho PKC alpha/ beta (Thr 638/641) levels in nuclear and cytoplasmic extracts. (B) Histograms showing the relative mean normalized intensities of the phospho-PKC alpha/ beta (Thr $638 / 641$ ) bands in cytoplasmic and nuclear fractions from muscle. Data are means \pm $\mathrm{SEM}, \mathrm{n}=3$ independent determinations on tissue from different animals. ${ }^{*}$ - Values for nuclear fractions are significantly different from the respective cytoplasmic values, $\mathrm{P}<$ 0.05 . 
Fig. 3.8:

A.

Euthermic Muscle

C

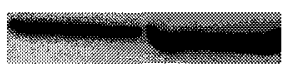

Hibernating

Muscle

C $\quad \mathbf{N}$

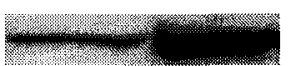

B.

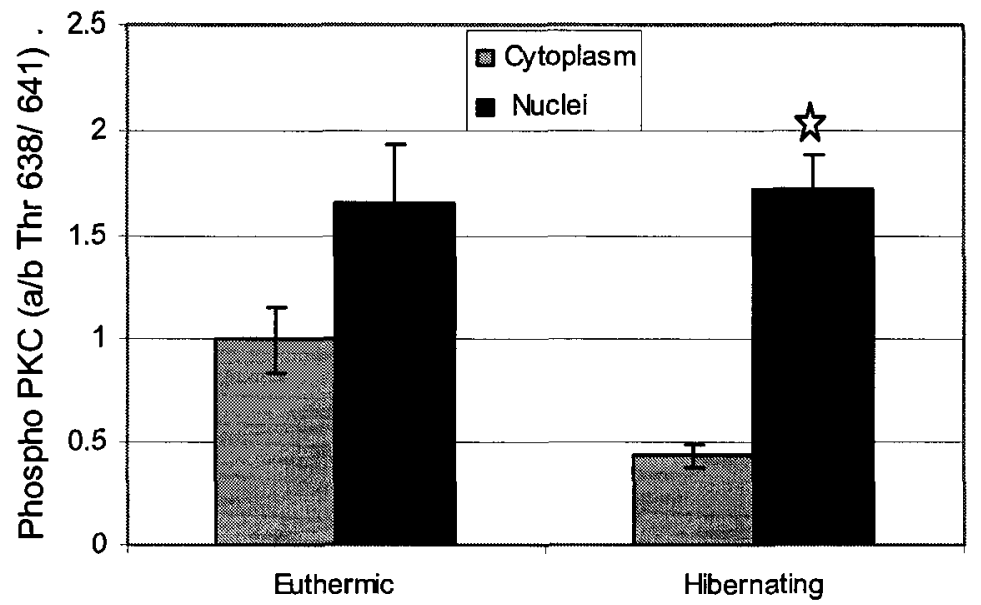


Fig. 3.9: Effect of hibernation on Ets $1 \mathrm{mRNA}$ levels in six tissues of thirteen-lined ground squirrels. (A) Representative RT-PCR product bands amplified from mRNA samples from six tissues of euthermic (E) and hibernating (H) squirrels. (B) Histogram showing the mean values for normalized Ets 1 PCR product levels (normalized against $\alpha$-tubulin) in tissues from hibernating versus euthermic ground squirrels. The highest dilutions for Ets $1\left(10^{-2}\right.$ or $\left.10^{-3}\right)$ and $\alpha-t u b u l i n$ from the same dilution which gave visible PCR product bands were chosen for quantification. Data are means \pm S.E.M., $n=4$ independent trials. Muscle is hind leg skeletal muscle. * - Value for hibernating sample is significantly different from the corresponding euthermic value, $\mathrm{P}<0.05$. 
Fig.3.9:
A.
Brain Heart
Lung
Kidney
Liver
Muscle
$\begin{array}{llllllllllllll}E & H & E & H & E & H & E & H & E & H & E & H\end{array}$
Ets1 2

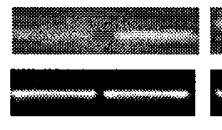

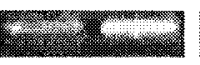
20.
a Tubulin
$-$
25:
mases

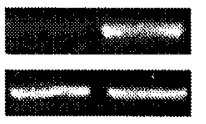

B.

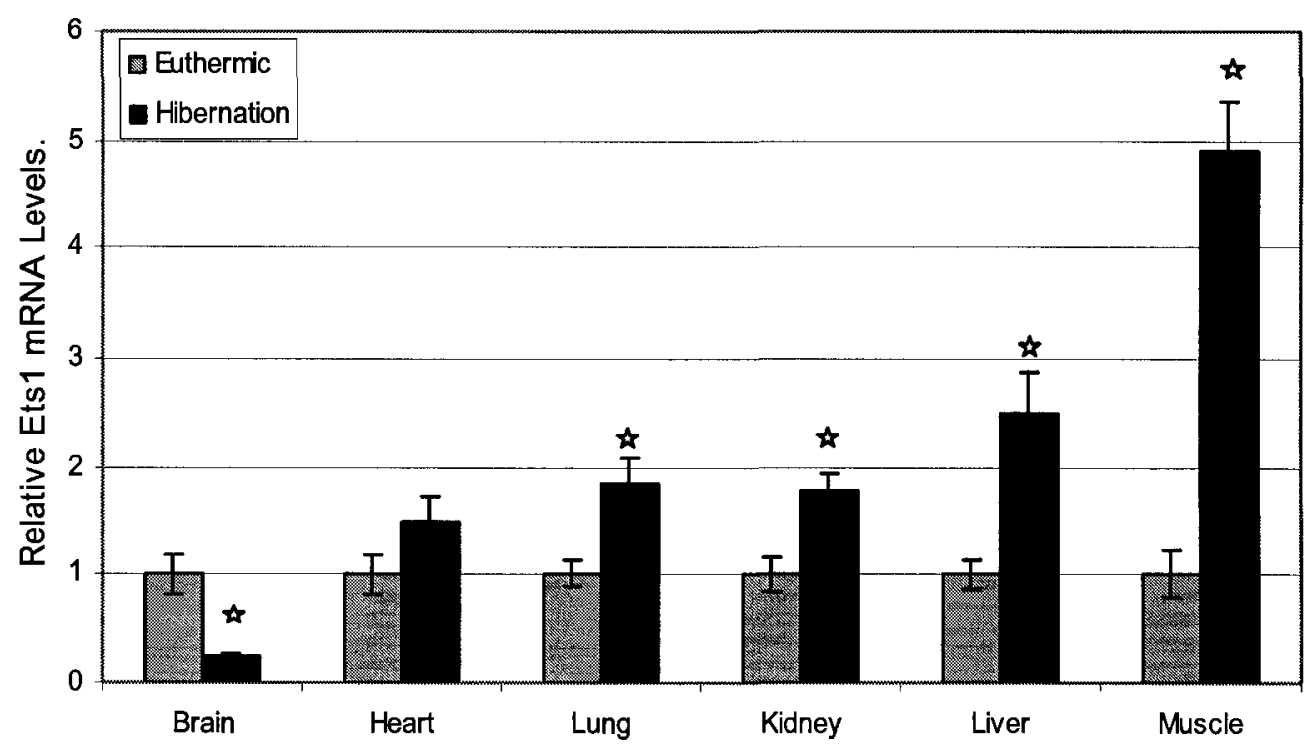


Fig. 3.10: (A) Partial cDNA sequence of Ets1 amplified from skeletal muscle of thirteenlined ground squirrels along with the translated amino acid sequence. Nucleotides and amino acids are numbered on the left. (B) Ground squirrel (Spermophilus tridecemlineatus) Ets1 partial amino acid sequence aligned with human (Homo sapiens), mouse (Mus musculus) and rat (Rattus norvegicus) sequences (Genbank accession numbers NP_005229, NP_001033731 and NP_036687, respectively). Dashes (-) represent amino acids in the human mouse or rat sequences that are identical with the squirrel sequence. 
Fig.3.10:

A.

1 GGTAAACTCGGGGGCCAGGACTCTTTTGAGAGCATAGAGAGCTACGATAGTTGCGACCGC

$\begin{array}{lllllllllllllllllllll}1 & G & K & L & G & G & Q & D & S & F & E & S & I & E & S & Y & D & S & C & D & R\end{array}$

61 CTCACCCAGTCCTGGAGCAGCCAGTCATCTTTCAACAGTCTGCAGCGTGTCCCCTCCTAT

$\begin{array}{llllllllllllllllllllll}21 & \mathrm{~L} & \mathrm{~T} & \mathrm{Q} & \mathrm{S} & \mathrm{W} & \mathrm{S} & \mathrm{S} & \mathrm{Q} & \mathrm{S} & \mathrm{S} & \mathrm{F} & \mathrm{N} & \mathrm{S} & \mathrm{L} & \mathrm{Q} & \mathrm{R} & \mathrm{V} & \mathrm{P} & \mathrm{S} & \mathrm{Y}\end{array}$

121 GACAGCTTCGACTCTGAGGACTATCCGGCTGCCCTACCCAACCACAAGCCCAAGGGCACC

$\begin{array}{lllllllllllllllllllll}41 & D & S & F & D & S & E & D & Y & P & A & A & L & P & N & H & K & P & K & G & T\end{array}$

181 TTCAAGGACTATGTGCGTGACCGTGCTGACCTCAACAAGGAAAGGCCTGTCACAAGCACA

$\begin{array}{lllllllllllllllllllll}61 & \text { F } & \text { K } & \text { D } & Y & \text { V } & \text { R } & \text { D } & \text { R } & \text { A } & \text { D } & \text { L } & \text { N } & \text { K } & \text { E } & \text { R } & \text { P } & \text { V } & \text { T } & \text { S } & \text { T }\end{array}$

B.

ORIGIN

Squirrel-Ets1(P) GKLGGODSFESIESYDSCDRLTOSWSSOSSFNSLORVPSY 40

Human-Ets 1

Mouse-Ets 1

C-

Rat-Ets 1

- 40

Squirrel-Ets1(P) DSFDSEDYPAALPNHKPKGTFKDYVRDRADLNKERPVTST 80

Human-Ets 1

Mouse-Ets1

- - - - - - - - - -

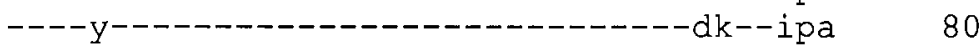

Rat-Etsl 1 
Fig. 3.11: (A) Representative Western blots showing Ets $1 / 2$ protein levels in six tissues from Euthermic $(\mathrm{E})$ and Hibernating $(\mathrm{H})$ ground squirrels. The antibody crossreacted with a single protein band at $55 \mathrm{kDa}$, consistent with the known molecular mass of Ets $1 / 2$ in other mammals. (B) Histogram showing the relative mean normalized intensities of the Ets $1 / 2$ protein bands in euthermic and hibernating animals. Data are means \pm S.E.M., $n=$ 4-5 independent trials. Muscle is hind leg skeletal muscle. * - Value for hibernating sample is significantly different from the corresponding euthermic value, $\mathrm{P}<0.05$. 
Fig.3.11
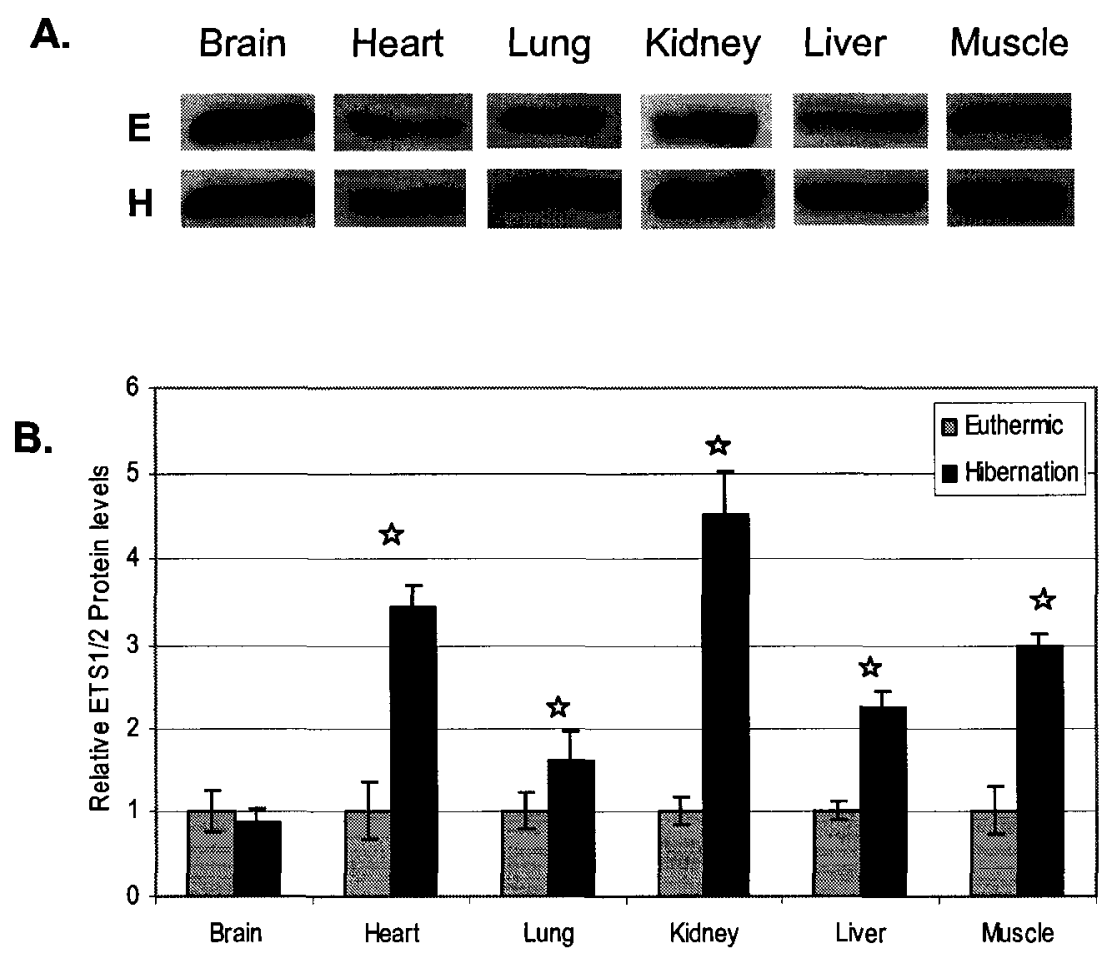
Fig. 3.12: Analysis of Ets $1 / 2$ distribution between cytoplasmic (C) and nuclear $(N)$ fractions in muscle and liver of euthermic and hibernating ground squirrels. (A) Representative Western blots and histograms showing Ets1/2 protein levels in cytoplasmic (C) vs nuclear (N) fractions of skeletal muscle from euthermic and hibernating ground squirrels. (B) Representative Western blots and histograms showing Ets1/2 protein levels in cytoplasmic (C) vs nuclear (N) fractions of liver from euthermic and hibernating ground squirrels. Data are means \pm S.E.M., $n=3$ independent trials. * Values for the nuclear fractions are significantly different from the corresponding cytoplasmic values, $\mathrm{P}<0.05$. 
Fig.3.12

A.

Euthermic

Hibernating
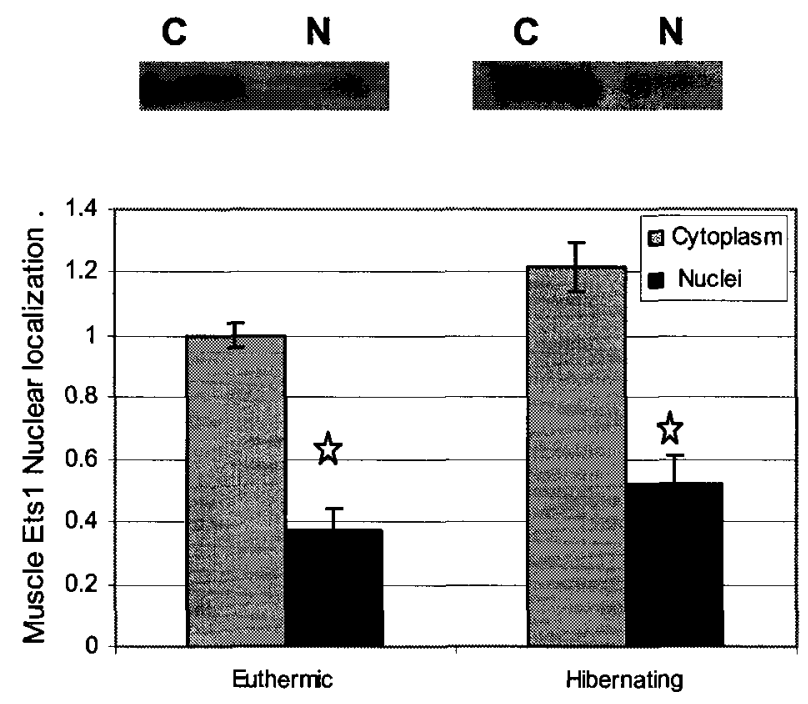

B.
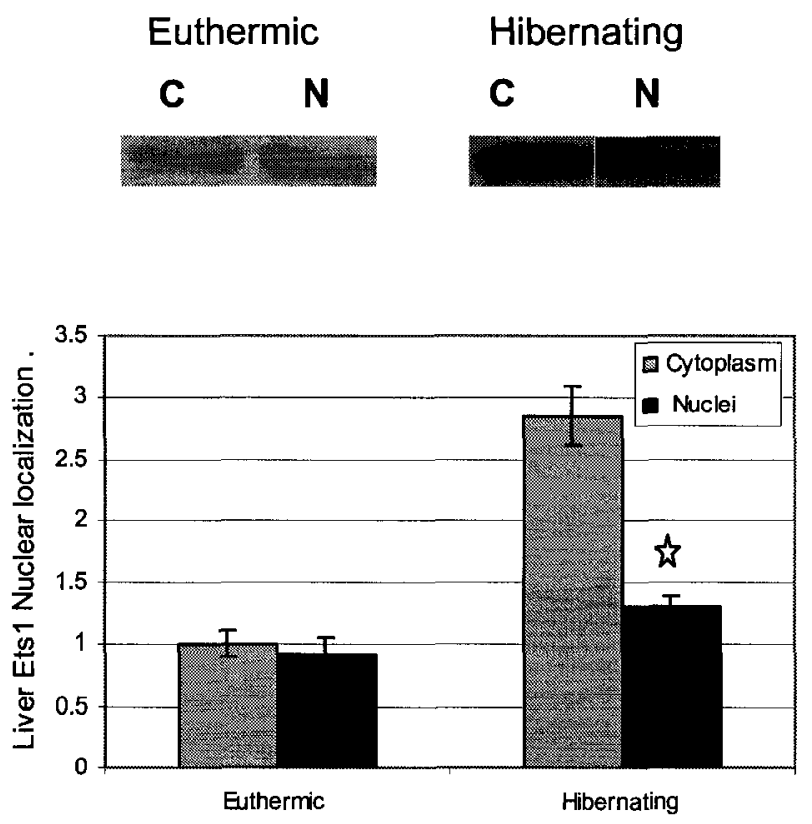
Fig. 3.13: Electrophoretic mobility shift assays using nuclear extracts from liver and muscle of 13-lined ground squirrels. The Ets1 probe (Panomics Inc.) contains the binding site for the transcription factor Ets1. Lane 1, control lane with euthermic muscle nuclear extract; Lane 2, nuclear extract from muscle of euthermic squirrels preincubated with competitors (unlabelled probes); Lanes 3 and 4, nuclear extracts from euthermic and hibernating liver respectively, with no competitors; Lane 5, free probes; Lanes 6 and 7, nuclear extracts from euthermic and hibernating muscle, respectively with no competitors. 
Fig.3.13

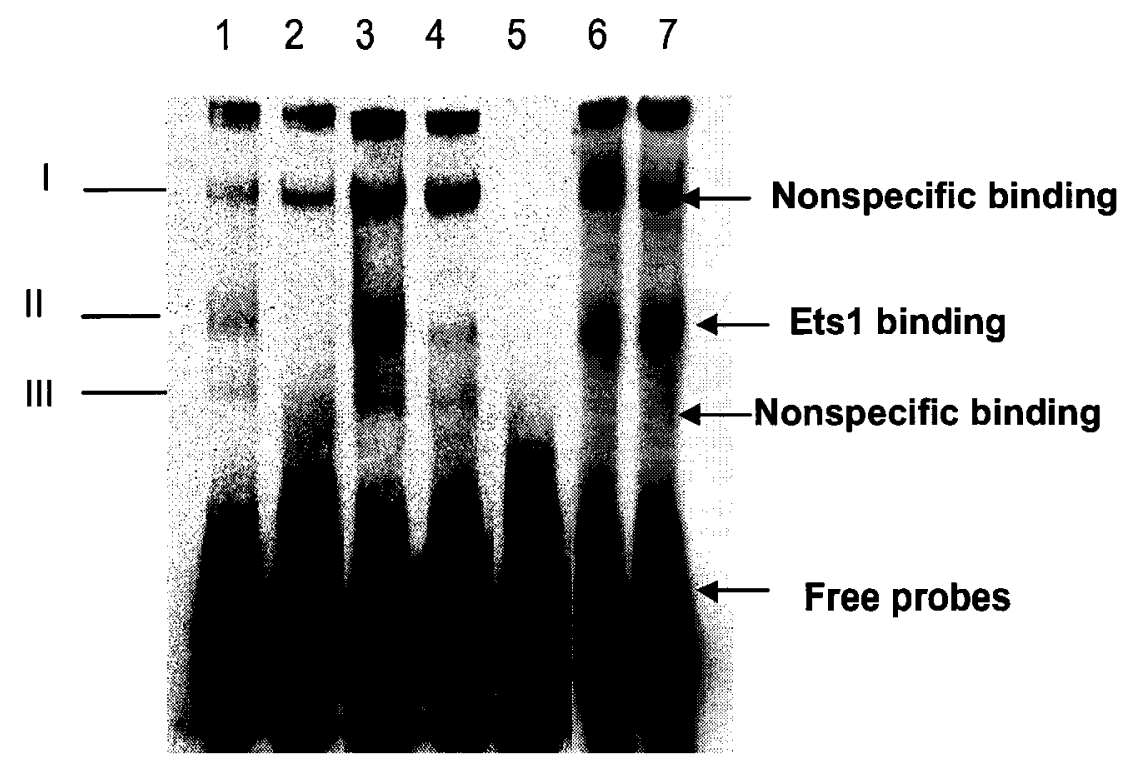


Chapter 4

\section{Roles of the Rb-E2F pathway in hibernating thirteen-lined ground squirrels}




\section{INTRODUCTION}

Hibernation is characterized by a profound decrease in metabolic rate mainly achieved by active suppression of all ATP-consuming processes. Hibernators also save more energy by allowing their $\mathrm{Tb}$ to fall to near ambient temperature so as to reduce the thermal gradient between themselves and the environment (Boyer and Barnes, 1999; Storey, 1997). Gene transcription and translation are two of the most energy expensive processes in cells. Gene transcription by itself can consume $1-10 \%$ of the overall cellular energy budget (Rolfe and Brown, 1997). Hence, rates of gene transcription and protein synthesis are typically greatly reduced during hibernation except for some hibernationresponsive genes that are up-regulated when animals enter torpor (Storey and Storey, 2004; Hittel and Storey, 2002).

Gene silencing may be accomplished in a number of ways. The acetylation of histones by histone acetyl transferase (HAT) is associated with transcriptionally active genes (Sterner and Berger, 2000; Nightingale et al., 1998). By contrast, the removal of acetyl groups by histone deactylases (HDAC) has a negative effect on transcriptional activity (Hassig and Schreiber, 1997). Morin and Storey (2006) reported a 1.8-fold increase in HDAC activities during hibernation in skeletal muscle of 13-lined ground squirrels along with decreased levels of acetylated and phosphorylated Histone H3. They also documented a reduced RNA polymerase II activity during hibernation. These factors collectively provide an insight into the control of the reduced transcriptional status during hibernation.

Multiple regulatory control mechanisms could be involved in gene silencing during hibernation. It is well known that the Rb-E2F pathway plays an important role in 
chromatin remodeling and gene silencing (DeGregory, 2004). Rb protein is a tumor suppressor protein usually found in association with the transcription factor E2F. Rb is a member of a gene family which includes the $\mathrm{Rb}, \mathrm{p} 107$ and p130 proteins. This family of proteins is regulated during the cell cycle by CDK phosphorylation (Stevaux and Dyson, 2002). Phosphorylation of $\mathrm{Rb}$ releases $\mathrm{E} 2 \mathrm{~F}$ and the cell cycle is switched on. E2F plays an important role in cell cycle progression by regulating the genes involved in cell cycle regulation, DNA replication and mitosis (DeGregori, 2002). $\mathrm{Rb}$ is also regulated by apoptotic stimulation by caspase-mediated cleavage and leads to its degradation (Chau and Wang, 2003). At least two distinct mechanisms involving RB-E2F pathway related gene silencing are found in the literature (Ross et al., 1995; Zhang and Dean, 2001; Frolov and Dyson, 2004). The association of $\mathrm{Rb}$ with E2F masks the transcriptional activation domain of $\mathrm{E} 2 \mathrm{~F}$. Then $\mathrm{Rb}$ functions as a transcriptional repressor by recruiting various co-factors involved in chromatin remodeling (Stevaux and Dyson, 2002). In a well-studied mechanism, Rb-E2F recruits HDACs to E2F target promoters. These remove acetyl groups from Lys 9 residues of the histone proteins at the promoter region of the target genes, leading to a closed chromatin state and transcriptional repression (Figure 4.1). In a second mechanism, the deacetylated Lys9 residues of histone $\mathrm{H} 3$ get methylated by SUV 39 histone methyl transferase (HMT). The SUV 39 methylation of histone $\mathrm{H} 3$ results in the recruitment of heterochromatin protein 1 (HP1) which promotes the formation of heterochromatin at the promoter region of the target genes. Assembly of such $\mathrm{Rb}-\mathrm{E} 2 \mathrm{~F}$ repressor complexes on promoters also play a distinct role in $\mathrm{Rb}$ mediated gene repression during senescence (Figue 4.1) (Vandel et al., 2001; Ross et al., 1995; Zhang and Dean, 2001; Frolov and Dyson, 2004). 
Transcriptional repression during hibernation could also employ some of the above criteria. Stresses that could occur during torpor, such as oxidative stress, could lead to transcriptional suppression. For example, protein $\mathrm{p} 21^{\text {Wafl/Cipl }}$ which belongs to the Cip/Kip family of Cdk inhibitors is known to be unregulated during oxidative stress (Hershenson, 2004). Hence, during oxidative stress, the Cdks are less functional and may not phosphorylate $\mathrm{Rb}$. It also has been shown that the $\mathrm{Rb}$ protein can be dephosphorylated directly by a protein phosphatase 2A (PP2A) dependant pathway during oxidative stress (Cicchillitti et al., 2003). Hence, a dephosphorylated $\mathrm{Rb}$ protein resulting from oxidative stress during hibernation may lead to a strong association of $\mathrm{Rb}$ E2F complex. This assembly then forms the chromatin remodeling complex in the promoter regions of the target genes as described above which functions to stop or reduce gene transcription.

The studies presented in this chapter look at the transcriptional state of six organs of euthermic and hibernating ground squirrels by assessing the protein levels of $\mathrm{Rb}$, E2F1, SUV39H1, HDAC and c-Myc proteins, as well as changes in $B c l 2$ mRNA transcript levels and the DNA binding activity of E2F1. c-Myc protein is a downstream target of E2F 1 and contains the E2F1 binding site in its promoter; hence, it was studied to assess E2F1-mediated gene silencing. The B-Cell Lymphoma $2(B c l 2)$ gene is an antiapoptotic gene that is also regulated by E2F1 (Sementchenko and Watson, 2000). Overall, the information gathered in this chapter provides strong evidence of gene silencing in ground squirrel tissues during hibernation. 


\section{METHODS AND MATERIALS}

\section{Animals}

All animals were captured, housed and organs harvested as previously described in Chapter 2. The skeletal muscle used was a mixture of several hind limb muscles.

\section{Western Blotting}

Western blotting was performed as described in Chapter 2. Total protein was isolated from samples of brain, heart, lung, kidney, liver and skeletal muscle of euthermic and hibernating ground squirrels. Aliquots containing 20-30 $\mu \mathrm{g}$ of protein were loaded into each well of $10-12 \%$ SDS gels, followed by electrophoresis, and then transfer to PVDF membrane. Mouse monoclonal antibodies for total $\mathrm{Rb}$ protein and rabbit polyclonal antibodies to phospho-Rb (Ser780), phospho-Rb (Ser795), HDAC4 and HDAC6 were purchased from Cell Signalling Technology. Rabbit polyclonal antibodies to E2F1 and goat polyclonal antibodies to SUV39H1 were purchased from Santa Cruz Biotechnology. Rabbit monoclonal antibodies to c-Myc were a kind gift from Epitomics. Prior to the addition of primary antibody, blots were blocked for 15-30 min in TBST containing $1 \%$ non-fat dried milk or $30-45 \mathrm{~min}$ in TBST containing $2.5 \%$ non-fat dried milk. All primary antibody incubations for Western blotting were carried out at $4^{\circ} \mathrm{C}$ overnight in $1 \mathrm{X}$ TBST at 1:5000 v/v dilution except for $\mathrm{Rb}$, phospho-Rb (Ser780) and phospho- $\mathrm{Rb}$ (Ser795) which were diluted 1:2000 v/v. Each blot was washed for $5 \mathrm{~min}$ in 1X TBST three times prior to the addition of secondary antibody. Secondary antibody $(1: 2000 \mathrm{v} / \mathrm{v}$ dilution) incubations were carried out for $90 \mathrm{~min}$ at room temperature and 
followed by 3 washes in 1X TBST for 5 min each. Detection and quantification of signal on the PVDF membrane was as described in Chapter 2.

\section{Distribution of E2F1 in cytoplasmic and nuclear extracts}

Cytoplasmic and nuclear extracts from skeletal muscle were prepared as described in Chapter 2. Protein samples from each fraction $(60 \mu \mathrm{g})$ were separated on $10 \%$ SDSPAGE minigels at $180 \mathrm{~V}$ for $45 \mathrm{~min}$, transferred onto PVDF membranes, and immunoblotted with total $\mathrm{Rb}$ and E2F1 antibodies as above.

\section{Nuclear extract preparation and electrophoretic mobility shift assay (EMSA)}

The EMSA E2F1 Gel-Shift kit was purchased from Panomics. Nuclear extracts from liver and muscle of euthermic and hibernating ground squirrels were prepared as described in Chapter2. The EMSA was performed as described by the manufacturer using biotin-labeled synthetic oligonucleotides (probe) containing a sequence corresponding to a cis-acting element, the E2F1 binding site 5'- ATTTAAGTTTCGCGCCCTTTCTCAA3'. The EMSA procedure was carried out as described in Chapter 3. Detection of signal on the nylon membrane was done using an enhanced chemiluminescence (ECL) system as recommended by the manufacturer (Immobilon). The membrane was scanned using the SynGene and the resulting image was analyzed.

\section{First strand cDNA synthesis and PCR amplification}

cDNA was synthesized as described in Chapter 2. The resulting cDNA samples from both euthermic and hibernating tissues were serially diluted $\left(10^{-1}, 10^{-2}, 10^{-3}, 10^{-4}\right.$, 
and $10^{-5}$ ) and amplified by the polymerase chain reaction (PCR) with $\mathrm{Bcl}_{2}$ primers that were designed from the consensus sequences of $\mathrm{Bcl}_{2}$ from several other mammals, using the Primer Designer program, version 3.0 (Scientific and Educational Software). The nucleotide sequences of the $B c l_{2}$ primer pairs were forward 5' GACTTCGCCGAGATGTCCAG- 3' and reverse 5' -TGCAGGTGCCGGTTCAGGTA3'. The PCR reaction for $\mathrm{Bcl}_{2}$ consisted of $25 \mu \mathrm{l}$ final volume composed as described previously. The reaction started with an initial step of $4 \mathrm{~min}$ at $94^{\circ} \mathrm{C}$ followed by 35 cycles of $30 \mathrm{sec}$ at $94^{\circ} \mathrm{C}, 30 \mathrm{sec}$ at $64^{\circ} \mathrm{C}$, and $30 \mathrm{sec}$ at $72^{\circ} \mathrm{C}$. The final step was $72^{\circ} \mathrm{C}$ for 7 min. The housekeeping gene $\alpha$-tubulin was also amplified as an internal control. PCR products were separated on a $1 \%$ agarose gel, stained with ethidium bromide, and the intensity of the most dilute cDNA sample that was visible was used for quantification purposes to make sure that the products had not reached their amplification saturation. Quantification was performed as described in Chapter 2.

\section{Sequencing}

RT-PCR products were sequenced by Canadian Molecular Research Services (Ottawa, ON). Sequences were verified as encoding the $B c l 2$ using the program BLASTN (http://www.ncbi.nlm.nih.gov/blast) at the NIH. The deduced amino acid sequences were also verified as being Etsl by using the program BLASTP at the same site.

\section{Statistical analysis}

Refer to Chapter 2 for the statistical analysis. 


\section{RESULTS}

\section{Total $\mathbf{R b}$ protein levels in $S$. tridecemlineatus}

The $\mathrm{Rb}$ protein is a $110 \mathrm{kDa}$ tumor suppressor protein that regulates cell cycle entry and progression in mammalian cells. Western blotting was performed to study expression levels of $\mathrm{Rb}$ protein in six tissues (brain, heart, lung, kidney, liver and muscle). Mouse monoclonal IgG cross reacted with a single protein band at $110 \mathrm{kDa}$ (Fig. $4.2 \mathrm{~A}$ ) that correspond with the known size of the $\mathrm{Rb}$ protein in other mammals. Figure $4.2 \mathrm{~B}$ shows the mean $\mathrm{Rb}$ protein levels in the six tissues. $\mathrm{Rb}$ protein levels increased significantly $(\mathbf{P}<0.05)$ in brain, lung, kidney and liver of hibernating animals, compared with controls, whereas, in heart and skeletal muscle no change was observed. In brain, lung, and kidney $\mathrm{Rb}$ protein levels were more than 2-fold up-regulated whereas liver showed a 1.7-fold increase in total $\mathrm{Rb}$.

\section{Phospho-Rb (Ser780) protein levels in S. tridecemlineatus}

$\mathrm{Rb}$ can be phosphorylated on different sites. Expression levels of $\mathrm{Rb}$ phosphorylated on Ser 780 were assessed in six tissues of ground squirrels via Western blotting. A rabbit polyclonal anti-phospho-Rb (Ser 780) antibody cross reacted with a single protein band at $110 \mathrm{kDa}$ (Fig. $4.3 \mathrm{~A}$ ) that corresponds with the known size of the phospho-Rb (Ser 780) protein in other mammals. Figure 4.3 B summarizes the data. Phospho-Rb $($ Ser 780$)$ protein levels were significantly $(\mathrm{P}<0.05)$ reduced in heart and kidney to 80 and $65 \%$ of the corresponding euthermic values, respectively. In other tissues phospho- $\mathrm{Rb}(\mathrm{Ser} 780)$ protein content did not change significantly. 


\section{Phospho-Rb (Ser795) protein levels in S. tridecemlineatus}

Expression levels of $\mathrm{Rb}$ protein phosphorylated on Ser 795 were also assessed in six tissues of ground squirrels via Western blotting. A rabbit polyclonal anti-phospho-Rb (Ser 795) antibody cross reacted with a single protein band at $110 \mathrm{kDa}$ (Fig. $4.4 \mathrm{~A}$ ) that corresponds with the known size of phospho-Rb (Ser 795) in other mammals. Figure 4.4B shows the phospho-Rb (Ser 795) protein levels in brain, heart, lung, kidney, liver and muscle of euthermic and hibernating animals. Phospho-Rb (Ser 795) protein levels were significantly $(\mathrm{P}<0.05)$ reduced in heart, kidney and liver during hibernation to levels that were about $80 \%$ of the corresponding euthermic values. However, phospho-Rb (Ser 795) content increased by 1.65-fold in brain during hibernation but was unchanged in lung and muscle.

\section{Distribution of total $\mathbf{R b}$ protein in cytoplasmic and nuclear extracts}

The distribution of total $\mathrm{Rb}$ protein in cytoplasmic and nuclear extracts of muscle and liver were assessed using Western blotting techniques. Figure 4.5A shows representative blots and a summary histogram of total $\mathrm{Rb}$ protein in subcellular fractions of muscle whereas Figure 4.5 B shows the same information for liver. The distribution of $\mathrm{Rb}$ protein between cytoplasmic and nuclear fractions of muscle did not change significantly between euthermic and hibernating conditions. In liver, the relative amount of $\mathrm{Rb}$ in the nuclear fraction increased substantially during hibernation resulting in a significant difference $(\mathrm{P}<0.05)$ between the amount of $\mathrm{Rb}$ in cytoplasmic and nuclear fractions during hibernation. 


\section{E2F1 protein levels in $S$. tridecemlineatus}

$\mathrm{Rb}$ exerts its effect through the transcription factor E2F1. Hence, Western blotting was performed to study the expression levels of E2F1 in six tissues of ground squirrels. A rabbit polyclonal IgG cross reacted with a single protein band at $55 \mathrm{kDa}$ (Fig. $4.6 \mathrm{~A}$ ) that corresponds with the known size of the E2F1 protein in other mammals. Figure 4.6B summarizes mean E2F1 protein levels in brain, heart, lung, kidney, liver and muscle of euthermic and hibernating animals. E2F1 protein levels increased significantly $(\mathrm{P}<0.05)$ in heart (by 3.2-fold), lung (1.4-fold), kidney (2.1-fold) and liver (2.45-fold) during hibernation. $\mathrm{Rb}$ protein levels did not change in brain and muscle.

\section{Distribution of E2F1 protein in cytoplasmic and nuclear extracts}

The distribution of E2F1 protein in cytoplasmic and nuclear extracts of muscle and liver tissues was assessed using Western blotting. Figure 4.7A and $\mathrm{B}$ show the representative Western blots and histogram of total E2F1 protein in subcellular fractions of muscle and liver, respectively. As shown in Figure $4.7 \mathrm{~A}$, the nuclear fraction of E2F1 protein increased significantly $(\mathrm{P}<0.05)$ by $\sim 1.6$-fold during hibernation as compared with the amount of E2F1 in the nuclear fraction of euthermic muscle. In liver also, the nuclear fraction of E2F1 increased significantly during hibernation with respect to its corresponding cytoplasmic content.

\section{SUV39H1 protein levels in $S$. tridecemlineatus}

In order to silence growth-related genes, the Rb-E2F complex recruits SUV39H1 and HDAC proteins to the promoter regions of their gene targets. Hence, Western 
blotting was performed to study expression levels of SUV39H1 in ground squirrel tissues. Goat polyclonal IgG cross reacted with a single protein band at $47 \mathrm{kDa}$ (Fig. 4.8 A) that corresponds with the known size of the SUV39H1 protein in other mammals. Figure 4.8B shows SUV39H1 protein content six tissues of euthermic and hibernating animals. SUV39H1 protein levels were significantly $(\mathrm{P}<0.05)$ elevated in five tissues during hibernation, except for skeletal muscle. In brain and kidney SUV39H1 increased by more than 2-fold whereas increases of 1.6-1.7 fold were seen in heart, lung and liver.

\section{HDAC6 and HDAC4 protein levels in S. tridecemlineatus}

In order to asses the role of histone deacetylases in gene silencing, HDAC6 and HDAC4 protein levels were analyzed in brain and heart, respectively as these are the only antibodies cross reacted with squirrel proteins. Rabbit polyclonal IgG recognizing HDAC6 and HDAC4 cross reacted with a single protein bands at $140 \mathrm{kDa}$ and $134 \mathrm{kDa}$, respectively (Fig. 4.9A and C) that correspond with the known size of the HDAC6 and HDAC4 protein in other mammals. Figure 4.9B and D show mean HDAC6 levels in brain and HDAC4 in heart of euthermic and hibernating animals. Levels of both increased significantly $(\mathrm{P}<0.05)$ during hibernation; HDAC6 increased by 1.45 -fold in brain and HDAC4 protein rose by $\sim 2$-fold in heart during hibernation.

\section{E2F1 DNA-Binding activity in S. tridecemlineatus}

Binding of transcriptional repressor complexes to the promoter regions of target genes is very important for the gene silencing. As shown in Figure 4.1, the binding of E2F family proteins to the promoters of downstream genes is critical. Hence, I studied the 
effect of hibernation in E2F1 transcriptional activity. Changes in DNA binding activity were assessed separately in nuclear extracts from liver and muscle of euthermic and hibernating ground squirrels. An electrophoretic mobility shift assay (EMSA) kit from Panomics was used with biotin labeled oligonucleotides containing the E2F binding site. Figure 4.10 shows that the biotin labeled probes bound to three different protein complexes on the gel (I, II and III). Competition studies were done with unlabelled probes leading to the conclusion that band II corresponded with E2F1 binding (Lane 7). There were no binding by E2F1 in liver during hibernation (Lane 2) but increased binding was observed under euthermic conditions (Lane1). In muscle, Ets1 DNA-binding increased (Lane 5) during hibernation as compared to euthermic (Lane 4) animals. Lanes 6 and 7 are the control lanes that confirm the correct E2F binding position in this experiment.

\section{Analysis of c-Myc protein levels in S. tridecemlineatus}

Expression levels of c-Myc, a downstream target for the transcription factor E2F1, were assessed in five tissues of ground squirrels via Western blotting. A rabbit anti-c-Myc antibody cross reacted with a protein band at $57 \mathrm{kDa}$ (Fig. $4.11 \mathrm{~A}$ ) that corresponds with the known size of c-Myc in other mammals. Protein levels of c-Myc were significantly $(P<0.05)$ reduced heart, liver and muscle during hibernation, falling to about $45 \%$ of euthermic levels in heart and about $75 \%$ of euthermic levels in liver and

muscle (Figure 4.11 B). Levels of c-Myc did not change significantly in brain and kidney. 


\section{Analysis of $B c l 2$ mRNA levels}

Using RT-PCR and primers designed from the consensus sequence of $B c l 2$ from other mammalian species including the 13-lined ground squirrel genomic sequence, a 220 bp cDNA was amplified from ground squirrel muscle. Using the NCBI website the product was confirmed as encoding a part of the $B c l 2$ gene.

The primers were then used to assess $B c l 2$ mRNA levels relative to $\alpha$-tubulin mRNA in six tissues of euthermic and hibernating animals. Figure $4.12 \mathrm{~A}$ shows bands for $B c l 2$ and $\alpha$-tubulin PCR products in each tissue. Mean relative $B c l 2$ mRNA levels were then plotted in Figure 4.12B. Bcl2 transcript levels decreased significantly in brain, kidney and liver during hibernation to levels approximately $50 \%, 55 \%$ and $25 \%$ of corresponding euthermic values. In skeletal muscle, however, $B c l 2$ transcript levels rose by about 1.75 -fold.

Figure 4.13A shows the nucleotide and deduced amino acid sequence of ground squirrel muscle Bcl2 and in Figure $4.13 \mathrm{~B}$ the amino acid sequence is aligned with the sequence from three other mammalian species. The nucleotide sequences shared $92 \%$ identity with other mammals' (human, mouse and rat) $B c l 2$ cDNA where deduced amino acid sequence shared $93 \%$ identity with other mammals' Bcl2 protein (Data not shown). 


\section{DISSCUSSION}

Many recent studies have shown that the overall rates of gene transcription and protein translation are strongly suppressed during hibernation (Story, 2003; Storey and Storey, 2004a; Osborne et al., 2004; Van Breukelen and Martin, 2002). Furthermore, Morin and Storey (2006) proposed some mechanisms of transcriptional control in hibernators that included modifications of histones, changes in histone deacetylase activities, and control of RNA polymerase activity. Adding to their mechanisms of transcriptional control, the role of the Rb-E2F pathway was studied in this chapter.

The Rb-E2F pathway plays an important role in gene silencing. The retinoblastoma (RB) protein controls cell cycle progression at the major G1 check point (restriction point) by inhibiting S-phase entry (reviewed by DeGregori, 2002). Typically, starting in late Gl phase, $\mathrm{Rb}$ is highly phosphorylated until mitosis occurs. The underphosphorylated form of $\mathrm{Rb}$ is the most active form that controls E2F activity and cell growth. Phosphorylation of Rb by cyclin-D- and cyclin-E-dependant kinases contributes to the inactivation of RB (Sherr and Roberts, 1999; Stevaux and Dyson, 2002). It has also been shown that oxidative stress induces the dephosphorylation of RB protein and leads to its association with its partner protein, E2F, to arrest growth (Cicchillitti et al., 2003). As mentioned in previous chapters, hibernators can experience changing levels of oxygen due to irregular breathing pattern which may leads to oxidative stress associated with hibernation. Hence, oxidative stress may be one cause of the activation of the Rb-E2F pathway leading to a reduced transcriptional state during torpor.

The mammalian $\mathrm{Rb}$ family of proteins includes $\mathrm{Rb}, \mathrm{p} 107$ and $\mathrm{p} 130$ which are known as the pocket proteins because of their sequence similarity in a domain called the 
pocket domain (Zhu et al., 1995). Rb protein has many biological functions such as tumor suppression, regulation of the cell cycle, differentiation, apoptosis and senescence. Each of these functions is mediated by several protein-protein interactions. The most studied binding partners of $\mathrm{Rb}$ are the E2F transcription factors (Morris and Dyson, 2001). Association of $\mathrm{Rb}$ with $\mathrm{E} 2 \mathrm{~F}$ inactivates the transcriptional activation domain of $\mathrm{E} 2 \mathrm{~F}$ and $\mathrm{Rb}$ also functions as a transcriptional repressor by recruiting various co-factors that are involved in chromatin remodeling (Stevaux and Dyson, 2002; Harbour and Dean, 2006). The active forms of E2F transcription factors are heterodimers that are composed of an E2F family gene and a dimerization partner (DP) family gene. In mammalian systems, there are at least eight E2F family members named E2F1 to E2F8 and two DP family members. E2F 1-4 mainly bind to the Rb protein (Dyson, 1998).

Initially, total $\mathrm{Rb}$ protein and the amount of phosphorylated $\mathrm{Rb}$ were measured in different organs of ground squirrels, comparing euthermic and hibernating conditions. Total $\mathrm{Rb}$ protein levels were elevated significantly in brain, lung, kidney and liver during hibernation whereas no significant changes were observed in heart and muscle. The amount of phosphorylated $\mathrm{Rb}$ protein (Ser 780) was significantly reduced in heart and kidney and Ser 795 phosphorylation was also reduced in heart, kidney and liver but elevated in brain during hibernation. The general trend of reduced phosphorylation status of $\mathrm{Rb}$ would indicate stronger associations of $\mathrm{Rb}$ with $\mathrm{E} 2 \mathrm{~F}$ proteins in the torpid state (DeGregori, 2002) which in turn would lead to reduced activity of E2F as a transcription factor in heart, kidney and liver during hibernation. Hence, these data are consistent with transcriptional suppression in these organs during hibernation. In brain, however, the amount of phosphorylated $\mathrm{Rb}$ protein (Ser 795) increased significantly during 
hibernation, and total $\mathrm{Rb}$ protein also showed a trend towards increasing. This indicates a different relationship between $\mathrm{Rb}$ and $\mathrm{E} 2 \mathrm{~F}$ in brain where $\mathrm{Rb}$ may have less influence on brain transcriptional activity during hibernation, potentially allowing E2F to continue to mediate gene expression while the animal is torpid. It is also possible that there could be another pathway that control gene transcription in brains of the hibernators.

Next, E2F1 protein levels were also evaluated in ground squirrel organs. Levels were strongly increased in heart, kidney and liver (and slightly in lung) but did not change in brain and muscle during torpor. The increased levels of E2F1 in lung, kidney and liver parallel the increases in $\mathrm{Rb}$ protein levels in these organs and suggest that coordinated changes in $\mathrm{Rb}$ and $\mathrm{E} 2 \mathrm{~F} 1$ occur during hibernation in these organs, which leads to a strong association of $\mathrm{Rb}$ with $\mathrm{E} 2 \mathrm{~F} 1$. In brain, again, elevated phospho- $\mathrm{Rb}$ protein and a lack of changes in E2F1 between euthermic and hibernating conditions could suggest a relatively unchanged level of transcriptional activity in this organ. Hence, there may be some other mechanism of transcriptional suppression at work in brain. When considering skeletal muscle, no changes in $\mathrm{Rb}$ or $\mathrm{E} 2 \mathrm{~F} 1$ content or in $\mathrm{Rb}$ phosphorylation state were found during torpor which suggests that this regulatory system is not a significant factor in transcriptional suppression in hibernator muscle.

$\mathrm{Rb}$ has three basic domains in its protein structure: $\mathrm{Rb} \_\mathrm{A}, \mathrm{Rb} B \mathrm{~B}$ and $\mathrm{Rb} \_\mathrm{C}$. $\mathrm{Rb} \_\mathrm{A}$ is the pocket domain, which contain an A-box portion and a B-box portion. The Abox portion appears to be required for the stable folding of the B-box and is highly conserved at the extensive A-B interface. The A and B boxes each contain the cyclin-fold structural motif, with the LXCXE-binding site on the B-box similar to a Cdk binding site. The $\mathrm{Rb}$ _C domain is at the $\mathrm{C}$-terminal and is required for high-affinity binding to E2F- 
DP complexes and for maximal repression of E2F-responsive promoters (Gibson et al., 1994; Lee et al., 1998; Rubin et al., 2005; Marchler-Bauer et al., 2007). E2F proteins have four major domains, the cyclin-A binding domain (cA), the DNA-binding domain (DB), the DIM domain for dimerization with DP (DIM), and the transactivation (TA)/ Pocket protein (PP) binding domain. The DNA binding domain is the one which binds to the promoter region of downstream genes (eg: $B c l 2, c-M y c$ ) to activate or repress them, whereas the Rb protein binds to the TA/PP domain (Müller and Helin, 2000; Du and Pogoriler, 2006; Bracken et al., 2004). The DP protein has two major domains, the DB domain and the DIM domain both of which are important for the E2F binding site (Bracken et al., 2004).

E2F1 can only carry out its role as a transcription factor if it is in the nucleus and, hence, the distribution of the protein between cytoplasmic and nuclear fractions can indicate its relative involvement in transcriptional control between two metabolic states. Analysis of the distribution of E2F1 in skeletal muscle indicated that the amount of protein in the nuclear fraction was higher during hibernation, compared with the amount in the nuclear fraction from euthermic animals. This could suggest that E2F1 may have an important role to play in muscle transcriptional control during hibernation. The liver nuclear fraction of E2F1 also was significantly increased than the cytoplasmic amount during hibernation, which suggests that the hibernation-responsive increase in total E2F1 may have mainly elevated the nuclear content of E2F1. This may have happened if E2F1 levels in the nuclei of hibernators had risen to the maximum needed for chromatin remodeling. 
Next, the subcellular distribution of $\mathrm{Rb}$ also was studied. The distribution of $\mathrm{Rb}$ between nuclear and cytoplasmic fractions did not change significantly between euthermic and hibernating conditions in skeletal muscle. However, $\mathrm{Rb}$ content in the nuclear fraction of liver increased significantly as compared with the cytoplasmic fraction during hibernation, indicating a high nuclear content of $\mathrm{Rb}$ during hibernation in liver. This could also be for the same reason as discussed for E2F1 nuclear content in the liver because total $\mathrm{Rb}$ in liver also was significantly increased in hibernating animals.

$\mathrm{Rb}$ and $\mathrm{E} 2 \mathrm{~F}$ control transcriptional activity through a variety of mechanisms. Modification of chromatin structure is one of the important mechanisms in regulation of the gene transcription. Binding of $\mathrm{Rb}$ to E2F not only blocks the transcriptional activation of E2F transcription factors, but also leads to its active repression. One of the mechanisms of $\mathrm{Rb}$ repression is recruitment of co-repressors. $\mathrm{Rb}$ is known to interact with HDAC through its pocket domain (Brehm et al., 1998). HDAC and E2F both bind to the pocket domain of the under-phosphorylated $\mathrm{Rb}$ protein. This type of repression is in direct contrast to the activation by E2F, which binds to histone acetylases (HAT) and makes the DNA more accessible to transcription factors (Frolov and Dyson, 2004). Another mechanism of repression involves the ability of $\mathrm{Rb}$ to recruit histone methylases. In this mechanism, the $\mathrm{Rb}-\mathrm{E} 2 \mathrm{~F}$ complex is found in association with the enzyme SUV39H1 which methylates lysine 9 residue on histone H3. Eventually, a protein known as HP1 binds to methylated lysine 9 of histone $\mathrm{H} 3$ and leads to heterochromatin structure, which is transcriptionally silent (Nielsen et al., 2001). It has been well documented that $\mathrm{Rb}$ could regulate cell cycle genes and apoptosis genes by inhibiting E2F activity 
(Harbour and Dean, 2000). Hence, there will be a balance between apoptosis and the antiapoptosis genes, which could be shut down by the chromatin remodeling procedure.

To assess the possibility of chromatin remodeling as part of transcriptional repression during hibernation, the levels of SUV39H1 and HDAC were evaluated in different organs of ground squirrels, comparing euthermic and hibernating conditions. SUV39H1 protein levels were strongly elevated in brain, heart, lung, kidney and liver during hibernation but did not change significantly in muscle. HDAC6 levels in brain and HDAC4 levels in heart were also elevated significantly during hibernation. In brain and heart, therefore, both SUV39H1 and HDACs together with the Rb-E2F complex may play an important role in chromatin remodeling and the suppression of transcription in these organs. Furthermore, in lung, kidney and liver the elevated levels of SUV39H1 together with the elevated levels of Rb-E2F complex argue for the same result transcriptional suppression of downstream targets during hibernation. Testing of downstream genes targeted by E2F may give a complete picture to this mechanism.

Next, the DNA binding activity by E2F1 protein was studied in muscle and liver. The electrophoretic mobility shift assays (EMSA) showed a very strong reduction in binding activity by E2F1 in liver during torpor. But in muscle the binding activity was slightly increased during torpor. This suggests that an increased level of chromatin remodeling complex (Rb-E2F-SUV39H1-HDAC) in liver may deny access of E2F1 to the downstream gene targets during hibernation while unchanged levels of this complex may still provide access of E2F1 to the downstream targets in muscle.

The E2F transcription factor suppresses many genes including those that are involved in the cell cycle (c-Myc), DNA synthesis and replication (CDC), negative 
regulators of the cell cycle (CDK), check point (BRCA), DNA damage repair (BRAD), apoptosis (Bcl2), development (HOXA) and differentiation (JUN) (Bracken et al., 2004). One well-established target of the Rb-E2F pathway in relation to cellular growth is cMyc, which has also been implicated in the apoptosis process (Zhao and Day, 2000; Elliott et al., 2001). Furthermore, recent studies have shown that the apoptotic function of E2F is independent of transcription factor activity and depends upon its DNA binding capability (Phillips et al., 1997; Krek et al., 1993). Another well-studied target of this pathway is Bcl2, which is involved in the anti-apoptotic process (Yang et al., 2001)

To assess downstream targets of E2F1 in hibernator tissues, the levels of c-Myc protein were quantified by Western blotting and $B c l 2$ transcript levels were evaluated by RT-PCR. Levels of c-Myc protein were reduced significantly in heart, liver and muscle during torpor suggesting reduced transcription of the $c-m y c$ gene. Even though c-Myc protein levels did not change significantly in brain and kidney, $B c l 2$ transcript levels were significantly reduced in these two organs as well as in liver during torpor. These observations together with the elevated chromatin remodeling complex suggest another possible mechanism for transcriptional repression in thirteen-lined ground squirrels during hibernation. These observations were further confirmed by the DNA binding activity assays. In liver the reduced levels of DNA-binding activity by E2F1 correlates with the reduced gene transcriptional state of $B c l 2$ and the implied reduction in $c-m y c$ transcription based on c-Myc protein suppression. In muscle, the chromatin remodeling complex levels did not change significantly during hibernation, which may lead to an open chromatin state of the downstream genes. Furthermore, the DNA binding activity of E2F1 also increased slightly and this could underlie an increased level of Bcl2 gene 
transcription in muscle. However, c-Myc protein levels were decreased in muscle during hibernation. The direct method of monitoring a reduction in transcriptional state is via the measurement of mRNA levels. Since only c-Myc protein levels were measured it is not possible to make definite conclusions about the transcriptional state of the $c-m y c$ gene. Other influences may affect the translation of $c$-myc transcripts including rates of mRNA decay, preferential transcription of selected transcripts, and sequestering of transcripts with polysome versus monosome fractions of ribosomes during torpor. Differential distribution of selected transcripts between polysomes and monosomes has been reported previously for hibernators; for example, transcripts of fatty acid binding protein (FABP) are preferentially retained with the translationally-active polyosme fraction during hibernation (Hittel and Storey, 2002). The genes/proteins analyzed, c-Myc and Bcl2, have apoptotic and anti-apoptotic functions, respectively. Reduced expression of these two genes are potentially important for long term cell viability during hibernation.

The cloned portion of the $B c l 2$ gene showed $92 \%$ nucleotide identity in its partial nucleotide sequence as compared with the three other mammalian species. The partial amino acid sequence of $\mathrm{Bcl} 2$ protein also showed $93 \%$ identity with other mammals. Four substitutions were observed within the ground squirrel amino acid sequences as compared to the non-hibernating mammals. These substitutions may play a role in $\mathrm{Bcl} 2$ function at the low $\mathrm{Tb}$ values that occur in hibernation. Specific sequence changes have previously been proposed to benefit low temperature function of FABP in hibernators (Hittel and Storey, 2001).

Overall, the results presented in this chapter indicate reduced transcriptional activity in ground squirrel organs during hibernation. These data also support the 
conclusions drawn from other methods of evaluating transcriptional suppression that also indicated a reduced metabolic state during hibernation. The differential expression of $\mathrm{Rb}$ E2F1-SUV39H1-HDAC may play a role in chromatin remodeling and hence reduced transcriptional activity during hibernation. Indeed, the increased levels of E2F1 may be involved primarily in the formation of chromatin remodeling complex during hibernation and down regulation of specific downstream target genes. 
Fig. 4.1: Model of Rb-E2F pathway: The machinery that regulates cell cycle entry and progression in mammalian cells. $\mathrm{Rb}$ protein associates with the transcription factor $\mathrm{E} 2 \mathrm{~F}$ and $\mathrm{Rb}$ functions as an active transcriptional repressor by recruiting various co-factors. Rb-E2F recruits histone deacetylases (HDAC) and SUV39H1 methyl transferase to E2F target promoters and removes acetyl groups from histone proteins and methylates them. Hence, the action of $\mathrm{Rb}-\mathrm{E} 2 \mathrm{~F}$ leads to a closed chromatin state and transcriptional repression. Picture from DeGregori (J. Cell Sci. 117, 3411-3413). 
Fig. 4.1:

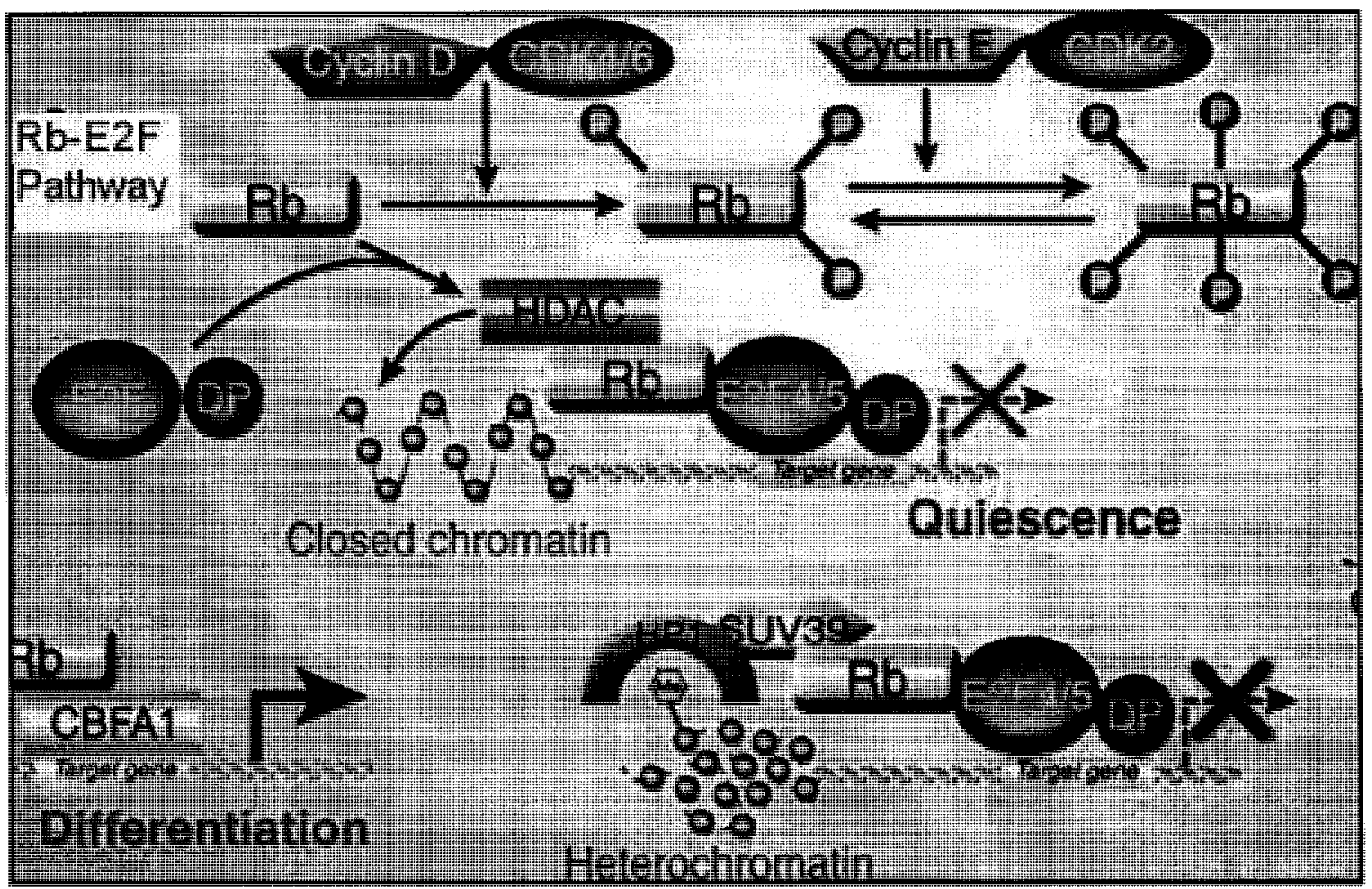


Fig. 4.2: (A) Representative Western blots showing total $\mathrm{Rb}$ protein in six organs from euthermic (E) and hibernating (H) ground squirrels. (B) Histogram showing mean total $\mathrm{Rb}$ protein levels. Data are means \pm S.E.M., $\mathrm{n}=4-5$ independent trials. Muscle is hind leg skeletal muscle. * - Value for hibernating sample is significantly different from the corresponding euthermic value, $\mathrm{P}<0.05$. 
Fig. 4.2:
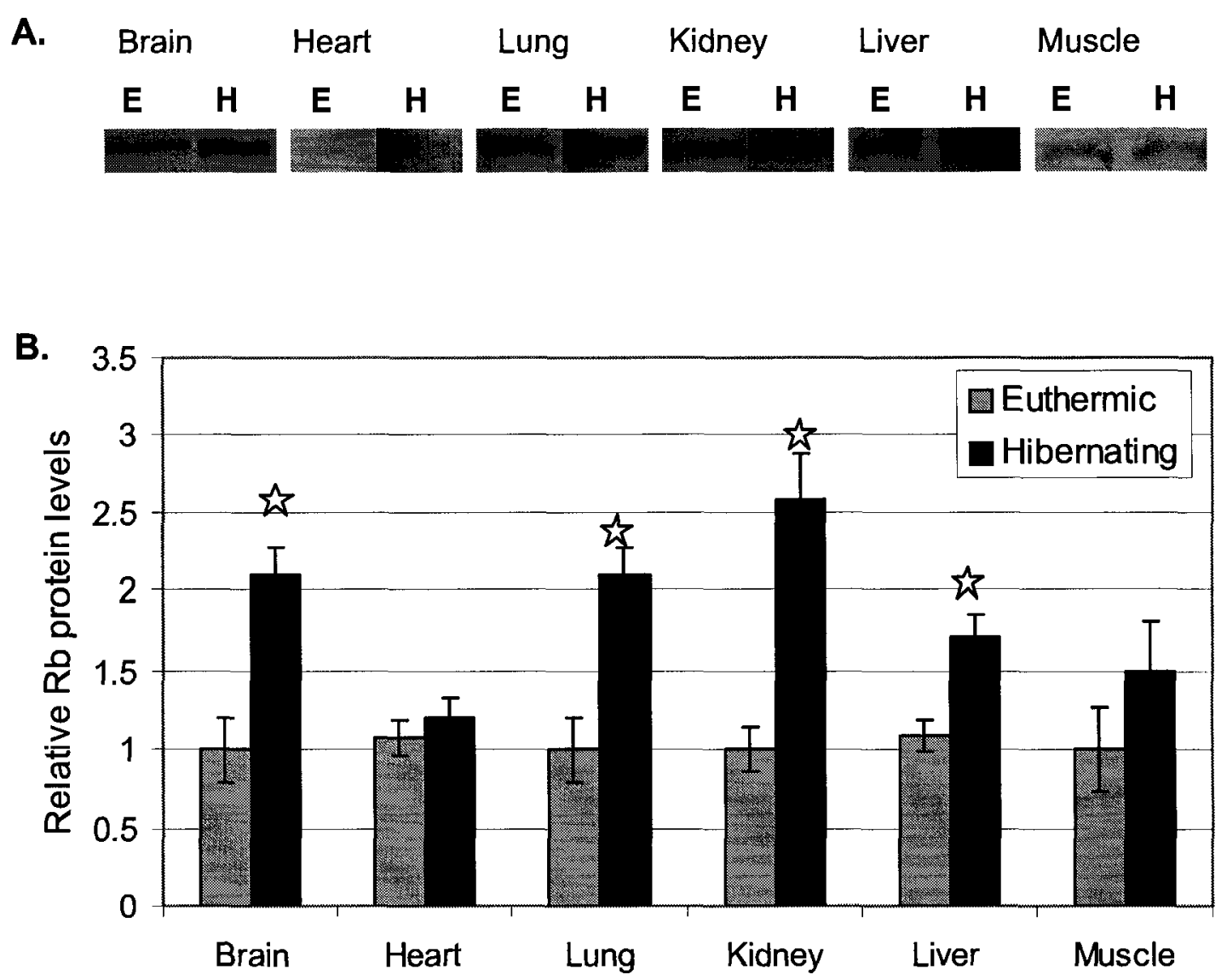
Fig. 4.3: (A) Representative Western blots showing the content of phospho-Rb (Ser 780) protein in six organs from euthermic (E) and hibernating (H) ground squirrels, respectively. (B) Histogram showing means \pm S.E.M. for $n=4-5$ independent trials. Muscle is hind leg skeletal muscle. * - Value for hibernating sample is significantly different from the corresponding euthermic value, $\mathrm{P}<0.05$. 
Fig. 4.3:

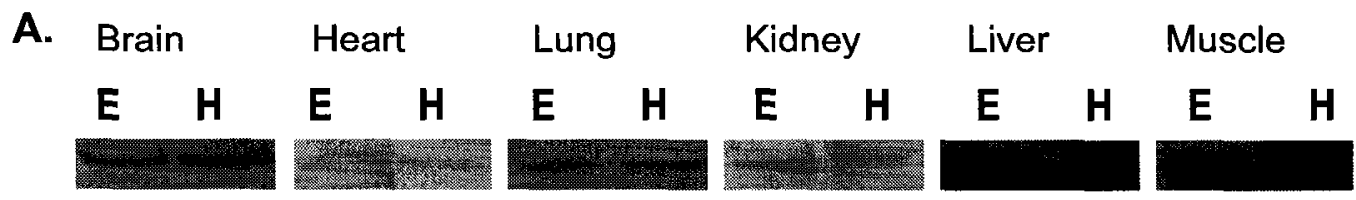

B.

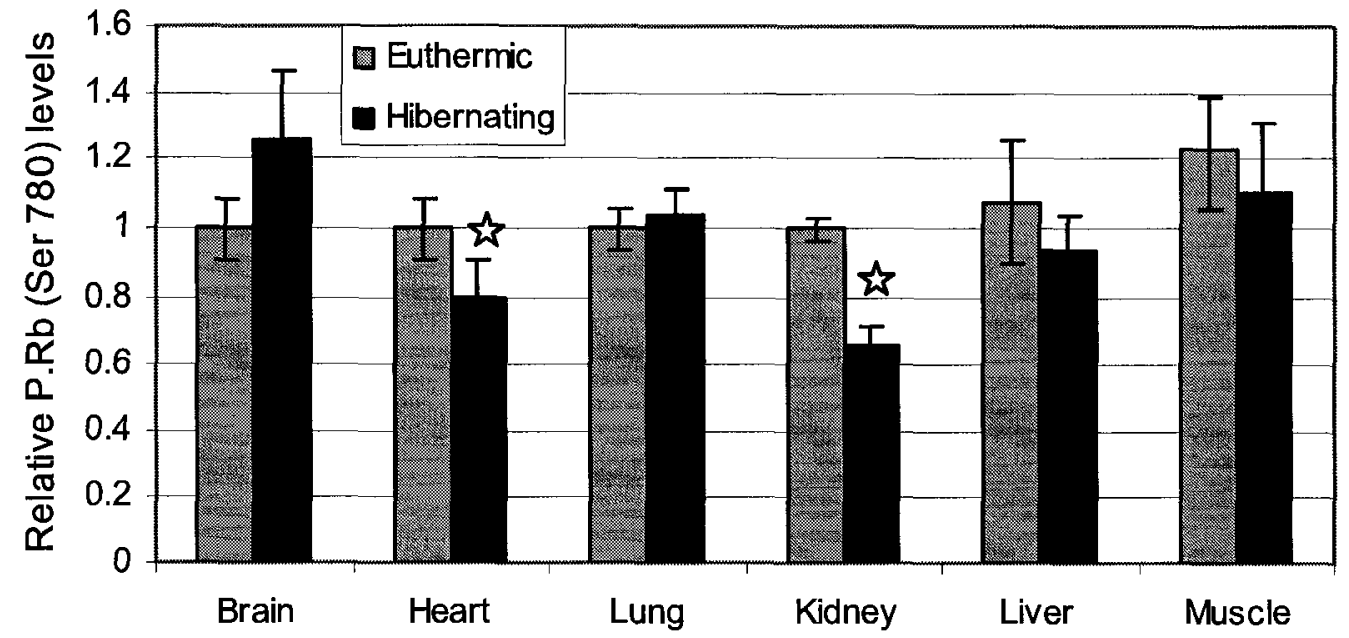


Fig. 4.4: (A) Representative Western blots showing the content of phospho-Rb (Ser 795) protein in six organs from euthermic (E) and hibernating $(\mathrm{H})$ ground squirrels. (B) Histogram summarizing the results. Data are means \pm S.E.M., $n=4-5$ independent trials. Muscle is hind leg skeletal muscle. * - Value for hibernating sample is significantly different from the corresponding euthermic value, $\mathrm{P}<0.05$. 
Fig. 4.4:

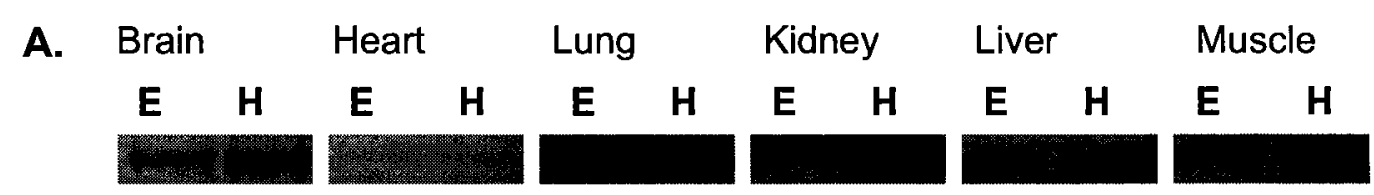

B.

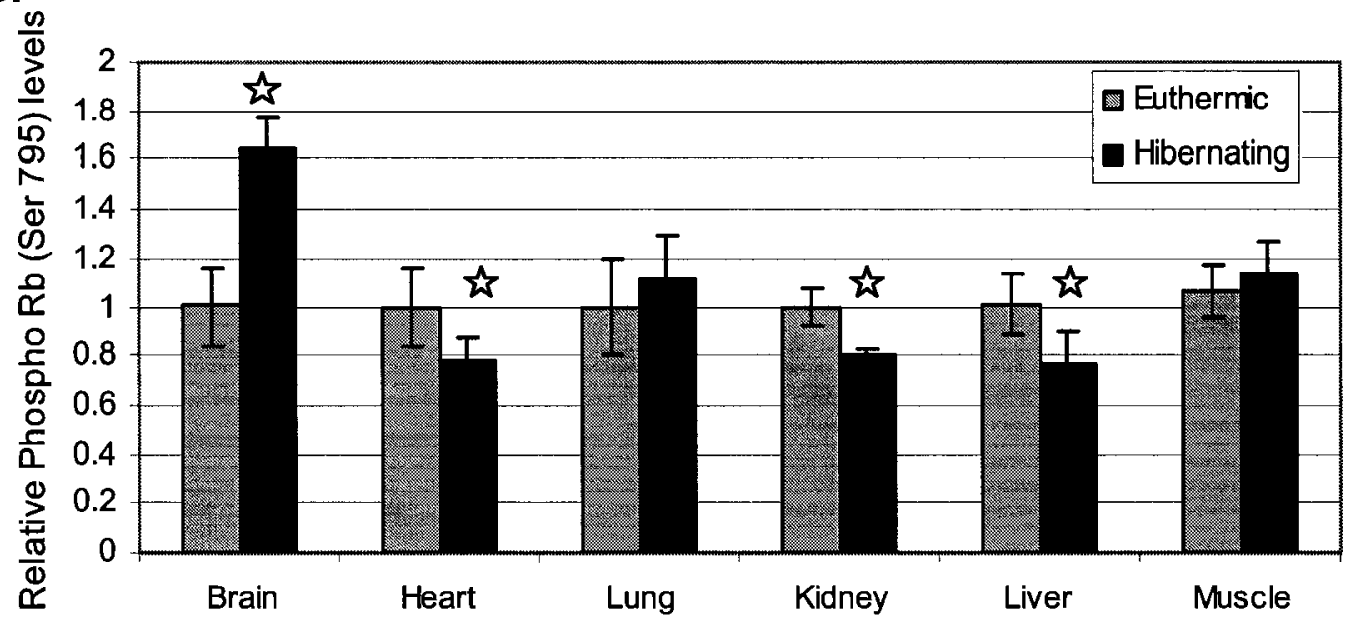


Fig. 4.5: Analysis of $\mathrm{Rb}$ distribution between cytoplasmic $(\mathrm{C})$ and nuclear $(\mathrm{N})$ fractions in euthermic and hibernating ground squirrels. (A) Representative Western blots and histograms showing $\mathrm{Rb}$ protein levels in cytoplasmic (C) vs nuclear (N) fractions of skeletal muscle. (B) Representative Western blots and histograms showing Rb protein levels in cytoplasmic $(C)$ vs nuclear $(N)$ fractions of liver. Data are means \pm S.E.M., $n=3$ independent trials. * - Values for the nuclear fractions are significantly different from the corresponding cytoplasmic values, $\mathrm{P}<0.05$. 
Fig. 4.5:

A. Euthermic

C $\quad \mathrm{N}$
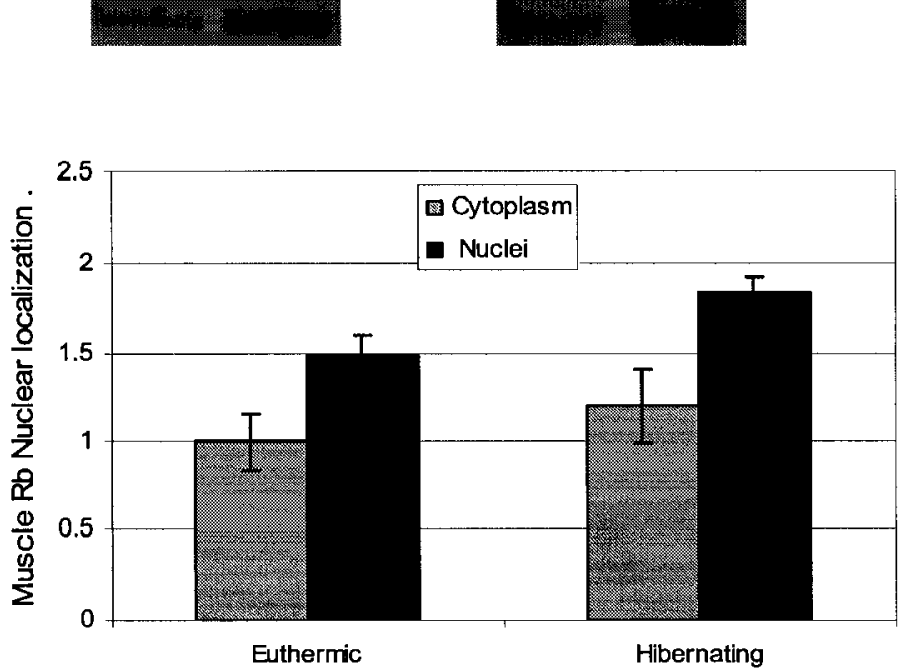

B. Euthermic
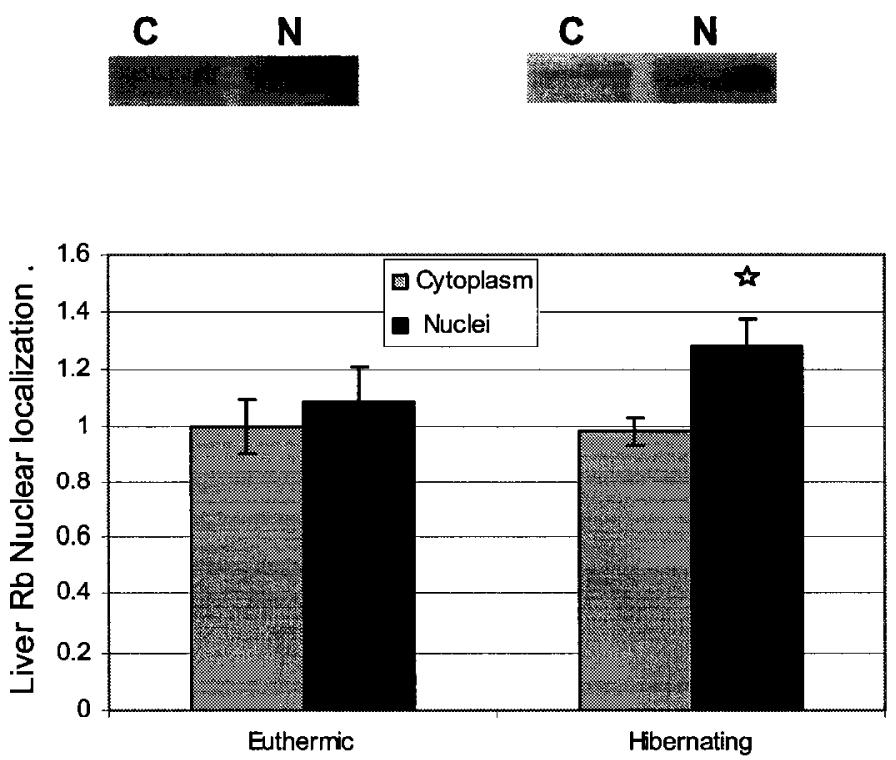

Hibernating

C $\quad \mathrm{N}$

Hibernating
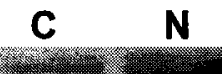
Fig. 4.6: (A) Representative Western blots showing E2F1 protein bands at $55 \mathrm{kDa}$ in six tissues from euthermic (E) and hibernating (H) ground squirrels. (B) Histogram summarizing the results. Data are means \pm S.E.M., $n=4-5$ independent trials. * - Value for hibernating sample is significantly different from the corresponding euthermic value, $\mathrm{P}<0.05$ 
Fig. 4.6:

A.

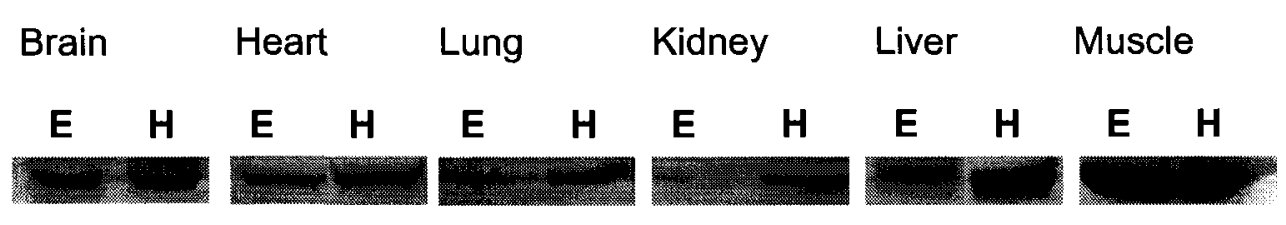

B.

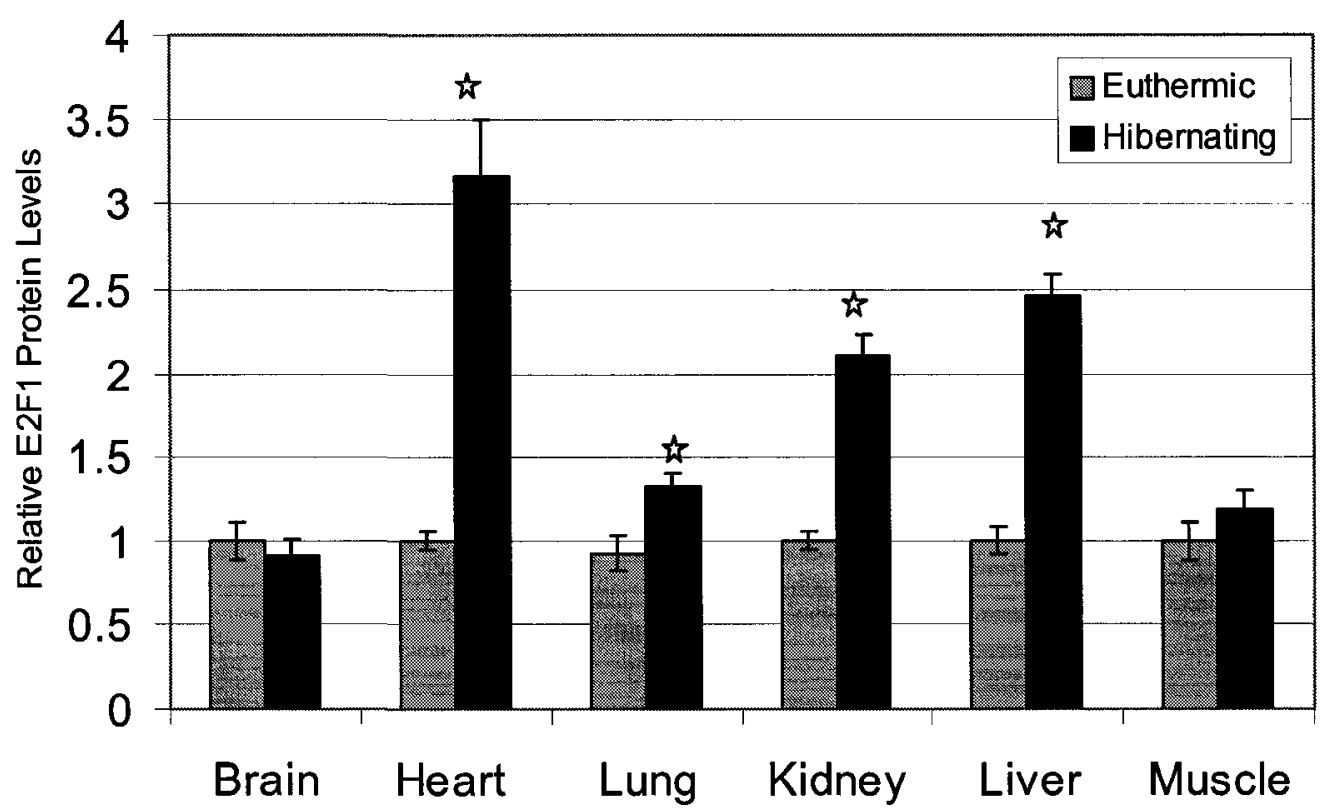


Fig. 4.7: Analysis of E2F1 distribution between cytoplasmic (C) and nuclear $(N)$ fractions in euthermic and hibernating ground squirrels. (A) Representative Western blots and histograms showing E2F1 protein levels in cytoplasmic (C) vs nuclear (N) fractions of skeletal muscle. (B) Representative Western blots and histograms showing E2F1 protein levels in cytoplasmic $(\mathrm{C})$ vs nuclear $(\mathrm{N})$ fractions of liver. Data are means \pm S.E.M., $\mathrm{n}=3$ independent trials. * - Values for nuclear fractions are significantly different from the corresponding cytoplasmic values, $\mathrm{P}<0.05 .+-$ Values for the nuclei of hibernating animals significantly different from the nuclei of euthermic animals, $\mathrm{P}<0.05$. 
Fig. 4.7:

A.

Euthermic

Hibernating
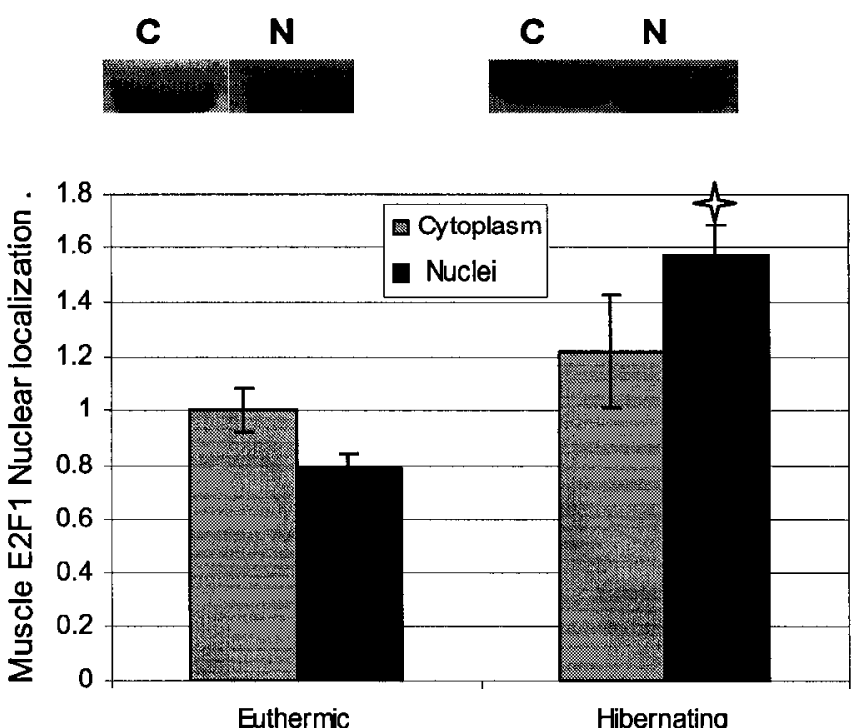

B.

Euthermic

Hibernating

C N

\section{C $\quad \mathbf{N}$}
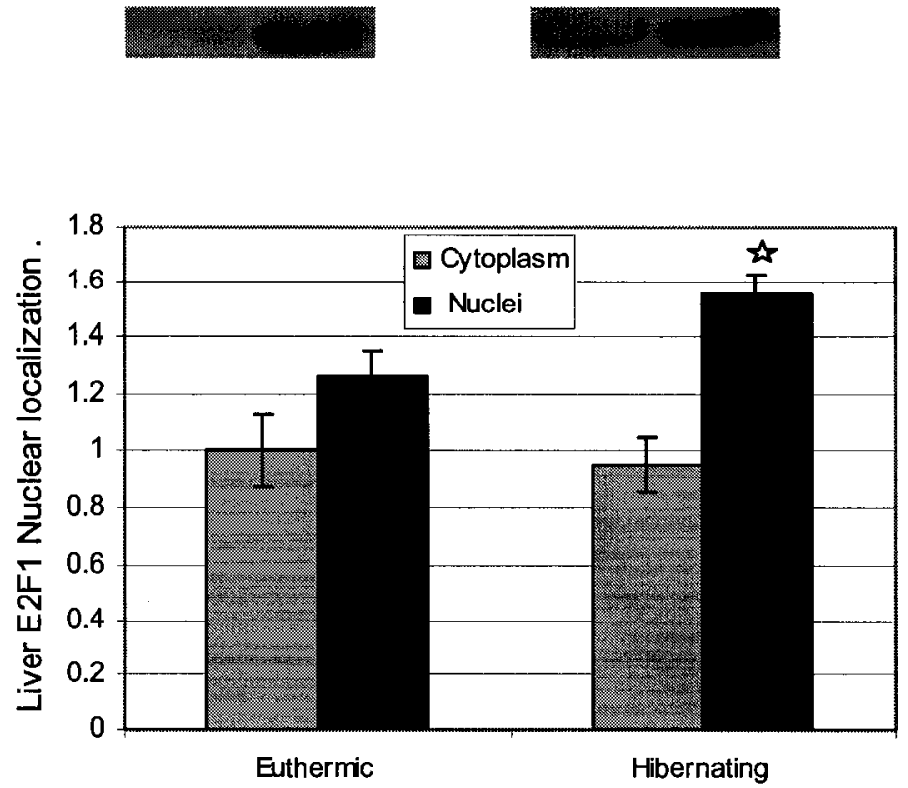
Fig. 4.8: (A) Representative Western blots showing SUV39H1 protein bands at $47 \mathrm{kDa}$ in six tissues from euthermic (E) and hibernating (H) ground squirrels. (B) Histogram summarizing the data. Data are means \pm S.E.M., $n=4-5$ independent trials. ${ }^{*}$ - Value for hibernating sample is significantly different from the corresponding euthermic value, $\mathrm{P}<$ 0.05 . 
Fig. 4.8:

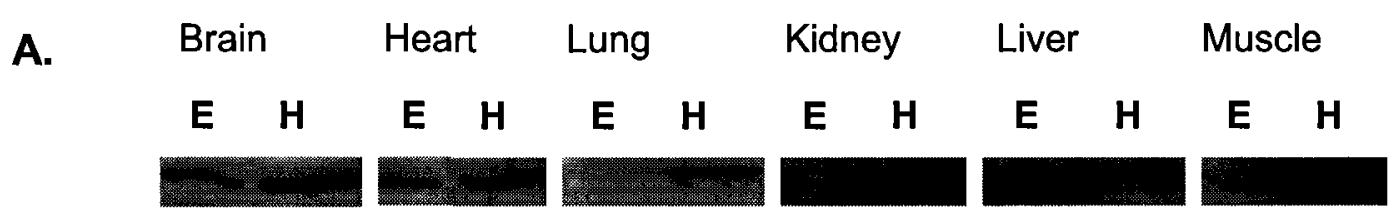

B.

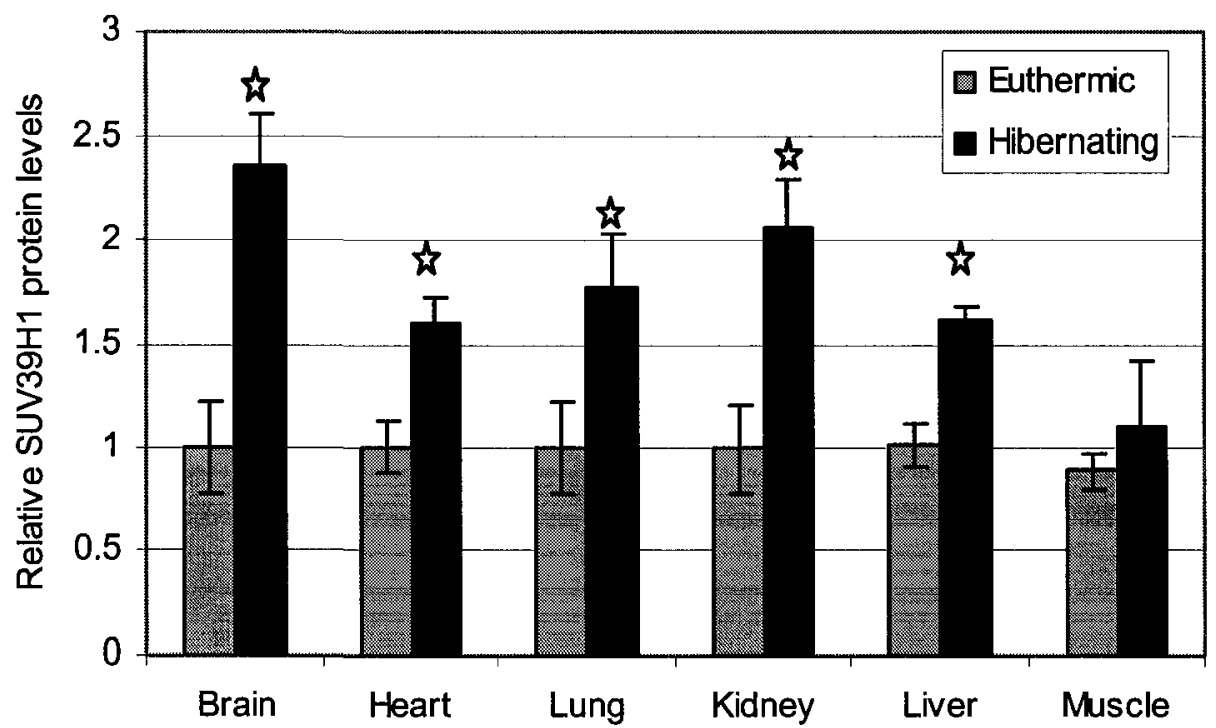


Fig. 4.9: Effects of hibernation on histone deacetylase. (A) Representative Western blots showing HDAC6 protein levels in brain from euthermic (E) and hibernating $(\mathrm{H})$ ground squirrels, (B) Histogram summarizing brain HDAC6 levels, (C) Representative Western blots showing HDAC4 protein levels in heart, and (D) Histogram summarizing heart HDAC4 levels. Data are means \pm S.E.M., $n=4-5$ independent trials. $E$ - euthermic, $H$ hibernating. ${ }^{*}$ - Value for hibernating sample is significantly different from the corresponding euthermic value, $\mathrm{P}<0.05$. 
Fig. 4.9:

A. Brain- HDAC6
E

H

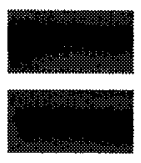

B.

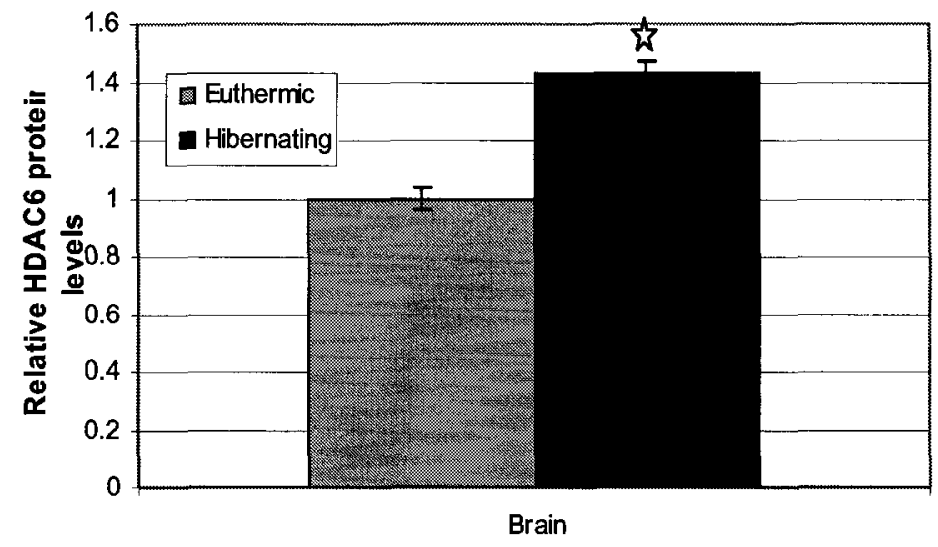

c. Heart- HDAC4

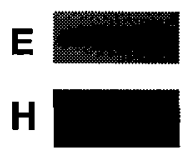

D

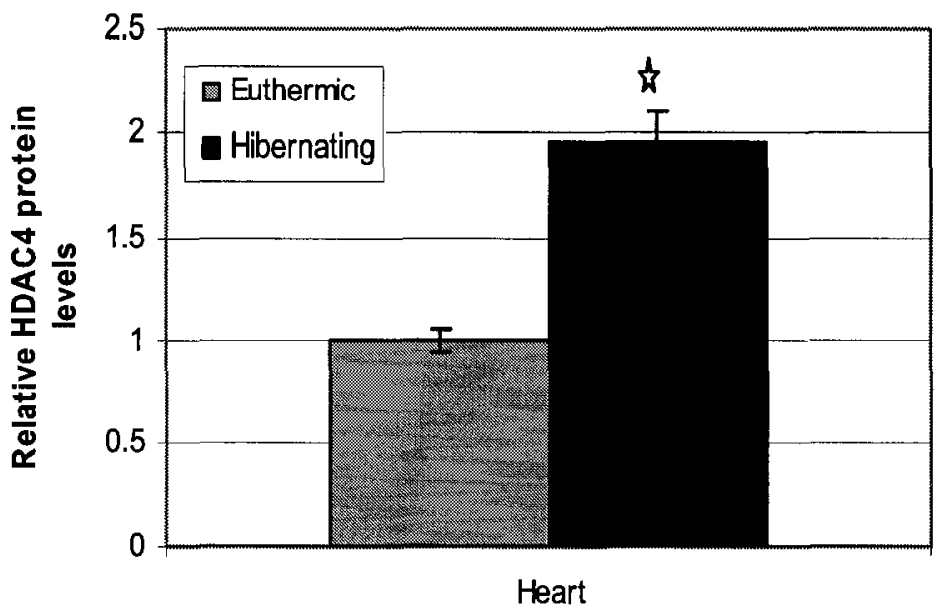


Fig. 4.10: Electrophoretic mobility shift assays using nuclear extracts from liver and muscle of 13-lined ground squirrels. The E2F1 probe (Panomics Inc.) contains the binding domain for the transcription factor E2F1. Lanes 1 and 2, nuclear extracts from euthermic and hibernating liver, respectively, with no competitor; Lane 3, probes only; Lane 4 and 5, nuclear extracts from euthermic and hibernating muscle, respectively, with no competitor; Lane 6, nuclear extracts from euthermic squirrel muscle preincubated with competitors (unlabelled probes) together with the labeled probes; Lane 7, positive control lane with the control muscle nuclear extracts for E2F1 binding. 
Fig. 4.10:

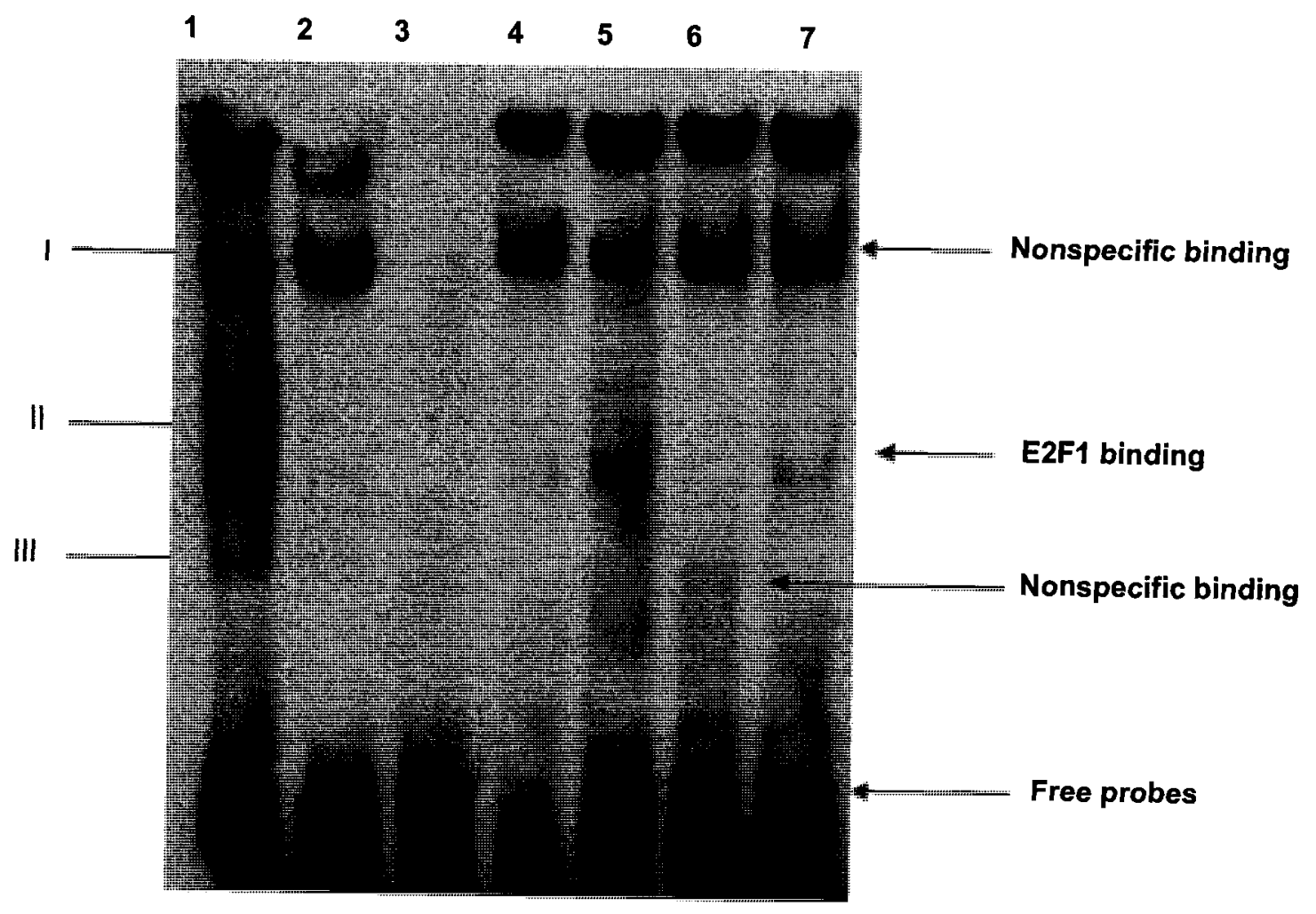


Fig. 4.11: (A) Representative Western blots showing c-Myc protein bands at $42 \mathrm{kDa}$ in five tissues from euthermic (E) and hibernating (H) ground squirrels. (B) Histogram summarizing the levels of c-Myc protein band in euthermic and hibernating animals. Data are means \pm S.E.M., $n=4-5$ independent trials. * - Value for hibernating sample is significantly different from the corresponding euthermic value, $\mathrm{P}<0.05$. 
Fig. 4.11:

A.

\begin{tabular}{|c|c|c|c|c|c|c|c|c|}
\hline Brain & & Heart & & & & Liver & & Muscle \\
\hline E & H & E & H & E & H & E & H & H \\
\hline
\end{tabular}

B.

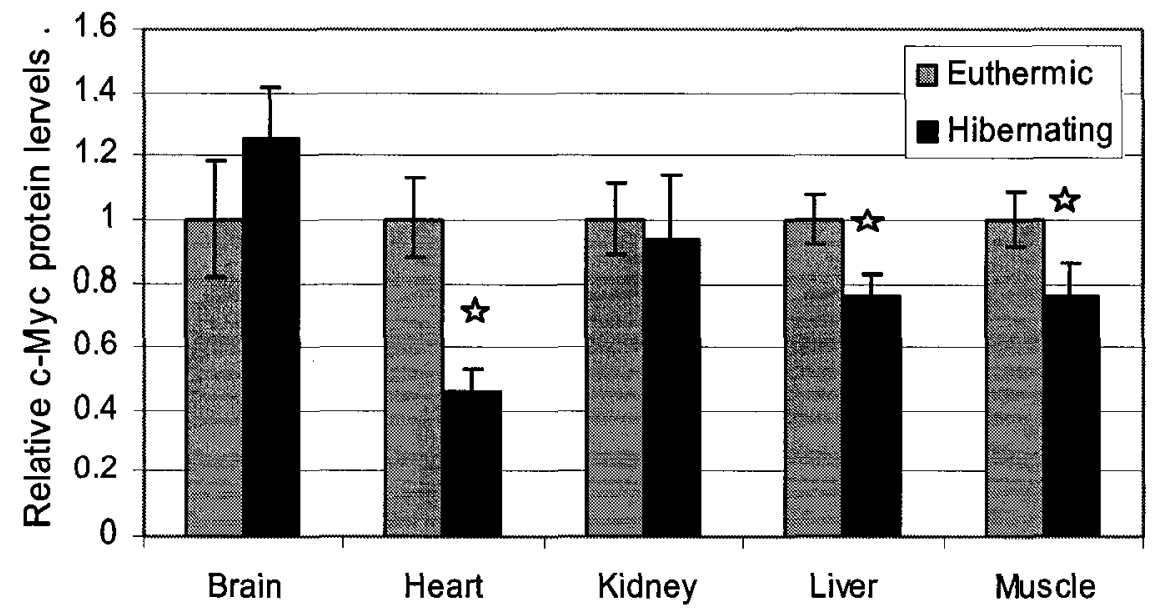


Fig. 4.12: Effect of hibernation on $B c l 2$ mRNA levels in six tissues of thirteen-lined ground squirrels. (A) Representative $B c l 2$ and $\alpha$-tubulin RT-PCR product bands amplified from mRNA samples from tissues of euthermic (E) and hibernating (H) squirrels. (B) Histogram showing the mean values of normalized PCR product levels for $B c l 2$ in tissues from hibernating versus euthermic ground squirrels. The highest dilutions for $B c l 2\left(10^{-2}\right.$ or $10^{-3}$ ) and $\alpha$-tubulin (from the same sample tube) which gave visible PCR product bands were chosen for quantification. Data are means \pm S.E.M., $n=4$ independent trials. Muscle is hind leg skeletal muscle. ${ }^{*}$ - Value for hibernating sample is significantly different from the corresponding euthermic value, $\mathrm{P}<0.05$. 
Fig.4.12:

A. Brain Heart Lung Kidney

B.

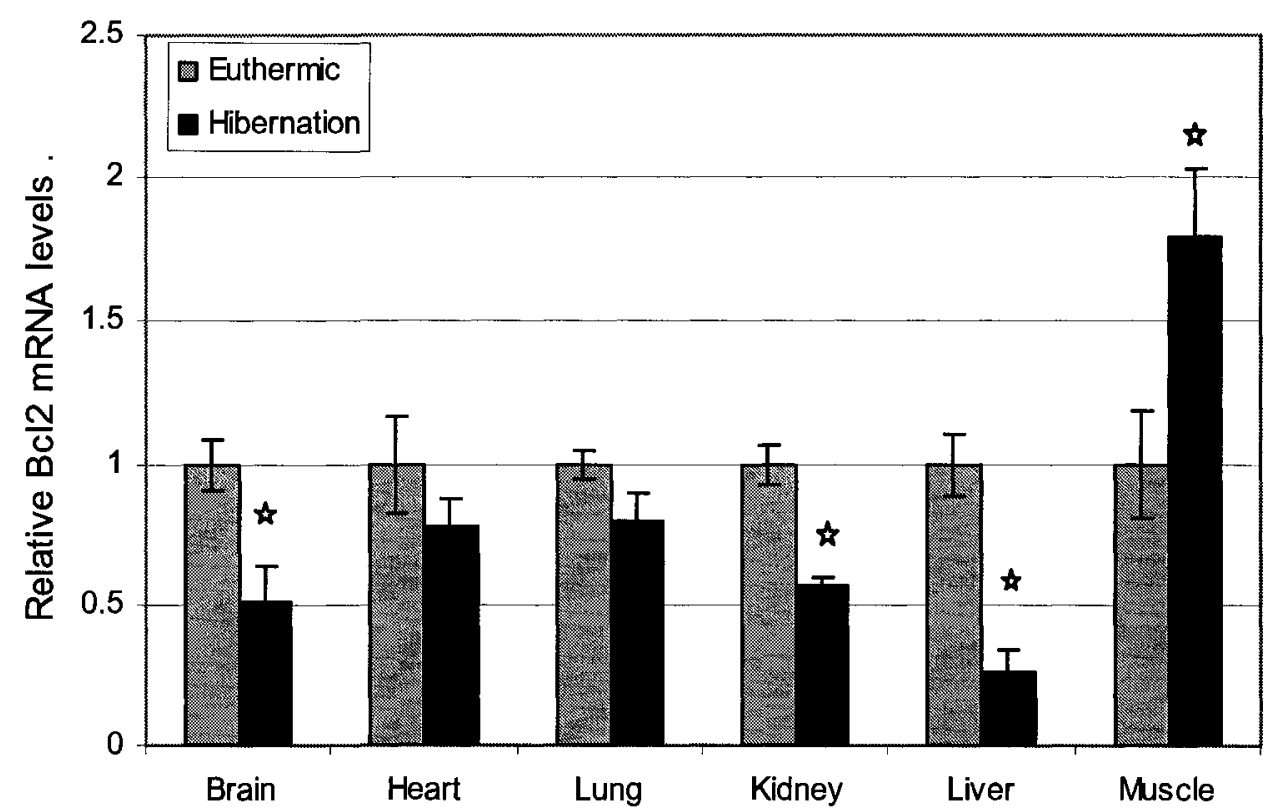


Fig. 4.13: (A) Partial cDNA sequence of $B c l 2$ amplified from muscle of thirteen-lined ground squirrels ( $S$. tridecemlineatus) along with the translated amino acid sequence. Nucleotides and amino acids are numbered on the left. (B) Ground squirrel Bcl2 partial amino acid sequence aligned with human (Homo sapiens), mouse (Mus musculus) and rat (Rattus norvegicus) sequences (Genbank accession numbers NP_000624.2, NP_033871.2 and NP_058689.1 respectively). Dashes (-) represent amino acids in the human, mouse or rat sequences that are identical with the squirrel sequence. Periods are present in the alignment to indicate where an amino acid is not present in the coding region of one of the species. 


\section{Fig.4.13:}

A:

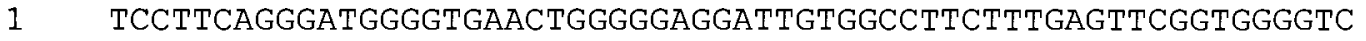

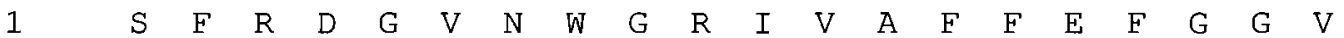

61 ATGTGTGTGGAGAGCGTCAACCGGGAGATGTCGCCCCTGGTGGACAACATCGCCCTGTGG

$\begin{array}{lllllllllllllllllllll}21 & M & C & V & E & S & V & N & R & E & M & S & P & L & V & D & N & I & A & L & W\end{array}$

121 ATGACTGAGTACCTGAACCGGCACCTGCAAAAAACT

$\begin{array}{lllllllllllll}41 & M & T & E & Y & I & N & R & H & L & Q & K & T\end{array}$

B:

ORIGIN

\begin{tabular}{|c|c|c|}
\hline Squirrel & 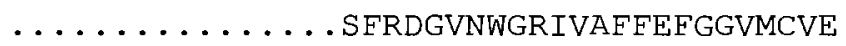 & 24 \\
\hline Human & 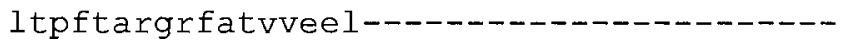 & 80 \\
\hline Mouse & ltpftargrfatvveel--------------------- & 77 \\
\hline Rat & ltpftargrfatvveel----------------------g & 77 \\
\hline Squirrel & SVNREMSPLVDNIALWMTEYLNRHLQKT . . . . & \\
\hline Human & 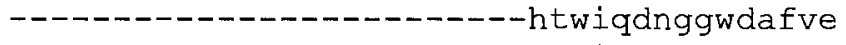 & 120 \\
\hline Mouse & ------- & 7 \\
\hline Rat & 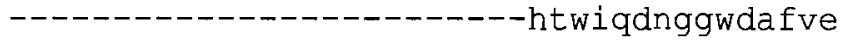 & \\
\hline
\end{tabular}




\section{Chapter 5}

\section{General Discussion}


Hibernation is a state of profound metabolic suppression, greatly reduced organ perfusion, and a large decrease in core body temperature, often to near $0^{\circ} \mathrm{C}$. Hence, there must be precise and coordinated control of changes in gene and protein expression in order to aid smooth transitions to and from the hypometabolic state. Within the organs and cells of hibernators there must be many molecular mechanisms that are involved in regulating gene/protein expression changes including controls acting at transcriptional, translational and posttranslational levels. Gene activity is regulated via multiple mechanisms including regulation of RNA polymerase, the action of transcription factors, epigenetic controls that affect chromatin accessibility, and mechanisms that process RNA transcripts such as splicing of the pre mRNA and 5' capping of the transcripts (Morin and Storey, 2006). Gene expression is also controlled at the translational level where regulation of eukaryotic initiation (eIF) and elongation factors (eEF) suppresses protein synthesis during torpor (Frerichs et al., 1998; Chen et al., 2001) and dissociation of polysomes into monosomes during hibernation also limits the overall capacity for protein production (Hittel and Storey, 2002). Posttranslational modification of enzymes and transcription factors by reversible phosphorylation is also critical to the control of enzyme function and gene expression in hibernation (Storey and Storey, 2004a; Storey and Storey, 2004b).

Although the expression of the majority of genes is switched off in torpor, a variety of genes are up-regulated to address specific metabolic needs during torpor. This process is regulated by transcription factors that bind to the promoter region of selected target genes. My thesis looked at the involvement of three different transcription factors 
and their associated upstream and downstream proteins in mammalian hibernation. None of these have been previously studied in hibernators. Measurement of transcription factor protein levels in euthermic versus hibernating animals was first used to identify transcription factors that changed significantly between the two states. Following identification of organs or tissues that showed a significant changes in the transcription factors, further experiments were carried out to investigate these factors including evaluating their mRNA transcript levels, nuclear versus cytoplasmic distribution patterns of the protein, and changes in DNA-binding activity in euthermic versus hibernating states. Upstream effectors that modulate transcription factor gene expression, activity (such as by phosphorylation), or subcellular distribution were also assessed as was the expression of downstream target genes (via RT-PCR or Western blotting).

Overall, the research presented in this thesis demonstrated that differential regulation of gene expression by transcription factors is involved in the suppression of carbohydrate metabolism, in inhibiting growth and differentiation, and in the global suppression of transcription. The data provided multiple insights into the importance of transcription factors in coordinating cellular responses that make hibernation successful.

\section{Carbohydrate regulation during hibernation}

It has long been clear that hibernators change from carbohydrate (CHO) catabolism to fat catabolism during torpor; indeed, early ultra structure studies of hibernator tissues during torpor supported this (Burlington et al., 1972) along with the well-documented accumulation of huge lipid depots by the animals during late summer feeding. The conversion of dietary CHO to lipids for storage is very important in this 
prehibernation period but when animals enter torpor, $\mathrm{CHO}$ catabolism is suppressed via many modifications at the cellular level. One well-studied mechanism is reversible phosphorylation control of key enzymes of $\mathrm{CHO}$ catabolism, including pyruvate dehydrogenase and phosphofructokinase (Storey, 1997). Various publications also showed specific changes in the expression of genes involved in carbohydrate versus fatty acid metabolism. For example, the gene for pyruvate dehydrogenase kinase isozyme 4 (PDK4) was up-regulated in the heart of hibernating ground squirrels (Andrews et al., 1998). PDK4 phosphorylates and inhibits pyruvate dehydrogenase, the enzyme that gates entry of $\mathrm{CHO}$ into the tricarboxylic acid cycle, to suppress $\mathrm{CHO}$ oxidation during torpor. Andrews et al. (1998) also reported up-regulation of pancreatic lipase (PLP) during torpor. These results indicate an enhancement of fatty acid oxidation during hibernation. ChREBP plays an important role in stimulating the conversion of the excess dietary CHO into lipids, as discussed previously, but I predicted that ChREBP action would be suppressed when the animals enter torpor to stop conversion of CHO into lipid for two reasons: (1) huge lipid depots are already present to fuel metabolism, and (2) remaining carbohydrates must be preserved for those cells/organs that cannot use lipid fuels (e.g. brain). The studies in Chapter 2 investigated this.

Liver is the major organ responsible for the converting of $\mathrm{CHO}$ into fats. As expected, the ChREBP levels in the liver were significantly reduced during hibernation, implying reduced $\mathrm{CHO}$ catabolism in the liver of hibernators. In most of the fat-storing hibernators, seasonal changes in food intake, triglycerol deposition and metabolism take place in a programmed manner. For example, food intake increases during late summer leading to a period of great increase in body mass caused by the build up of huge white 
adipose lipid depots. Once the animals have entered hibernation, however, they are no longer eating and hence there is no longer dietary $\mathrm{CHO}$ available to be converted into lipids. Thus, liver ChREBP should either be shut down or remain phosphorylated to halt its activities during hibernation. Recently, Uyeda et al. (2002) showed direct evidence for ChREBP in the glucose regulation of acetyl-CoA carboxylase and fatty acid synthase, two major enzymes involved in fatty acid synthesis. Since fat depots are the predominant energy source during hibernation, ChREBP need not be actively involved in transcription of fatty acid producing enzymes at this time. My findings confirm this idea.

ChREBP phosphorylation at Ser 196 by PKA prevents its nuclear entry whereas phosphorylation at Ser 568 by AMPK inhibits DNA-binding activity (Kawaguchi et al., 2001a). MacDonald and Storey (1998) reported a 33\% increase in PKA activity during hibernation and Horman et al. (2005) reported significantly elevated levels of AMPK during hibernation. Taken together, the increased levels of phosphoserine residues as well as increased PKA and AMPK activities, would suggest that ChREBP is mostly phosphorylated in the organs tested except for liver and kidney during hibernation.

The subcellular distribution studies revealed that ChREBP protein tended to be in the cytoplasmic fraction of liver during hibernation whereas it tended to be in the nuclei of muscle during torpor. As liver is not actively involved in making fat during hibernation, it is certain that the ChREBP stays outside the nuclei. According to the literature, the other major organ in which ChREBP is highly expressed is muscle. The observed increase of ChREBP in nuclei compared to the cytoplasm during torpor may not guarantee the binding of ChREBP to downstream targets since ChREBP also requires another co-factor in order to aid its DNA binding. Recently, Towle et al. (2006) showed 
that a co-factor, the Max like factor $\mathrm{X}(\mathrm{Mlx})$, is needed to aid the DNA binding activity of ChREBP. ChREBP and Mlx dimerize and function together as a glucose responsive transcription factor to regulate target genes such as $p k l$ and fasn.

However, the increased level of DNA-binding activity in muscle during torpor implies that ChREBP transcription factor could be in its active stage during torpor. Hittel and Story (2001) reported the up-regulation of the adipose and heart isoforms of fatty acid binding proteins (A- and H-FABP) in multiple tissues including brown adipose tissue (BAT), heart and muscle of hibernating ground squirrels. Hence, this might lead to the conclusion that in muscle the reducing levels of fat storage may induce ChREBP to its active stage to activate lipogenic genes in order to meet the demand by the skeletal muscle as lipid oxidation is extensively needed for skeletal muscle for thermogenesis during arousal. FABPs are involved in moving lipids around cells, transporting lipids across the cytoplasm to the mitochondria. The A type picks up lipids being released from intracellular lipid droplets whereas the $\mathrm{H}$ type picks up lipids coming in at the cell surface from the blood after being released from adipose tissue. Another possibility is that the activated ChREBP may be involved in the production of ketone bodies since when there is an imbalance in the carbon going into the TCA cycle (too much fat and not enough carbohydrate), the ketone bodies are formed derived from acetyl-CoA. In addition, ChREBP activates PDH, which produces acetyl-CoA from pyruvate (Ma et al., 2006). The ketone bodies serve as the fuel choice for skeletal muscle and brain by hibernators (Krilowicz, 1985). In contrast, the reduced binding activity by liver nuclear extracts indicates an inactive state of ChREBP during torpor. This was as expected. 
In order to get a clearer picture of the active or inactive state of ChREBP during torpor, two of the downstream genes that it regulates were selected for further studies. The mRNA levels of fatty acid synthase (Fasn) and the liver isozyme of pyruvate kinase $(P k l)$ were analyzed using RT-PCR. Interestingly, either a significant down-regulation or unchanged levels of Fasn mRNA transcript levels were observed in most organs except for heart and skeletal muscle during torpor. The increased levels of muscle Fasn mRNA transcripts correlated with the reduced phosphorylation status and increased DNA binding activity of ChREBP in muscle. However, these changes were only assessed at the mRNA level, and it is possible that various methods could be used prevent the actual expression of Fasn protein including both translational control and posttranslational modifications regulating Fasn activity; the latter inactivates Fasn enzyme in these organs (Mostafa et al., 1993). The reduced levels of $P k l$ transcripts in liver agree perfectly with the reduced ChREBP activity in liver.

In addition to activating lipogenic genes, ChREBP also activates genes such as thioredoxin-interacting protein (TXNIP) (Minn et al., 2006) and $\mathrm{G}_{0} / \mathrm{G}_{1}$ switch gene (G0S2) (Ma et al., 2006). TXNIP is highly involved in maintaining the cellular redox potential and G0S2 is possibly involved in growth arrest. Hence, changes in ChREBP could also be related to the Ets1 and Rb/E2F pathways which deal with oxidative stress and growth arrest related functions.

\section{Regulation of Ets transcription factor}

For many small mammals such as ground squirrels, the only solution to winter survival is hibernation. By allowing $\mathrm{Tb}$ to fall to near ambient temperature, these animals 
save $85-90 \%$ of the energy that would have been needed to maintain $\mathrm{Tb}$ at $37^{\circ} \mathrm{C}$ over the whole winter (Wang and Wolowyk, 1988). During hibernation, all aspects of physiology and biochemistry are reduced dramatically. Since metabolic rate is typically measured by oxygen consumption, a decrease in metabolic rate in torpor to about $1-5 \%$ of the euthermic resting value also means the same decrease in oxygen consumption. Blood flow is also decreased dramatically, selected organs may be specifically under-perfused, and hibernators also sometimes show long periods of breath hold. All of these changes may lead to hypoxic conditions in some organs during torpor. Studies in our lab showed that these types of hypometabolic conditions and hypoxic conditions are regulated by transcription factors. Changes in oxygen levels may affect the nuclear localization, DNA binding, dimerization, ligand binding or activation/ repression functions of transcription factors.

The transcription factor v-ets avian erythroblastosis virus E26 oncogene homolog (Ets) 1 is known to be activated via hypoxic conditions (Peters et al., 2004). Ets1 plays a major role in many cellular activities including growth, differentiation, migration, angiogenesis, pro-apoptosis and anti-apoptosis. A number of factors are known to regulate the transcriptional activity of Ets1. Binding of other factors to the Exon VII domain of the Ets1 inhibits its transcription factor activity. Hypoxia-inducible factor (HIF) $2 \alpha$ also binds to the Exon VII domain and inhibits its activity (Elvert et al., 2003), whereas the binding domain of Ets1 to HIF1 is not yet known. Furthermore, the Ets 1 protein is known to be regulated via reversible phosphorylation. Phosphorylation on different domains of Ets1 regulates its activity differently; for example, PKC phosphorylation at the Exon VII domain blocks Ets1 transcriptional activity whereas 
phosphorylation in the pointed domain activates Ets1 transcriptional activity (Liu and Grundstrom, 2002; Foulds et al., 2004). PKC activity is induced by EGFR phosphorylation and both PKC and EGFR are known to be activated by hypoxic stress (Goldberg et al., 1997; Franovic et al., 2007).

Chapter 3 investigated the levels of Ets 1 and its upstream effectors, PKC and EGFR. The increased levels of EGFR protein together with a parallel increase in phosphorylated EGFR proteins (pY1173 and pY1086) in brain, lung, kidney and liver during torpor indicates a possible activation of EGFR in these organs as a result of hypoxic conditions. The Ets pathway was further investigated by measuring the levels of the PKC and phospho-PKC in these organs. Increased levels of at least one form of the PKCmu/ phospho PKCmu (ser 744/748)/ PKC alpha/ beta (Thr 638/641) indicated a possible activation of this pathway in these organs during hibernation.

As described previously, metabolic rate falls greatly and heart beat is also reduced dramatically during torpor, which can lead to hypoxic condition in these animals. Most of the damaging effects of hypoxia may be derived from Reactive Oxygen Species (ROS) attack. ROS generation occurs especially during the transition from hypoxia to normal oxygen levels due to overwhelmed ROS generation when oxygen levels rise rapidly back to normal levels (Hermes et al., 2001). ROS also activate EGFR and can lead to autophosphorylation of EGFR (Goldkorn et al., 1998). Furthermore, PKCs have been shown to be activated by many cellular stresses including oxidative stress as well as by EGFR in response to ROS. Hence, the increased levels of EGFR, its phosphorylated forms and PKCs (especially PKC $\mu$ and PPKC $\alpha / \beta$ ) could play a pivotal role in the survival of hibernating tissues under stress conditions. 
HIF $1 \alpha$ is a transcription factor that up-regulates genes that are needed for hypoxia survival in hibernating ground squirrels (Morin and Storey, 2001). It is known that HIF $1 \alpha$ mediates transcriptional activation of several genes including Heme Oxygenase 1 (HO1) (Lee et al., 1997) and Ets1 (Dittmer, 2003). Previous studies have shown that the HO1 gene is up-regulated during torpor in 13-lined ground squirrels (Ni. Z, 2004, M.Sc Thesis, Carleton University). Up-regulation of the Ets 1 gene is reported in this study. The measured levels of mRNA transcript and protein levels of Ets1 showed up-regulation during hibernation. The mRNA and protein levels of Ets1 were correlated and both seemed to be increased in heart, lung, kidney, liver and muscle during torpor. The increased levels of Ets 1 expression may contribute to hypoxic survival during hibernation via activating cell survival genes or deactivating growth-related genes depending on the phosphorylation at different domains.

Ets1 binding also plays a major role in its transcription factor activity as discussed above. When considering the Ets1 DNA-binding activities, the EMSA analysis revealed that the DNA-binding activity did not change much during hibernation in skeletal muscle, whereas it was highly reduced in liver. The increased levels of PKCs in liver may contribute to the Exon VII domain phosphorylation of Ets1 and may lead to its reduced DNA-binding activity. However, the unchanged levels of DNA-binding activity of Ets 1 in muscle between euthermic and hibernating conditions may indicate that Ets-mediated gene transcription is vital for maintaining muscle mass during hibernation. Indeed, whereas nonhibernating mammals including humans undergo severe atrophy when their muscles are inactive for a long time, hibernators show little or no atrophy. Perhaps there are Ets-mediated genes that contribute to fighting atrophy and maintaining muscle mass 
during hibernation. Furthermore, the increased level of Ets1 mRNA transcript levels and protein levels in other organs may either contribute to the activation or deactivation of Ets1 via different levels of DNA-binding activities.

Ets1 is expressed by numerous cell types and in each it may exert its activity differently. Hence, studies of each organ separately may provide clearer insights into Ets 1 action in different organs. Ets1 functionally and physically interacts with a variety of transcription factors and other proteins. Most of the proteins directly bind to the Ets domain whereas others associate with the exon VII domain or the activation domain or the pointed domain. A number of transcription factors have been shown to regulate the transcriptional activity of Ets1 by modulating Ets1 DNA binding affinity (Dittmer, 2003). Ets1 itself regulates its activity by dimerizing the exon VII domain which blocks the inhibitory module of Ets1 allowing these proteins to increase their DNA-binding activity (Baillat et al., 2002).

Overall, then, Chapter 3 provides a clear picture that hypoxia could be the cause of the increased EGFR-PKC-Ets1 proteins in this pathway and may contribute to cell survival during hibernation. These proteins (EGFR-PKC) may increase as an immediateearly response to stress and cause the phosphorylation of increased Ets1 protein in liver. This in turn reduces the DNA-binding activity of Ets 1 and may contribute to survival in hibernator tissues by switching "off" the growth-related genes in liver, whereas in muscle Ets1 may still transcribe genes involved in fighting atrophy during torpor. The increased level of Ets1 expression in heart, lung and kidney may be actively involved in transcribing the target genes needed for long term survival during torpor or may be involved in the switching off growth-related genes depending on the domain which is 
phosphorylated by different kinases. Hence, further studies of DNA-binding activity in each of these organs could provide details on what is happening in each organ.

\section{Transcriptional control during hibernation}

The specific activation of selected transcription factors may contribute to the specific up-regulation of selected genes that aid hibernation, whereas the actions of some other transcription factors may lead to the shut down of many genes that are not needed during hibernation. Many studies have shown a global reduction in transcriptional and translational status during hibernation (reviewed in Storey, 2003; Storey and Storey, 2004a). Even though the shut down mechanisms for the translational machinery are quite well understood, the mechanisms involved in transcriptional suppression during torpor are still not fully defined. Recent work by our lab has investigated some aspects of transcriptional suppression in hibernating ground squirrels. Morin and Storey (2006) found that posttranslational modifications of histones by acetylation and phosphorylation were strongly decreased during torpor, actions that would reduce the ability to transcribe various target genes. They also reported an increased level of histone deacetylase (HDAC) activity that would mediate the reduction in histone acetylation as well as a reduced activity of RNA polymerase II during torpor. The Rb-E2F pathway which involves HDACs is a strong candidate that could also contribute to transcriptional suppression in ground squirrels during torpor.

Chapter 4 analyzed the factors involved in this pathway. The increased levels of $\mathrm{Rb}$ protein in brain, lung, kidney and liver of ground squirrels indicated that $\mathrm{Rb}$ protein could play an important role during hibernation. Hence, phosphorylated Rb protein levels 
were analyzed in the next step. The reduced level of phosphorylated $\mathrm{Rb}$ (Ser780/ Ser795) in most of the organs analyzed (heart, kidney, liver) revealed a strong association with E2F together with the increased E2F 1 protein levels in these organs. Hence, E2F1 cannot exert its effect as a transcription factor. Most probably, the increased levels of Rb-E2F proteins may involved in gene silencing in these organs during hibernation.

At the cellular level, $\mathrm{Rb}$ protein has been shown to control a major $\mathrm{G} 1$ check point, inhibiting S-phase entry and progression (Weinberg, 1995) and mediating cellular survival in the presence of various pro-apoptotic stresses such as DNA damaging agents (Chau and Wang, 2003). At the cellular level, most of these functions mainly depend on the activity of Rb-E2F complexes in the promoter region of cell cycle genes. Hence, my findings strongly support the cellular survival and growth arrest by Rb-E2F complexes in 13-lined ground squirrels during hibernation. According to an alternate model $\mathrm{Rb}$ can also directly inhibit stress-induced apoptosis in addition to its antiproliferative function (Chau and Wang, 2003). Early studies also reported a strong correlation between Rb and p53 (Weinberg, 1995). Unpublished data from our lab also showed an up-regulation of p53 during hibernation. Hence, it is certain that Rb-E2F by itself can act alone as a tumor suppressor as well as an antiapoptotic gene depending on the situation.

Apart from the above functions, the Rb-E2F complex actively suppresses gene transcription by recruiting various co-factors. The factors involved in at least two of the distinct mechanisms of transcriptional suppression were analyzed in my study.

The first one is the formation of closed chromatin and the second is heterochromatin formation in the promoter region of the target genes. The acetylation of histones is associated with transcriptionally active genes (Sterner and Berger, 2000). 
HDACs reduce the transcription of the genes by promoting the formation of closed chromatin at the promoter region of the target genes (Fig. 4.1). The elevated levels of HDACs in brain and heart clearly suggest a deacetylation of histones in these organs, which may lead to transcriptional suppression of many genes during torpor. Histone acetylation is an important concept which affects chromatin structure and transcriptional activity (Hu and Colburn, 2005). Increased acetylation is generally correlated with transcriptionally active genes, where the acetylated histones increase the accessibility of transcription factors to their binding site. As mentioned previously, the HDACs can remove the acetylation effect leading to transcriptional suppression. The increased level of HDACs in 13-lined ground squirrel organs together with the $\mathrm{Rb} / \mathrm{E} 2 \mathrm{~F}$ proteins definitely leads to transcriptional suppression in these animals during torpor.

In a second mechanism, the enzyme SUV39H1 methylates histones to promote the formation of heterochromatin (Fig. 4.1) at the promoter region of target genes. The elevated protein levels of this enzyme in brain, heart, lung, kidney and liver during hibernation suggests increased histone methylation and the probable enhanced formation of heterochromatin at the promoter region of the target genes to stop transcribing them during torpor.

The DNA-binding activity of E2F1 revealed a strongly reduced level of binding in liver which further confirms the transcriptional suppression of downstream target genes during hibernation. The significantly reduced expression levels of c-Myc and $B c l 2$ transcript levels in liver clearly support a reduced transcription of the target genes of $\mathrm{Rb}$ E2F pathway during torpor. Liver is the major organ that controls metabolic activities and these activities are highly suppressed during torpor in hibernators. However, in muscle, 
the observed increased level of DNA-binding activity leads to increased levels of $B c l 2$ transcript levels. Even though $\mathrm{Rb}$ protein levels increased in muscle neither E2F1 nor SUV39H1 levels changed much during torpor. Hence, in muscle, some other mechanisms may take place to control transcription during hibernation.

Overall, then, new mechanisms for transcriptional suppression were studied in Chapter 4. All of the data gathered indicate strong overall transcriptional suppression in ground squirrel organs during torpor. These findings support the previous studies that used other methodologies to show evidence of decreased rates of transcription in hibernating animals (Van Breukelen and Martin, 2002; Osborne et al., 2004; Morin and Storey, 2006).

\section{Conclusions}

The data gathered in this thesis mainly focused on the transcriptional state of organs in hibernating animals. The transcription factors ChREBP, Ets1 and $\mathrm{Rb} / \mathrm{E} 2 \mathrm{~F}$ were initially identified from an examination of DNA microarray data (obtained by our lab) as showing differential expression during hibernation. Hence, they were good candidates for follow-up studies. This thesis looked at three objectives related to the regulation of hibernation at the molecular level. The expression and potential role of ChREBP was studied first. In liver (the main organ that converts $\mathrm{CHO}$ into fat) and kidney, the ChREBP protein levels were reduced significantly during hibernation indicating a reduced $\mathrm{CHO}$ metabolism during torpor. Even though the protein levels of this transcription factor were up-regulated initially in brain, heart and muscle, subsequent studies showed posttranslational modification, possibly by reversible phosphorylation in 
these organs, which could lead to a reduced transcriptional factor activity by ChREBP during torpor. Secondly, activation of Ets1 and its upstream effectors were studied. Ets1 protein levels were elevated in most of the organs tested. The upstream factors, PKCs and EGFR, were also increased in parallel in these organs. PKCs could be involved in the exon VII domain phosphorylation of Ets1 and lead to its reduced transcriptional activity during torpor. Finally, the third objective dealt with transcriptional status in hibernating animals. Analysis of $\mathrm{Rb}$, phospho- $\mathrm{Rb}$ (Ser 780/ Ser 795) and E2F1 protein levels together with HDAC and SUV39H1 strongly supported reduced transcriptional activity during hibernation. This was further confirmed by the reduced transcription of selected downstream target genes. These data also highlighted new possible mechanisms of transcriptional control that may also be used by other animals under stress and may be a general principle of hypometabolism.

\section{Future Directions}

This thesis focused primarily on three major transcription factors that are differentially expressed during hibernation. There are clearly different mechanisms of gene activation or transcriptional suppression in mammalian hibernation. Some genes are mainly activated by stress conditions faced by hibernators and many of the genes support cell survival during hibernation. For example, the ChREBP expression levels were upregulated in brain, heart, muscle and BAT. Apart from reversible phosphorylation control, the increased levels of ChREBP in these organs may be involved in other mechanisms such as activation of TXNIP or G0S2 genes to take care of the cellular redox potential or cell survival depending on the needs of the hibernators. Hence, future studies 
need to examine the nonlipogenic actions of ChREBP, focusing on the responses of other types of genes that are regulated by this transcription factor in order to gain a clear and complete picture of the role of ChREBP in hibernation. Furthermore, use of phosphospecific ChREBP antibodies (when they become commercially available) could be used to identify the particular phosphorylation site(s) that are modified during hibernation in order to confirm nuclear entry and DNA-binding activities since different phosphorylation sites on ChREBP are involved in mediating each of these activities. In addition, ChREBP needs its co-factor Mlx to bind to target genes. Hence, Mlx levels need to be analyzed under euthermic versus hibernating conditions. ChREBP levels should also be measured at different time points such as in summer active animals, winter active animals, and at multiple points over the hibernation/arousal cycle. It is suspected that ChREBP would be most active during times when lipogenesis is high but, given that ChREBP can influence a variety of other genes, we could gain important insights into all of the possible roles of ChREBP by assessing its action under many different phases of the yearly and hibernation cycles.

When considering the Ets pathway, further studies could evaluate PLC, PIP2 and DAG levels to gain expanded insights into this pathway. It is clear that Ets1 plays an important role in the control of growth and development process as well as in apoptosis. Overlap between specific protein-protein interactions may alter the mechanism of action of Ets1 under different conditions. Future studies could be performed to identify the precise interactions between Ets interacting proteins, co-activators and other bridging proteins that are critical for the transcription factor activity in hibernators. The precise 
characterization of Ets interacting proteins during hibernation is important to determine the target gene selection and transcriptional activation or repression.

The Rb-E2F pathway has been extensively studied in other systems. In hibernators, this is the first report of the existence of this pathway. The role of Rb-E2F complex in transcriptional suppression could be further studied by considering the responses of each of the E2F family members during hibernation. Some target genes are controlled by specific E2F and Rb family members and further understanding of the specific interactions between $\mathrm{Rb} / \mathrm{E} 2 \mathrm{~F}$ family members and other transcription factors may explain the specific actions that occur during hibernation. Several different histone modifications and chromatin remodeling complexes can be found at E2F regulated promoters which activate or repress the transcriptional activity. Hence, the specific one that is important for the transcriptional suppression could be identified. For example, in hibernator muscle there could be another type of mechanism, other than the one reported in this study may exist which allows differential regulation or stabilization of muscle mass during hibernation. 


\section{CONTRIBUTIONS TO CONFERENCES}


- Mathialagan, M. and Storey, K.B., Investigation of ETS1 (avian erythroblastosis virus E26 oncogene homolog1) and $\mathrm{Rb}$ (Retinoblastoma) protein during hibernation in 13- lined ground squirrel (Spermophilus tridecimlineatus). CRYO-2007, 44th Annual Meeting of the Society for Cryobiology, Lake Louise, Alberta, July 28-August 1, 2007.

- Mathialagan, M. and Storey, K.B. Changes in the Rb-E2F pathway in thirteen-lined ground squirrels during hibernation. $5^{\text {th }}$ meeting, Canadian Oxidative Stress Consortium, Montreal, PQ, May 3-6 2007.

- Mathialagan, M. and Storey, K.B. Changes in the Rb-E2F pathway in thirteen-lined ground squirrels during hibernation. Ottawa Carleton Institute of Biology Symposium, Carleton University, Ottawa, ON1-2 May 2007.

- Mathialagan.M. and Storey, K.B.Investigation of ETS1 (avian erythroblastosis virus $\mathrm{E} 26$ oncogene homolog1) and $\mathrm{Rb}$ (Retinoblastoma) protein during hibernation in 13- lined ground squirrel (Spermophilus tridecimlineatus). 9th Annual Chemistry and Biochemistry Symposium, Concordia University, Montreal, PQ, Nov.24-25, 2006. 
- Mathialagan.M. and Storey, K.B. Up regulation of the Transcription factor ChREBP (Carbohydrate Response Element Binding Protein) in thirteen lined ground squirrel (Spermophilus tridecimlineatus) and Wood frogs (Rana sylvatica).9th Annual Chemistry and Biochemistry Symposium, Concordia University, Montreal, PQ, Nov.24-25, 2006

- Mathialagan.M. and Storey, K.B. Role of the ChREBP (Carbohydrate Response Elem ent Binding Protein) in 13-lined ground squirrel (Spermophilus tridecimlineatus) and Wood frogs (Rana sylvatica) Biotech In the North: Biosolutions for Industry and Medical Sciences, 2nd Annual Biotech Symposium, Lakehead University, Thunderbay, ON, Sept. 27-28, 2006.

- Mathialagan.M. and Storey, K.B. Role of ETS1 (avian erythroblastosis virus E26 oncogene homolog1)and $\mathrm{Rb}$ (Retinoblastoma) protein during hibernation in 13lined ground squirrel (Spermophilus tridecimlineatus). Biotech In the North: Biosolutions for Industry and Medical Sciences, $2^{\text {nd }}$ Annual Biotech Symposium, Lakehead University, Thunderbay, ON, Sept. 27-28, 2006

- Naganathan.M and Gunawardena. A, Investigation of root anatomy of rice (Oryza sativa) and maize (Zea mays) grown in aerated and stagnant conditions, $\mathbf{3 5}^{\text {th }}$ Plant Development Workshop, Wilfred Laurier University, Waterloo, ON, Dec.2001. 
- Naganathan.M and Gunawardena. A, Investigation of root anatomy of rice (Oryza sativa) and maize (Zea mays) grown in aerated and stagnant conditions, Proceedings of the University annual research sessions, University of Peradeniya, Sri Lanka.6:19, Nov 2001. 


\section{REFERENCES}


Andrews. M. T, Squire. T. L, Bowen. C.M and Rollins. M. B. 1998. Low-temperature carbon utilization is regulated by novel gene activity in the heart of a hibernating mammal. Proc. Natl. Acad. Sci. USA 95: 8392-8397.

Andrews. M. T. 2004. Genes controlling the metabolic switch in hibernating mammals. Biochem. Soc. Trans. 32:1021- 1024.

Avaldano. M. I and Bazan. N. G. 1975. Rapid production of diacylglycerols enriched in arachidonate and stearate during early brain ischemia. J. Neurochem. 25: 919920.

Baillat. D, Begue. A, Stehelin. D and Aumercier. M. 2002. ETS-1 transcription factor binds cooperatively to the palindromic head to head ETS-binding sites of the stromelysin-1 promoter by counteracting autoinhibition. J Biol Chem. 277:2938629398.

Barros. R. C. H, Zimmer. M. E, Branco. L. G. S and Milsom. W.K. 2001. Hypoxic metabolic response of the golden-mantled ground squirrel. J Appl Physiol 91: 603-612.

Blake. B. H. 1972. The annual cycle and fat storage in two populations of goldenmantled ground squirrels. J Mammal. 53: 157-167.

Boyer. B. B and Barnes. B. M. 1999. Molecular and metabolic aspects of mammalian hibernation. Bioscience 49: 713-724.

Bracken. A. P, Ciro. M, Cocito. A and Helin. K. 2004. E2F target genes: unraveling the biology. Trends in Biochem. Sci. 29 (8): 409-417 
Brehm.A, Miska. E. A, McCance. D.J, Reid. J. L, Bannister. A. J and Kouzarides. T. 1998. Retinoblastoma protein recruits histone deacetylase to repress transcription. Nature. 391: 597-601.

Brooks. S.P.J and Storey. K.B. (1992) Mechanisms of glycolytic control during hibernation in the ground squirrel Spermophilus lateralis. J Comp Physiol B. 162: 23-28.

Buck. M. L, Squire. T. L and Andrews. M. T. 2002. Coordinate expression of the PDK4 gene: a means of regulating fuel selection in a hibernating mammal. Physiol. Genom. 8: 5-13.

Burlington. R.F and Wiebers. J. E. 1966. Anaerobic glycolysis in cardiac tissue from a hibernator and non-hibernator as effected by temperature and hypoxia. Comp Biochem Physiol 17: 183-189.

Burlington. R.F, Bowers. W. D. Jr, Daum. R. C and Ashbaugh, P. 1972. Ultrastructural changes in heart tissue during hibernation. Cryobiology. 9: 224-8.

Castex. C, Tahri. A, Hoo-Paris. R and Sutter. B. C. 1984. Insulin secretion in the hibernating edible dormouse (Glis glis): in vivo and in vitro studies. Biochem. Physiol. 79A:179-83.

Chau. B. N and Wang. J. Y. 2003. Coordinated regulation of life and death by RB. Nat. Rev. Cancer 3: 130-138.

Chen. Y, Matsushita. M, Nairn. A.C, Damuni. Z, Cai. D, Frerichs. K.U and Hallenbeck. J.M. 2001 Mechanisms for increased levels of phosphorylation of elongation factor-2 during hibernation in ground squirrels. Biochemistry 40: 11565-70. 
Churchill. T.A, Cheetham. K. M, Simpkin.S, Green. C. J, Wang. L. C. H and Fuller. B. J. 2004. Liver metabolism in cold hypoxia: a comparison of energy metabolism and glycolysis in cold-sensitive and cold-resistant mammals. J. of Comp. Physiol. B: Biochemical, Systemic, and Env. Physiol. 164 (5): 396-404.

Cicchillitti. L, Fasanaro. P, Biglioli. P, Capogrossi. M. C and Martelli. F. 2003. Oxidative Stress Induces Protein Phosphatase 2A-dependent Dephosphorylation of the Pocket Proteins pRb, p107, and p130. Biol. Chem. 278 (21): 19509-19517.

Cowley. D. O and Graves. B.J. 2000. Phosphorylation represses Ets-1 DNA binding by reinforcing autoinhibition. Genes Dev. 14:366-376.

Dark. J. 2005 Annual lipid cycles in hibernators: Integration of Physiology and Behavior. Annu. Rev. Nutr. 25: 469-97.

DeGregori, J. 2002. The genetics of the E2F family of transcription factors: shared functions and unique roles. Biochim. Biophys. Acta 1602, 131-150.

DeGregori. J. 2004. The Rb network. Journal of Cell Science 117: 3411-3413

Dentin. R, Benhamed. F, Paul Pégorier. J. P, Foufelle. F, Viollet. B, Vaulont. S, Girard. J and Postic. C. 2005. Polyunsaturated fatty acids suppress glycolytic and lipogenic genes through the inhibition of ChREBP nuclear protein translocation. J. Clin. Invest. 115: 2843-2854.

Dentin. R, Pégorier. J. P, Benhamed. F, Foufelle. F, Ferré. P, Fauveau.V, Magnuson. M. A and Girard. J. P. 2004. Hepatic glucokinase is required for the synergistic action of ChREBP and SREBP-1c on glycolytic and lipogenic gene expression. J. Biol. Chem. 279:20314-20326. 
Dery. M. A, Michaud. M. D and Richard. D.E. 2005. Hypoxia-inducible factor 1: regulation by hypoxic and non-hypoxic activators. Int J Biochem Cell Biol 37: $535-540$.

Dittmer. J (2003) The Biology of the Ets-1 Proto-Oncogene, Molecular Cancer, 2:29 (Review)

Dittmer. J and Nordheim. A.1998. Ets transcription factors and human disease. Biochim Biophys Acta. 1377:F1-11

Downward. J, Parker. P and Waterfield. M. D. 1985. Autophosphorylation and protein kinase $\mathrm{C}$ phosphorylation of the epidermal growth factor receptor. Effect on tyrosine kinase activity and ligand binding affinityNature 311: 483-485.

Drew. K. L, Harris. M. B, LaManna. J. C, Smith. M. A, Zhu. X. W and Ma. Y. L. 2004. Hypoxia tolerance in mammalian heterotherms. Review. The J. of Exp. Biol. 207: 3155-3162.

Du. W and Pogoriler. J. 2006. Retinoblastoma family genes. Oncogene. 25: 5190-5200.

Durkin. J. P, Tremblay. R, Chakravarthy. B, Mealing. G, Morley. P, Small. D and Song. D (1997) Evidence that the early loss of membrane protein kinase C is a necessary step in the excitatory amino acid-induced death of primary cortical neurons. J Neurochem 68: 1400-1412.

Dyson. S. 1998. The regulation of E2F by pRB-family proteins. Genes and Dev. 12 (15): $2245-2262$

El Ouezzani. S, Lafon. P, Tramu. G. and Magoul. R. 2001. Neuropeptide Y gene expression in the jerboa arcuate nucleus: modulation by food deprivation and relationship with hibernation. Neurosci. Lett. 305: 127-130. 
Elliott. M. J, Dong. Y. B, Yang. H and McMasters. K. M. 2001. E2F-1 Up-Regulates cMyc and $\mathrm{p} 14^{\mathrm{ARF}}$ and Induces Apoptosis in Colon Cancer Cells. Clinical Cancer Res. 7: 3590-3597.

Elvert. G, Kappel. A, Heidenreich. R, Englmeier. U, Lanz. S, Acker. T, Rauter. M, Plate. K, Sieweke. M, Breier. G and Flamme. I. 2003. Cooperative interaction of hypoxia-inducible factor-2alpha (HIF-2alpha ) and Ets-1 in the transcriptional activation of vascular endothelial growth factor receptor-2 (Flk-1). J Biol Chem. 278(9): 7520-30.

Epperson. L. E. and Martin. S.L. Quantitative assessment of ground squirrel mRNA levels in multiple stages of hibernation. Physiol Genomics. 2002. 10: 93-102.

Fahlman. A, Storey. J. M and Storey. K. B. 2000. Gene up-regulation in the heart during mammalian hibernation. Cryobiology 40: 332-342.

Fawett. D. W. and C. P. Lyman. 1954. The effect of low environmental temperature on the composition of depot fat in relation to hibernation. J. Physiol. Lond. 126:235247.

Fischer. O. M, Hart. S, Gschwind. A, Prenzel. N and Ullrich. A. 2004. Oxidative and Osmotic Stress Signaling in Tumor Cells Is Mediated by ADAM Proteases and Heparin-Binding Epidermal Growth Factor. Mol Cell Biol. 24(12): 5172-5183.

Fisher. R. J, Favash. M, Casas-Finet. J, Erickson. J. W, Kondoh. A, Bladen. S. V, Fisher. C, Watson. D. K and Papas.T. 1994. Real-time DNA binding measurements of the ETS1 recombinant oncoproteins reveal significant kinetic differences between the p42 and p51 isoforms. Protein Sci. 3:257-266. 
Fisher. R. J, Koizumi. S, Kondoh. A, Mariano. J. M, Mavrothalassitis. G, Bhat. N. K and Papas. T. 1992. Human ETSl Oncoprotein. J. Biol. Chem. 267 (25): 1795717965.

Florant. G. L, Hester. L, Ameenuddin. S and Rintoul. D. A. 1993. The effect of a low essential fatty acid diet on hibernation in marmots. Am. J. Physiol. 264: R747R753.

Florant. G. L. 1998. Lipid metabolism in hibernators: the importance of essential fatty acids. Am. Zool. 38: 331-340.

Foulds. C.E, Nelson. M. L, Blaszczak. A. G and Graves. B.J. 2004. Ras/mitogenactivated protein kinase signaling activates Ets-1 and Ets-2 by CBP/p300 recruitment. Mol. Cell Biol. 24: 10954-10964.

Frank. C. L and Storey. K. B. 1995. The optimal depot fat composition for hibernation by golden-mantled ground squirrels (Spermophilus lateralis). J. Comp. Physiol. B, 164: 536-542.

Frank. C. L. 1991. Adaptations for hibernation in the depot fats of a ground squirrel (Spermophilus beldingi). Can. J. Zool. 69: 2707-2711.

Frank. C. L. 1992. The influence of dietary fatty acids on hibernation by golden-mantled ground squirrels (Spermophilus lateralis). Physiol. Zool. 65: 906-920.

Frank. C.L, Brooks. S. P. J, Harlow. H. J and Storey. K. B. 1998. The influence of hibernation patterns on the critical enzymes of lipogenesis and lipolysis in prairie dogs. Exp. Biol. Online 3:9. 
Franovic. A, Gunaratnam. L, Smith. K, Robert. I, Patten.D and Lee.S. 2007. Translational up-regulation of the EGFR by tumor hypoxia provides a nonmutational explanation for its overexpression in human cancer. Proc. Natl. Acad. Sci. USA. 104 (32): 13092-13097.

Frerichs. K.U, Kennedy. C, Sokoloff. L and Hallenbeck. J. M. 1994. Local cerebral blood flow during hibernation, a model of natural tolerance to "cerebral ischemia." J. Cereb. Flow. Metab. 14: 193-205.

Frolov. M. V and Dyson. N. J. 2004. Molecular mechanisms of E2F-dependent activation and pRB-mediated repression $J$. Cell Sci 117: 2173-2181

Geiser. F and Kenagy. G. J. 1987. Polyunsaturated lipid diet lengthens torpor and reduces body temperature in a hibernator. Am J Physiol Regulatory Integrative Comp Physiol 252: 897-901.

Geiser. F, McAllan. B. M and Kenagy. G. J. 1994. The degree of dietary fatty acid unsaturation affects torpor patterns and lipid composition of a hibernator. $J$. Comp. Physiol. B, 164: 299-305.

Geiser. F. 1988. Reduction of metabolism during hibernation and daily torpor in mammals and birds: temperature effect or physiological inhibition. J. Comp. Physiol. B 158: 25-38.

Geiser. F. and Ruf. T. 1995 . Hibernation versus daily torpor in mammals and birds: physiological variables and classification of torpor patterns. Physiol. Zool. 68: 935-966. 
Ghysdael. J and Boureux. A. 1997. The ETS family of transcriptional regulators. In Oncogenes as transcriptional regulators (Edited by: Yaniv $M$, Ghysdael J). Basel: Birkhäuser. 1:29-88.

Gibson. T. J, Thompson. J. D, Blocker. A and Kouzarides T. 1994. Evidence for a protein domain superfamily shared by the cyclins, TFIIB and RB/p107. Nucleic Acids Res. 22: 946-952.

Goldberg. M, Zhang H. L and Steinberg S. F. 1997. Hypoxia alters the subcellular distribution of protein kinase $\mathrm{C}$ isoforms in neonatal rat ventricular myocytes. $J$. Clin. Invest. 99:55-61.

Goldkorn. T, Khan. E. M, Ravid. T and Heidinger. J. M. 2005. Insights into the activation of EGF receptor under Oxidative stress. FEBS Journal 272 (s1). abstract number: C3-023P.

Graves. B. J and Petersen. J. M. 1998. Specificity within the ets family of transcription factors. Adv Cancer Res.75:1-55

Harbour. J. W and Dean. D. C. 2006. The Rb/ E2F pathway: expanding roles and emerging paradigms. Genes and Dev. 14: 2393- 2409.

Hassig. C.A and Schreiber. S. L. 1997. Nuclear histone acetylases and deacetylases and transcriptional regulation: HATs off to HDACs. Curr. Op. in Chem. Biol. 1 (3): $300-308$.

Hershenson. M. B. 2004. $\mathrm{p} 21^{\mathrm{Waf} 1 / \mathrm{Cip} 1}$ and the prevention of oxidative stress. $A m J$ Physiol. 286: 502-505. 
Hiestand. W. A, Rockhold. W. T, Stemler. F. W, Stullken. D. E. and Wiebers. J. E. 1950. The comparative hypoxic resistance of hibernators and nonhibernators. Physiol. Zool. 23: $264-268$.

Hill. V. L and Florant G. L. 1999. Patterns of fatty acid composition in free-ranging yellow bllied marmots (Marmota flaviventris). Can. J. Zool. 77: 1494-1503.

Hittel. D. and Storey. K.B. 2001. Differential expression of adipose- and heart-type fatty acid binding proteins in hibernating ground squirrels. Biochem. Biophys. Acta 1522: 238-243.

Hittel. D. and Storey. K.B. 2002. The translation state of differentially expressed mRNAs in the hibernating 13-lined ground squirrel (Spermophilus tridecemlineatus). Arch. Biochem. Biophys. 401: 244-254.

Holden. C. P, Storey. J and Atorey. K. B. 1998. Protein Kinase A from Bat Skeletal Muscle: A Kinetic Study of the Enzyme from a Hibernating Mammal. Presented at INABIS '98 - 5th Internet World Congress on Biomedical Sciences at McMaster University, Canada, Dec 7-16th. Available at URL http://www.mcmaster.ca/inabis98/cellbio/holden0436/index.html

Horman. S, Hussain. N, Dilworth. S. M, Storey. K. B and Rider. M. H. 2005. Evaluation of the role of AMP-activated protein kinase and its downstream targets in mammalian hibernation. J Comp Physiol [B]. 142: $374-382$.

Hu. J and Colburn. N. H. 2005. Histone Deacetylase Inhibition Down-Regulates Cyclin D1 Transcription by Inhibiting Nuclear Factor-KB/p65 DNA Binding. Mol Cancer Res. 3(2): 100-109 
Hunter. T and Cooper. J. A. 1985 . Protein-tyrosine kinases Annu. Rev. Biochem. 54: $897-930$

Iizuka. K, Bruick. R. K, Liang. G, Horton. J. D and Uyeda. K. 2004. . Deficiency of carbohydrate response element-binding protein (ChREBP) reduces lipogenesis as well as glycolysis. Proc. Natl. Acad. Sci. U. S. A. 101::7281-7286.

Ishii. S, IIzuka. K, Miller. B. C and Uyeda. K. 2004. Carbohydrate response element binding protein directly promotes lipogenic enzyme gene transcription. Proc. Natl. Acad. Sci. U. S. A. 101(44): 15597-1560.

Johannes. F. J, Prestle. J, Eis. S, Oberhagemann. P and Pfizenmaier. K. 1994. PKCu Is a Novel, Atypical Membero $f$ the Protein KinaseC Family. The Ame. Soc. for Biochem. and Mol. Biol. 269 (8): 6140-6148.

Jonsen. M. D, Petersen. J. M, Xu. Q. P and Graves. B. J. 1996. Characterization of the cooperative function of inhibitory sequences in Ets-1. Mol. Cell. Biol., 16 (5): 2065-2073.

Jump. D.B and Clarke. S.D. 1999. Regulation of gene expression by dietary fat. Annu. Rev. Nutr. 19:63-90

Kawaguchi. T, Osatomi. K, Yamashita. H and Uyeda. K. 2001(b). Mechanism for fatty acid "sparing" effect on glucose-induced transcription: regulation of carbohydrate-responsive element-binding protein by AMP-activated protein kinase.. J Biol Chem. 8: 277(6): 3829-35.

Kawaguchi. T, Osatomi. K, Yamashita. H, Kabashima. T and Uyeda. K. 2002. Mechanism for fatty acid "sparing" effect on glucose-induced transcription: 
regulation of carbohydrate-responsive element-binding protein by AMP-activated protein kinase. J. Biol. Chem. 277:3829-3835.

Kawaguchi. T, Takenoshita. M, Kabashima. T and Uyeda. K. 2001(a). Glucose and cAMP regulate the L-type pyruvate kinase gene by phosphorylation/ dephosphorylation of the carbohydrate response element binding protein. Proc. Natl. Acad. Sci. USA 98: 13710-13715.

Kilduff. T.S, Miller. J. D, Radeke. C. M, Sharp. F. R. and Heller. H.C. $1990 .{ }^{14}$ C-2deoxyglucose uptake in the ground squirrel brain during entrance to and arousal from hibernation. J. Neurosci. 10: 2463-2475.

King.C. S and Cooper. J. A. 1986. Effects of protein kinase C activation after epidermal growth factor binding on epidermal growth factor receptor phosphorylation. $J$. Biol. Chem. 261 (22): 10073-10078.

Klemsz. M. J, McKercher. S. R, Celada. A, Van Beveren. C and Maki. R. A. 1990. The macrophage and B cell-specific transcription factor PU.1 is related to the ets oncogene. Cell 61: 113-124

Knebel. A, Rahmsdorf. H, Ullrich. A and Herrlich. P. 1996. Dephosphorylation of receptor tyrosine kinases as target of regulation by radiation, oxidants or alkylating agents. EMBO J. 15:5314-5325.

Knight. J. E, Narus. E. N, Martin. S. L, Jacobson. A, Barnes. B. M. and Boyer. B. B. 2000. mRNA stability and polysome loss in hibernating Arctic ground squirrels (Spermophilus parryii). Mol Cell Biol. 20: 6374-6379 
Krek. W, Xu. G and Livingston. D. M. 1993. Cyclin A-kinase regulation of E2F-1 DNA binding function underlies suppression of a S phase checkpoint. Cell. 83: $1149-1158$.

Krilowicz. B. L. 1985. Ketone body metabolism in a ground squirrel during hibernation and fasting. Am J Physiol Regul Integr Comp Physiol. 249: R462-R470

Lee. J. B. O, Russo. A. A and Pavletich. N. P. 1998. Structure of the retinoblastoma tumour-suppressor pocket domain bound to a peptide from HPV E7. Nature. 391:859-865.

Lee. M, Choi. I and Park. K. 2002. Activation of stress signaling molecules in bat brain during arousal from hibernation. $J$. Neurochemistry. 82 (4): 867-873.

Lee. P. J, Jiang. B. H, Chin. B. Y, Iyer. N. V, Alam. J, Semenza. G. L, Choi. A. M 1991.Hypoxia-inducible factor1 mediates transcriptional activation of the heme oxygenase-1 gene in response to hypoxia. J. Biol Chem. 272(9): 5375-81

Li. R, Pei. H and Watson. D. 2000. Regulation of Ets function by protein-protein interactions, Oncogene. 19: 6514-23.

Lindemann. R. K, Ballschmieter. P, Nordheim. A and Dittmer J. 2001. Transforming growth factor beta regulates parathyroid hormone-related protein expression in MDA-MB-231 breast cancer cells through a novel Smad/Ets synergism. $J$ Biol Chem. 276:46661-46670.

Lindemann. R. K, Braig. M, Ballschmieter. P, Guise. T. A, Nordheim and Dittmer. J. 2003.Protein kinase C $\alpha$ regulates Ets 1 transcriptional activity in invasive breast cancer cells. Intl. J. Oncol. 22: 799-805. 
Liu. H and Grundstrom. T. 2002. Calcium Regulation of GM-CSF by CalmodulinDependent Kinase II Phosphorylation of Ets1. Mol Biol Cell. 13:4497-4507

Liu. W.S and Heckman. C. A 1988. The seven-fold way of PKC regulation. Cell Signal 10: $529-542$.

Ma. L, Robinson. L. N and Towle. H. C. 2006. ChREBP•Mlx Is the Principal Mediator of Glucose-induced Gene Expression in the Liver. J. Biol. Chem. 281 (39): $28721-28730$

Ma. R, Li. W-P, Rundle. D, Kong. J, Akbarali. H. I and Tsiokas. L . 2005. PKD2 functions as an epidermal growth factor-activated plasma membrane channel. Mol. Cell. Biol. 25: 8285-8298.

MacDonald. J. A and Storey K. B. 1998. cAMP-dependent protein kinase from brown adipose tissue: temperature effects on kinetic properties and enzyme role in hibernating ground squirrels. J Comp Physiol [B]. 168: 513-525

MacDonald. J. A and Storey. K. B. 2005. Mitogen-activated protein kinases and selected downstream targets display organ-specific responses in the hibernating ground squirrel. The Intl. J. Biochem. Cell Biol. 37: 679-691.

Marchetti M. P. Z, Castedo. M, Decaudin. D, Macho. A, Hirsch. T, Susin. S. A, Petit. P. X, Mignotte. B and Kroemer. G. 1995. Sequential Reduction of Mitochondrial Transmembrane Potential and Generation of Reactive Oxygen Species in Early Prograrmned Cell Death. J. Exp. Med. 182: 367-377.

Marchler-Bauer. A, Anderson. J. B, Derbyshire. M. K, DeWeese-Scott C, Gonzales. N. R, Gwadz. M, Hao. L, He. S, Hurwitz. D. I, Jackson. J. D, Ke. Z, Krylov. 
D, Lanczycki. C. J, Liebert. C. A, Liu. C, Lu. F, Lu. S, Marchler. G. H, Mullokandov. M, Song. J. S, Thanki. N, Yamashita. R. A, Yin. J. J, Zhang. D and Bryant. S. H. 2007. CDD: a conserved domain database for interactive domain family analysis. Nucleic Acids Res. 35: D237-40

McArthur. M.D and Milsom. W. K. 1991. Changes in ventilation and respiratory sensitivity associated with hibernation in Columbian (Spermophilus columbianus) and golden-mantled (Spermophilis lateralis) ground squirrels. Physiol. Zool. 64: $940-959$.

Mehrani. H and Storey. K. B. 1997. Protein Kinase C from Bat brain: The enzyme from a hibernating mammal. Neurochem. Int. 31:139-150.

Mellor. H and Parker. P.J 1988. The extended protein kinase C superfamily. J.Biochem 332: $281-292$.

Milsom. W. K., Zimmer. M. B and Harris. M. B. 1999. Regulation of cardiac rhythm in hibernating mammals. Comp. Biochem. Physiol. A 124: 383-391.

Minn. A. H, Hafele. C and Shalev. A. 2005. Thioredoxin-Interacting Protein Is Stimulated by Glucose through a Carbohydrate Response Element and Induces beta cell Apoptosis. Endocrinol. 146(5): 2397-2405.

Morin .P Jr and Storey. K. B. 2005. Cloning and expression of hypoxia-inducible factor lalpha from the hibernating ground squirrel, Spermophilus tridecemlineatus. Biochim Biophys Acta. 1729(1):32-40

Morin. P Jr and Storey. K. B. 2006. Evidence for a reduced transcriptional state during hibernation in ground squirrels. Cryobiology. 53: 310-318. 
Morris. E. J and Dyson. N. J. 2001. Retinoblastoma Protein Partners. Adv. Cancer Res. 82: $1-54$.

Mostafa. N, Everett. D. C, Chou. S. C, Kong. P. A, Florant. G. L and Coleman. R. A. 1993. Seasonal changes in critical enzymes of lipogenesis and triacylglycerol synthesis in the marmot (Marmota tlaviventris). J Comp Physiol B. 163:463469

Müller. H and Helin. K. 2000. The E2F transcription factors: key regulators of cell proliferation. Biochimica et Biophysica Acta. 1470: M1- M12

Ni. Z. 2004. Antioxident defense in the hibernating thirteen lined Ground squirrels (Spermophilus tridecemlineatus). M. Sc thesis.

Nielsen. S. J, Schneider. R, Bauer. U. M, Bannister. A. J, Morrison. A and O'Carroll. D. 2001. Rb targets histone H3 methylation and HP1 to promoters Nature. 412: 561-565.

Nightingale. K. P, Wellinger. R. E, Sogo. J. M and Becker. P. B. 1998. Histone acetylation facilitates RNA polymerase II transcription of the Drosophila hsp26 gene in chromatin. The EMBO Journal. 17: 2865-2876.

Nishizuka. Y. 1992. Intracellular signaling by hydrolysis of phospholipids and activation of protein kinase C. Science 258: 607-613.

O'Hara. B, Watson. F. O, Srere. H. K, Kumar. H, Wiler. S. W, Welch. S. K, Bitting, L, Heller. H. C and Kilduff. T.S. 1999. Gene expression in the brain across the hibernation cycle. J. Neurosci. 19: 3781-3790.

Oda. K, Matsuoka. Y, Funahashi. A and Kitano. H. 2005. A comprehensive pathway map of epidermal growth factor receptor signaling. Mol. Sys. Biol. 1: 20050010.Review. 
Oikawa. M, Abe. M, Kurosawa. H, Hida. W, Shirato K and Sato. Y. 2003. Hypoxia induces transcription factor ETS-1 via the activity of hypoxia-inducible factor-1. Biochem Biophys Res Commun. 289(1): 39-43

Ono. Y, Fujii. T, Ogita. K, Kikkawa. U, Igarashi. K and Nishizuka Y. 1988. The structure, expression, and properties of additional members of the protein kinase C family. J Biol Chem.263(14): 6927-32.

Osborne. P.G, Gao. B and Hashimoto. M. 2004. Determination in vivo of newly synthesized gene expression in hamsters during phases of the hibernation cycle. Japan J Physiol 54: 295-305.

Pégorier. J. P, May. C. L and Girard. J. 2004. Control of Gene Expression by Fatty Acids. J. Nutr. 134: 2444S-2449S.

Peters. C. L, Morris. C. J, Mapp. P. I, Blake. D. R, Lewis. C. E and Winrow. V. R. 2003. The transcription factors hypoxia-inducible factor $1 \alpha$ and Ets-1 colocalize in the hypoxic synovium of inflamed joints in adjuvant-induced arthritis. Arthritis \& Rheumatism. 50 (1): 291 - 296.

Phillips. A. C, Bates. S, Ryan. K. M, Helin. K and Vousden. K. H. 1997. Induction of DNA synthesis and apoptosis are separable functions of E2F-1. Genes Dev. 11: $1853-1863$.

Prenzel. N, Fischer. O. M, Streit. S, Hart. S and Ullrich. A. 2001. The epidermal growth factor receptor family as a central element for cellular signal transduction and diversification. Endocr. Relat. Cancer. 8:11-31.

Rolfe. D.F and Brown, G.C. (1997). Cellular energy utilization and molecular origin of 
standard metabolic rate in mammals. Physiol Rev 77: 731-758.

Ross. J. F, Liu. X and Dynlacht. B. D. 1999. Mechanism of Transcriptional Repression of E2F by the Retinoblastoma Tumor Suppressor Protein. Cell. 3: 195-205.

Rubin. S. M, Gall. A. L, Zheng. N and Pavletich. N. P. 2005. Structure of the Rb Cterminal domain bound to E2F1-DP1: a mechanism for phosphorylation-induced E2F release. Cell. 123:1093-1106.

Sementchenko. V. I and Watson. D. K. 2000. Ets target genes: past, present and future. Oncogene. 19 (55): 6533-6548.

Sementchenko. V. I and Watson. D. K. 2000. Ets target genes: past, present and future. Oncogene. 19: 6533- 6548.

Shan-Rui Han, Momeni. A, Strach. K, Suriyaphol. P, Fenske. D, Paprotka. K, Hashimoto. S. I, Torzewski. M, Bhakdi. S, Husmann. M. 2003. Enzymatically Modified LDL Induces Cathepsin $\mathrm{H}$ in Human Monocytes. Arteriosclerosis, Thrombosis, and Vascular Biology. 23: 661.

Sharrocks. A. D, Brown. A. L, Ling. Y and Yates. P. R. 1997. The ETS-domain transcription factor family. Int J Biochem Cell Biol. 29:1371-1387.

Sherr. C. J and Roberts. J. M. 1999. CDK inhibitors: positive and negative regulators of G1-phase progression. Genes Dev. 13, 1501-1512.

Shih. H. M, Liu. Z and Towle. H. C. 1995. Two CACGTG motifs with proper spacing dictate the carbohydrate regulation of hepatic gene transcription. $J$ Biol Chem. 270(37): 21991-7 
Song. M. J, Wang. Y. Q and Wu. G. C. 2007. Lipopolysaccharide-induced protein kinase D activation mediated by interleukin-1beta and protein kinase C. Brain Res. 1145:19-27.

Srere. H. K, Wang. L.C.H. and Martin. S.L. Central role for differential gene expression in mammalian hibernation. Proc Natl Acad Sci USA. 1992. 89:71197123.

Sterner. D. E and. Berger. S. L. 2000. Acetylation of Histones and TranscriptionRelated Factors. Am. Soc. Microbiol. 64 (2): 435- 459.

Stevaux. O. and Dyson. N. J. 2002. A revised picture of the E2F transcriptional network and RB function. Curr. Opin. Cell Biol. 14, 684-691.

Storey. K. B and Storey. J. M. 2004b. Biochemical adaptation to extreme environments. In: Integrative Physiology in the Proteomics and Post-Genomics Age (Walz, W., editor). Humana Press, New Jersey: 169-200.

Storey. K. B. 1987. Regulation of Liver Metabolism by Enzyme Phosphorylation during Mammalian Hibernation. J. Biol. Chem. 262 (4): 1670-1673.

Storey. K. B. 1997. Metabolic regulation in mammalian hibernation: enzyme and protein adaptations. Comp. Biochem. Physiol. A 118: 1115-1124.

Storey. K. B. 2000 .Gene expression and protein adaptations in mammalian hibernation. In Life in the Cold (ed. G. Heldmaier \& M. Klingenspor): 303-313. Berlin: Springer-Verlag.

Storey. K. B. 2003. Mammalian hibernation. Transcriptional and translational controls. Adv Exp Med Biol 543: 21-38. 
Storey. K. B. and Storey J. M. 2004a. Metabolic rate depression in animals: transcriptional and translational controls. Biol. Rev. 79: 207-233.

Tashima. L. S, Adelstein. S. J, Lyman. C. P. 1970. Radioglucose utilization by active,hibernating, and arousing ground squirrels.Am. J. Physiol. 218:303-309.

Towle. H. C. 2005. Glucose as a regulator of eukaryotic gene transcription. TRENDS in Endocrinol and Metabol. 16 (10): 489-494.

Towle. H. C. Kaytor. E. N and Shih . H. M. 1997. Regulation of the expression of lipogenic enzyme genes by carbohydrate. Annu. Rev. Nutr. 17: 405-433.

Uyeda. K, Yamashita. H and Kawaguchi. T.2002. Carbohydrate responsive elementbinding protein (ChREBP): a key regulator of glucose metabolism and fat storage. Biochem Pharmacol. 15: 63(12): 2075-80. Review.

Valverde. A. M, Sinnett-Smith. J, Lint. J. V and Rozengurt. E. 1994. Molecular cloning and characterization of protein kinase D: a target for diacylglycerol and phorbol esters with a distinctive catalytic domain. Proc. Natl. Acad. Sci. U. S. A. 91: 8572-8576.

Van Breukelen. F and Martin. S.L. 2002. Reversible depression of transcription during hibernation. J Comp Physiol B 172: 355-361.

Vandel. L, Nicolas. E, Vaute. O, Ferreira. R, Ait-si-ali. S and Trouche. D. 2001. Transcriptional repression by the retinoblastoma protein through recruitment of a histone methyltransferase. Mol Cell Biol. 21: 6484-6494.

Vetter. M, Blumenthal. S. G, Lindemann. R. K, Manns. J, Wesselborg. S, Thomssen. C and Dittmer. J. 2004.Ets1 is an effector of protein kinase Ca in cancer cells. Oncogene, 24: 650-661. 
Waldron. R. T, Rey. O, Zhukova. E and Rozengurt. E. 2005. Oxidative stress induces protein kinase $\mathrm{C}$ mediated activation loop phosphorylation and nuclear redistribution of protein kinase D. J. Biol. Chem. 280(14): 13205 - 13208

Waldron. R.T, Rey.O, Iglesias. T, Tugal. T, Cantrell. D and Rozengurt. E. 2001. Activation loop Ser744 and Ser748 in protein kinase D are transphosphorylated in vivo. J. Biol. Chem. 276(35): 32606-32615.

Wang. L. C, Lee. T.F and Jourdan, M. L. (1987) Seasonal difference in thermoregulatory responses to opiates in a mammalian hibernator. Pharmacol. Biochem. Behav. 26: 565-71.

Wang. L.C.H. and Lee. T.F. 1996. Torpor and hibernation in mammals: metabolic, physiological and biochemical adaptations. In Handbook of Physiology: Environmental Physiology. Ed. M.J. Fregley and C.M. Blatteis. Oxford University Press, New York. Section 4. 1: 507-532.

Wang. L.C.H. and Wolowyk. M. W. 1988. Torpor in mammals and birds. Can. J. Zool. 66: 133-137.

Wang. T, Niki. T, Goto. A, Ota. S, Morikawa. T, Nakamura. Y, Ohara. E, Ishikawa.S, Aburatani. H, Nakajima. J and Fukayama. M. 2007. Hypoxia increases the adenocarcinoma cell line A549 via activation of the epidermal growth factor receptor pathway. Cancer. Sci. 98 (4): 506-511.

Watson. D. K, McWilliams. M. J, Lapis. P, Lautenberger. J. A, Schweinfest. C. W and Papas. T. S. 1988. Mammalian ets-1 and ets-2 Genes Encode Highly Conserved Proteins Proc. Natl. Acad. Sei. U. S. A. 85: 7862-7866. 
Weinberg. R. A. 1995. The retinoblastoma protein and cell cycle control. Cell. 81: 323330.

Wickler. S. J, Hoyt. D. F. and Kott. K. S. 1991. Disuse atrophy in the hibernating golden-mantled ground squirrel, Spermophilus lateralis. Am. J. Physiol. 261: R1214-R1217.

Yamashita. H, Takenoshita. M, Sakurai. M, Bruick. R. K, Henzel. W. J, Ahillinglaw. W, Arnot. D, and Uyeda. K. 2001. A glucose responsive transcription factor that regulates carbohydrate metabolism in the liver. Proc. Natl. Acad. Sci. USA 98: 9116-9121.

Yan. S. F, Lu. J, Zou. Y. S, Kisiel. W, Mackman. N, Leitges. M, Steinberg. S, Pinsky. D and Stern. D. 2000. Protein Kinase C- $\boldsymbol{\beta}$ and Oxygen Deprivation. $J$ Biol Chem. 275(16): 11921-11928

Yang. H. l, Dong. Y. B, Elliott. M. J, Liu. T. J and McMasters. K. M. 2001. Caspase Activation and Changes in Bcl-2 Family Member Protein Expression Associated with E2F-1-mediated Apoptosis in Human Esophageal Cancer Cells. Clinical Cancer Res. 6:1579-1589

Yordy. J. S and Muise-Helmericks. R. C. 2000. Signal transduction and the Ets family of transcription factors. Oncogene. 9: 6503-13.

Zatzman. M. L. 1984. Renal and cardiovascular effects of hibernation and hypothermia. Cryobiology $21:$ 593-614.

Zatzman. M. L. and South. F. E.(1972) Renal function of the awake and hibernating marmot Marmota flaviventris. Am. J. Phisiol. 2: 1035-1039. 
Zhang. H. S and Dean. D. C. 2001. Rb-mediated chromatin structure regulation and transcriptional repression. Ocogene. 2024: 3134-3138.

Zhao. X and Day. M. L. 2001. Rb activation and repression of c-Myc transcription precede apoptosis of Human prostrate epithelial cells. Urology. 57 (5): 860-865.

Zhou. F, Smith. M. A, Castellani. R. J, Stimmelmayr. R, Perry. G, Drew. K. L and Zhu. X. 2001. Hibernation, a model of neuroprotection. Sci. World J. 1 (1 Suppl 3): 108.

Zhu. L, Harlaw. E and Dynlacht. B. D. 1995. p107 uses a p21CIP1-related domain to bind cyclin/cdk2 and regulate interactions with E2F.Genes Dev. 9: 1740-1752. 